UNIVERSIDADE DE SÃO PAULO

ESCOLA POLITÉCNICA DA UNIVERSIDADE DE SÃO PAULO

DEPARTAMENTO DE ENGENHARIA DE PRODUÇÃO

FLAVIO FISCH

Capacidades de inovação nas multinacionais de países emergentes - as condições do país de origem as influenciam? 



\section{FLAVIO FISCH}

Capacidades de inovação nas multinacionais de países emergentes - as condições do país de origem as influenciam?

Dissertação apresentada à Escola Politécnica da Universidade de São Paulo para a obtenção do título de Mestre em Ciências 



\section{FLAVIO FISCH}

Capacidades de inovação nas multinacionais de países emergentes - as condições do país de origem as influenciam?

Dissertação apresentada à Escola Politécnica da Universidade de São Paulo para a obtenção do título de Mestre em Ciências

Área de concentração: Engenharia de Produção

Orientador: Prof. Dr. Afonso Carlos Correa Fleury 
Catalogação-na-publicação

Fisch, Flavio

Capacidades de inovação nas multinacionais de países emergentes - as condições do país de origem as influenciam? / F. Fisch -- São Paulo, 2017. $108 \mathrm{p}$.

Dissertação (Mestrado) - Escola Politécnica da Universidade de São Paulo. Departamento de Engenharia de Produção.

1.Competência-Chave 2.Internacionalização de Empresas 3.Empresas Multinacionais 4.Países em Desenvolvimento I.Universidade de São Paulo. Escola Politécnica. Departamento de Engenharia de Produção II.t. 
A minha esposa Célia e ao nosso filho Paulo, que me inspiram e apoiam em todos os momentos, com muito amor, carinho e admiração 



\section{AGRADECIMENTOS}

Este trabalho não seria possível sem os ensinamentos, supervisão e dedicação do meu orientador, Prof. Dr. Afonso Fleury. Seu conhecimento, energia e entusiasmo inesgotáveis são fontes de inspiração, respeito e admiração;

Ao Prof. Dr. Felipe Borini agradeço os ensinamentos sobre metodologia e negócios internacionais. Seus insights sobre ambiente institucional nortearam pontos importantes desta dissertação;

À Profa. Dra. Maria Teresa Fleury meus sinceros agradecimentos pelo acesso às bases de dados dos surveys utilizados neste trabalho;

À Profa. Dra. Dinorá Floriani agradeço à disposição para discutir e compartilhar conhecimentos sobre o amplo tema de internacionalização;

Aos Professores, do Departamento de Engenharia de Produção da Escola Politécnica da USP, agradeço os ensinamentos que se incorporam ao trabalho. Em particular, agradeço aos Profs. Drs. Dario Miyake e Mário Sergio Salerno pelas críticas da qualificação e pela orientação nas disciplinas e extraclasse;

Aos Colegas do PPGEP, cujas discussões, convívio e suporte animaram e enriqueceram a experiência da pós-graduação. Em particular, agradeço ao Willerson pelas revisões dos meus primeiros textos e ao Luis Fernando pelos ensinamentos e suporte em temas relacionados a negócios internacionais e cadeias globais de valor; Agradeço aos Funcionários do PPGEP pelos esforços, atenção e convívio do nosso dia-a-dia;

Não poderia de agradecer e prestar homenagem a meus pais, Ramiro (in memorian) e Rachela, pessoas à frente do seu tempo, e à memória de meus avós que construíram suas vidas no Brasil e nos proporcionaram a oportunidade de crescer e prosperar neste país maravilhoso e imprevisível. 

If we knew what it was we were doing, it would not be called research, would it?

(Albert Einstein)

Change brings opportunities. On the other hand, change can be confusing.

(Michael Porter) 



\section{RESUMO}

A Teoria de Negócios Internacionais sugere que ao aumentar o seu grau de internacionalização, as Empresas Multinacionais dos Países Emergentes dependerão cada vez menos dos efeitos dos seus países de origem, escapando assim das mazelas e deficiências desses países e igualando-se às Empresas Multinacionais dos Países Desenvolvidos. Essa argumentação de escape do país de origem, ou argumentação de escape, enfrenta, no entanto, dois desafios. O primeiro refere-se à geração das vantagens competitivas das multinacionais. As firmas originárias dos países desenvolvidos utilizam-se principalmente de capacidades tecnológicas e marketing para construir suas vantagens com base em seus produtos e marcas diferenciados, enquanto as multinacionais dos países emergentes o fazem a partir do aproveitamento de condições específicas do seu país de origem, utilizando-se de capacidades de inovação em processos e operações e em funções administrativas. $O$ segundo desafio refere-se a evidências empíricas de que efeitos de país de origem se fazem sentir mesmo nas empresas multinacionais maduras de países desenvolvidos. A presente pesquisa busca ampliar o conhecimento sobre as capacidades de inovação das empresas multinacionais de países emergentes através do estudo dos limites do argumento do escape. Uma análise longitudinal das capacidades de inovação das empresas multinacionais brasileiras é utilizada para este fim. Estuda-se um período de cinco anos em que o ambiente de negócios do Brasil mudou de estável e favorável a turbulento e desafiador. A análise utiliza dois "surveys" aplicados em 2010 e 2015, além de informação complementar de fontes primárias e secundárias. Os resultados sugerem que as capacidades de inovação dessas empresas multinacionais ainda podem sofrer influência do ambiente institucional político e econômico do seu país de origem, mesmo com incremento do seu grau de internacionalização. Observam-se ainda diferentes consequências conforme a estratégia de internacionalização utilizada pelas firmas. As implicações dos achados são discutidas.

Palavras-Chave: Efeitos do País de Origem (COE). Empresas Multinacionais de Países Emergentes (EMNEs). Capacidades Dinâmicas de Inovação. Ambiente Institucional. Estratégia de Internacionalização. 



\begin{abstract}
The international Business theory suggests that as they increase their degree of internationalization, Multinationals from Emerging Markets reduce their dependency on their Country of Origin Effects, escaping from these countries' instabilities and deficiencies, therefore leveling with Multinationals from developed countries. The escape from the country of origin, or escape argument, faces two challenges. The first is that firms from developed countries base their advantages on technology and marketing capabilities to build strong products and brands, whereas firms from emerging countries do so mainly by exploiting their country of origin effects using innovative capabilities related to process and operations and to administrative functions. The second challenge relates to empirical evidence of the persistence of country of origin effects on mature multinational firms from developed countries. This research attempts to improve the knowledge on the innovation capability of Emerging Markets Multinational Enterprises through studying the limits of the escape argument. A longitudinal analysis of the innovative capabilities of Brazilian Multinational firms is used for that purpose. The five-year period studied involves a shift in Brazil's conditions from a stable and positive institutional environment to one of turbulence and instability. The research uses data from two surveys executed in 2010 and 2015, as well as other primary and secondary sources. The results suggest that the innovative capabilities from Emerging Market Multinationals can still suffer influences from changes in their home country political and economic institutional environment, even with an increase in their degree of internationalization. The outcomes vary according to the internationalization strategy used by the firms. Implications of these findings are discussed.
\end{abstract}

Keywords: Country of Origin Effects (COE). Emerging Market Multinational Enterprises (EMNEs). Innovative Capabilities. Institutional Environment. Internationalization Strategy. 



\section{LISTA DE FIGURAS}

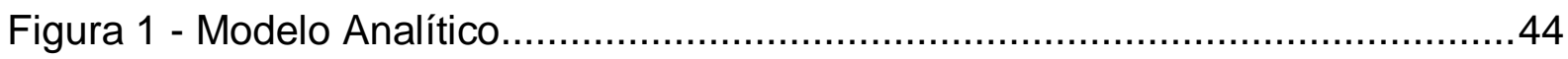

Figura 2 - Evolução das BrMNEs por setor ..................................................... 48

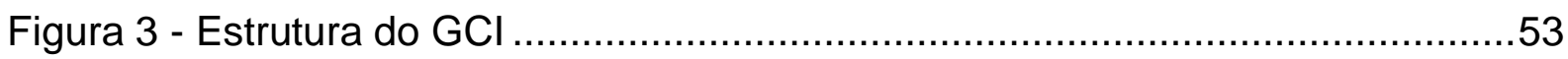

Figura 4 - Evolução do $\mathrm{GCl}$ e componentes do Brasil entre 2008 e 2016 ................57

Figura 5 - Evolução do GCl do Brasil e de países selecionados...............................60

Figura 6 - Comparação da taxa de crescimento do PIB, da taxa de inflação e da taxa de desemprego no Brasil e em outros países selecionados ....................................61

Figura 7 - Observações atípicas nos surveys de 2010 e 2015 ...............................67

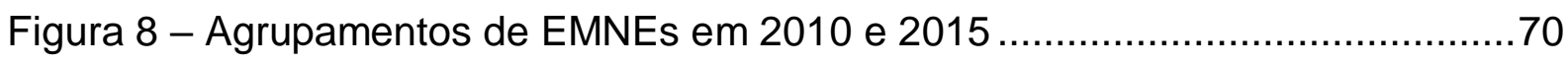

Figura 9 - TNI - evolução anual entre 2010 e 2015 .............................................. 



\section{LISTA DE QUADROS}

Quadro 1 - Estratégias de Internacionalização Genéricas das EMNEs 



\section{LISTA DE TABELAS}

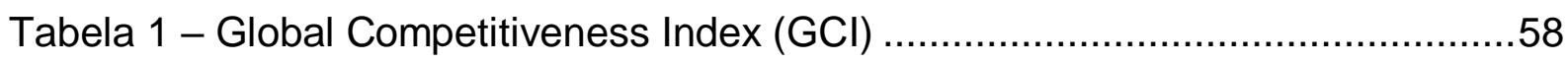

Tabela 2 - Carga fatorial da Matriz de Componentes Rotacionada .........................64

Tabela 3 - Resumo dos resultados da análise fatorial contra critérios de aceitação 65

Tabela 4 - Comparação entre capacidades de inovação - surveys de 2010 e 2015.66

Tabela 5 - BrMNEs com cada estratégia nos surveys USP2010 e FGV/USP2015 ..68

Tabela 6 - Capacidades de inovação por agrupamento de BrMNEs - 2010 e 2015..69

Tabela 7 - Resultados de Testes T para TNI das BrMNEs entre 2010 e 2015 ..........82 



\section{LISTA DE ABREVIATURAS E SIGLAS}

ADM Fator relacionado a capacidades de inovação de funções administrativas

BRIC Grupo de países formados por Brasil, Rússia, Índia e China

BrMNE Empresa multinacional brasileira (do inglês, Brazilian Multinational Enterprise)

COE Efeitos do País de Origem (do inglês, Country of Origin Effects)

CORE Fator relacionado a capacidades de inovação essenciais

DMNE Empresa multinacional de país desenvolvido (do inglês, Developed Market Multinational Enterprise)

EMNE Empresa multinacional de país emergente (do inglês, Emerging Market Multinational Enterprise)

FATA Ativos no Exterior por Ativos Totais (do inglês, Foreign Assets per Total Assets)

FDC Fundação Dom Cabral

FETE Empregados no Exterior por Empregados Totais (do inglês, Foreign Employees per Total Employees)

FGV Fundação Getúlio Vargas

FMI Fundo Monetário Internacional

FSTS Vendas no Exterior por Vendas Totais (do inglês, Foreign Sales / Total Sales)

GCl Índice de Competitividade Global (do inglês, Global Competitiveness Index)

GRI Grau de Internacionalização

IBGE Instituto Brasileiro de Geografia e Estatística

IDE Investimento Direto no Exterior

KMO Kaiser-Meyer-Olkin

MNE Empresa Multinacional

MSA Medida de Adequação da Amostra (do inglês, Measurement of Sample Adequacy)

OCDE Organização para Cooperação e Desenvolvimento Econômico

P\&D Pesquisa e Desenvolvimento

PIB Produto Interno Bruto 
SPSS Statistical Package for the Social Sciences (software)

TNI Índice de Transnacionalidade (do inglês, Transnationality Index)

UNCTAD Conferência das Nações Unidas para o Comércio e Desenvolvimento (do inglês, United Nations Conference for Trade and Development)

USP Universidade de São Paulo

WDI Indicadores de Desenvolvimento Globais (do inglês, World Development Indicators)

WEF $\quad$ Fórum Econômico Mundial (do inglês, World Economic Forum) 


\section{SUMÁRIO}

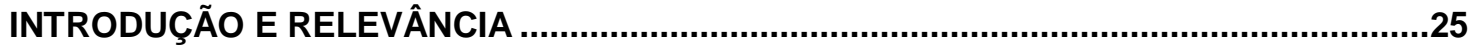

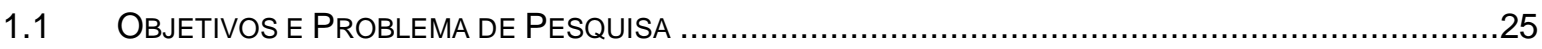

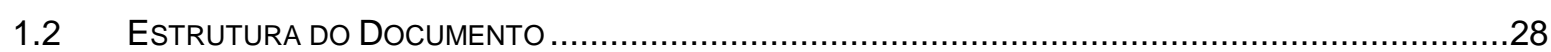

2 REFERENCIAL TEÓRICO .30

2.1 As Empresas Multinacionals (MNES), Multinacionais de Países Emergentes (EMNES) TeOrias, os Efeitos do País de Origem (COES) E o ARgumento do Escape .30

2.2 Transformando COES EM VANTAGENS Competitivas atraVÉS de CAPACIDADES DE INOVAÇÃO;

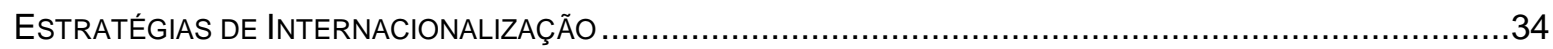

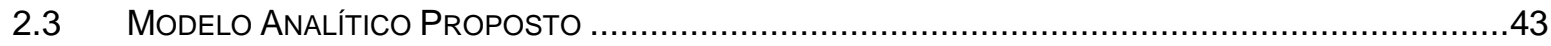

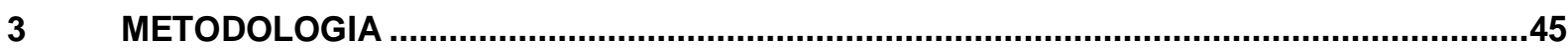

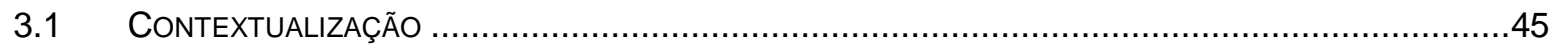

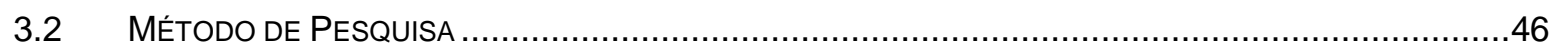

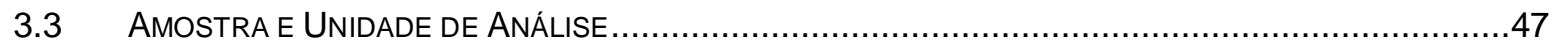

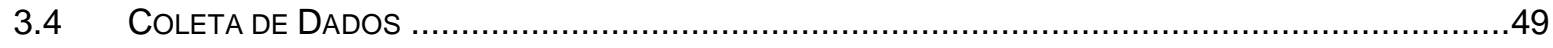

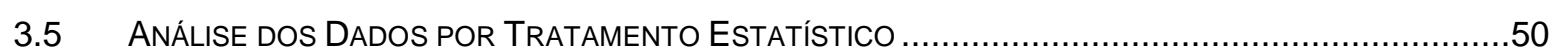

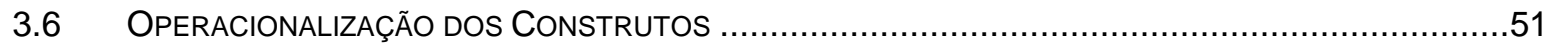

3.6.1 Competências e Capacidade de Inovação ………....................................................

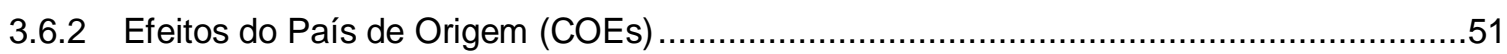

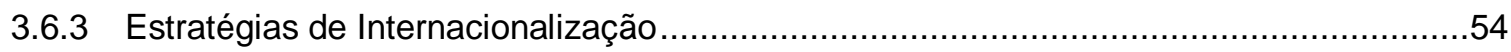

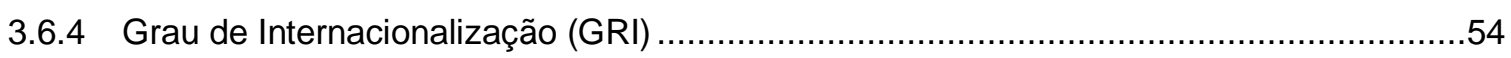

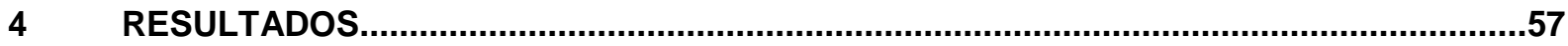

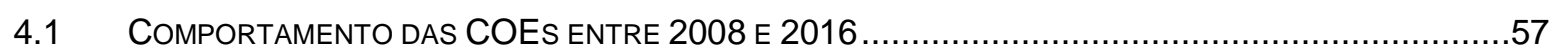

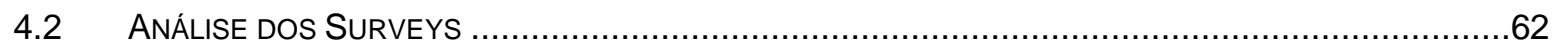

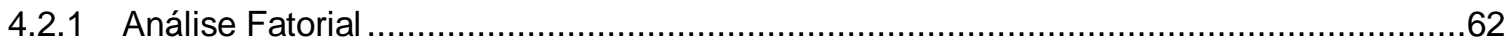

4.2.2 Comparação e análise dos fatores de capacidades de inovação entre 2010 e 2015 ......65

4.2.3 Análise de Agrupamentos das capacidades de inovação..............................................66

5 DISCUSSÃO

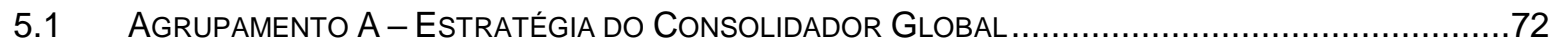

5.2 AGRUPAMENTO B - INTEGRADOR VERTICAL DE RECURSOS NATURAIS.......................................74

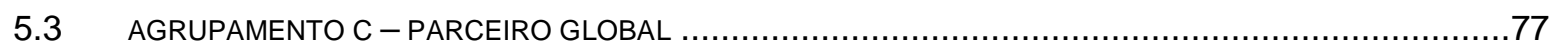

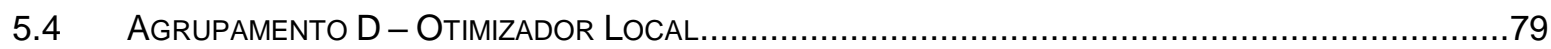

6 A MUdANÇA NO AMBIENTE INSTITUCIONAL POLÍTICO E ECONÔMICO DO BRASIL AFETOU A EXPANSÃO INTERNACIONAL DAS BRMNES? ..................................................81

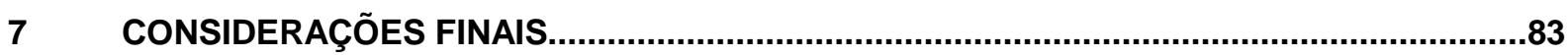




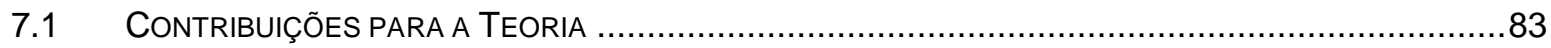

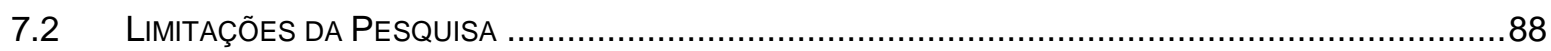

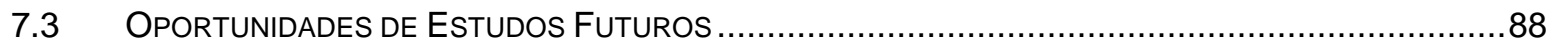

REFERÊNCIAS

APÊNDICE A - MATRIZES DE CORRELAÇÃO E ANTI-IMAGEM SURVEY FGV/USP 2015 ........100

APÊNDICE B - MATRIZES DE CORRELAÇÃO E ANTI-IMAGEM ...........................................102

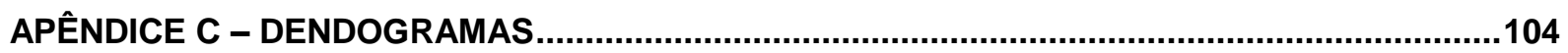

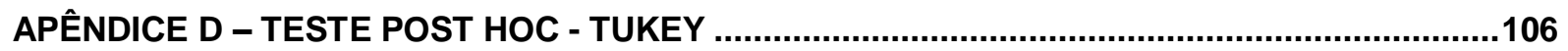

APÊNDICE E - COMPARAÇÃO DAS CAPACIDADES DE INOVAÇÃO SEM OS OUTLIERS PARA

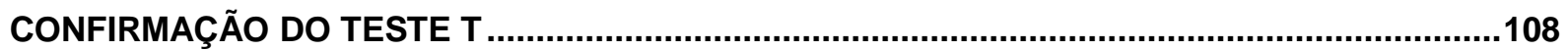




\section{INTRODUÇÃO E RELEVÂNCIA}

\subsection{OBJETIVOS E PROBLEMA DE PESQUISA}

A internacionalização das empresas de países emergentes (EMNEs) tem sido associada à busca do desenvolvimento de capacidades de inovação (FLEURY; FLEURY; BORINI, 2013; LUO; TUNG, 2007; WILLIAMSON et al., 2013). Ao competir com concorrentes de outros países emergentes e desenvolvidos nos mercados globais, as EMNEs precisam construir novas capacidades, seja por aprendizagem própria, seja por aquisição e absorção (LUO; TUNG, 2007). Há evidências de que essas empresas procuram escapar das desvantagens, limitações e deficiências institucionais de seus países de origem para aumentar seu potencial competitivo (CUERVO-CAZURRA; NARULA; UN, 2015). A argumentação do escape sugere que ao aumentar sua internacionalização, as EMNEs logram reduzir a influência de seus países de origem e se igualam às suas concorrentes dos países desenvolvidos. Mas será que escapam? Será que ao avançar em seu processo de internacionalização as EMNEs ficam menos sujeitas às restrições existentes em seus países de origem?

Este estudo analisa a questão do escape ao acompanhar a evolução da capacidade de inovação de empresas multinacionais brasileiras (BrMNEs) em um período de mudanças nos efeitos de seu país de origem (COEs). Se o aumento de internacionalização reduz a influência de COEs conforme prevê o argumento do escape, as capacidades de inovação das EMNEs deveriam sempre aumentar. No entanto, esse pressuposto pode não ocorrer se os efeitos de país de origem seguirem influindo no comportamento das BrMNEs.

As empresas multinacionais de países emergentes (EMNEs), responsáveis por um quarto de todos os investimentos diretos no exterior (IDE) realizados em 2013 (CUERVO-CAZURRA, 2015), contam em geral com ambientes institucionais mais instáveis ou frágeis que os de países desenvolvidos. Elas sofrem influência desses ambientes domésticos em seu desempenho e em sua estratégia de internacionalização conforme Meyer et al. (2009), Peng (2003), Ramsey e Almeida (2010) e Sull e Escobari (2004). A Teoria de Negócios Internacionais, embasada por autores como Cuervo-Cazurra (2012), Lessard e Lucea (2008) e Rugman (2009), propõe que o país de origem é relevante às EMNEs apenas no início de sua 
internacionalização, perdendo importância nos estágios mais avançados em que, de um ponto de vista teórico, essas firmas se equiparariam às equivalentes multinacionais de países desenvolvidos (DMNEs). Cuervo-Cazurra, Narula e Un (2015) argumentam que o principal motivo para as EMNEs se internacionalizarem é para escapar dos efeitos de seus países de origem (COEs). Segundo a argumentação do escape, a maior internacionalização das EMNEs as deixaria mais parecidas com as DMNEs e menos sujeitas às condições adversas de seus países de origem. No entanto, essa argumentação do escape sofre dois desafios.

O primeiro desafio refere-se à origem das vantagens competitivas das multinacionais. As firmas originárias dos países desenvolvidos utilizam-se principalmente de capacidades tecnológicas e marketing para construir suas vantagens com base em produtos e marcas fortes e assim se internacionalizar (BUCKLEY; CASSON, 1976, 2009; DUNNING, 1979, 1998; VERNON, 1966), enquanto as multinacionais dos países emergentes o fazem a partir do aproveitamento de condições específicas do seu país de origem, utilizando-se de capacidades de inovação em funções administrativas e em processos e operações (FLEURY; FLEURY, 2012; GUILLÉN; GARCÍA-CANAL, 2009; MATHEWS, 2006; WILLIAMSON et al. 2013). Portanto, mesmo em estágios avançados de internacionalização as EMNEs ainda assim seriam diferentes das DMNEs ao usarem diferentes capacidades de inovação como base de sua expansão. Ramamurti e Singh (2009) lembram ainda que alguns efeitos dos países de origem (COEs) podem não ser tão efêmeros, apontando como exemplos vantagens de acesso a fontes de recursos naturais ou financiamentos públicos, fatores que persistiriam além dos estágios iniciais de internacionalização.

O segundo desafio refere-se à persistência de COEs mesmo nos estágios mais avançados de internacionalização das multinacionais de países desenvolvidos. As teorias clássicas da internacionalização das firmas, tais como Ciclo de Vida do produto (Vernon, 1966), eclética (Dunning,1979) e Visão Estratégica da Empresa (Porter, 1990) são lembradas por Nachum, Jones e Dunning (2001, p. 280, tradução nossa): "há tempos se reconhece que a competitividade das firmas é relacionada com os recursos e condições de seus países de origem". Marano et al. (2016) sugerem que a relação entre internacionalização e desempenho das empresas multinacionais é influenciada pelo contexto institucional do pais de origem ao estudar 32 países desenvolvidos e emergentes no período entre 1972 e 2012. Nachum, Jones e Dunning (2001) demonstram que mudanças institucionais no país de origem afetam o 
desempenho de suas multinacionais ao estudar o Reino Unido e suas firmas, mesma conclusão a que chega Dimitratos (2002) ao observar pequenas multinacionais gregas. Segundo essas evidências, mesmo ao amadurecer sua internacionalização as EMNEs ainda assim estariam sujeitas aos efeitos de seus países de origem.

Portanto, não está claro até que ponto a argumentação do escape do ambiente institucional mais frágil e instável dos países emergentes perde relevância quando as EMNEs aumentam sua internacionalização. Nesse contexto apresenta-se o seguinte problema de pesquisa:

A internacionalização de uma Empresa Multinacional de País Emergente (EMNE) reduz sua exposição às condições do seu país de origem (COEs) ou não?

Mais especificamente, as seguintes questões de pesquisa podem ser enunciadas:

a) Como o ambiente institucional do país de origem afeta as multinacionais e suas capacidades de inovação ao longo do tempo?

b) A estratégia adotada para internacionalizar tem algum papel nesse processo, e caso afirmativo qual é esse papel?

A abordagem conceitual utilizou as seguintes definições e tipologias para construir o modelo analítico que permitiu estudar as questões de pesquisa formuladas: a definição de Elango e Sethi (1999) para Efeitos do País de Origem (COEs) como geradores de vantagens competitivas para as firmas; a definição da empresa como uma rede de competências (PRAHALAD; HAMEL, 1990) que se desenvolvem a partir das COEs; a definição e o papel das capacidades dinâmicas de inovação na organização das competências (EISENHARDT; MARTIN, 2000; LAWSON; SAMSON, 2001); a tipologia de capacidades de inovação de Fleury, Fleury e Borini (2013); e a tipologia de estratégias de internacionalização de Ramamurti e Singh (2009).

A abordagem metodológica possuiu enfoque empírico ao acompanhar a evolução de um país emergente e suas empresas multinacionais através de análise comparativa. O Brasil foi o país utilizado neste estudo. Seus COEs, representados pelo ambiente institucional, eram positivos e promotores até 2010 , mas a partir de então mudaram drasticamente apresentando instabilidades institucionais econômica e política que atingiram seu auge em 2015. Essa transformação do ambiente institucional foi 
avaliada com a utilização de análise gráfica. A evolução das multinacionais brasileiras (BrMNEs) foi estudada através de suas capacidades de inovação, mensuradas por meio de dois surveys aplicados nos anos de 2010 e 2015. A utilização de técnicas estatísticas exploratórias multivariadas (FÁVERO; BELFIORE, 2015; HAIR et al., 2006) possibilitou identificar fatores que representassem diferentes capacidades de inovação em 2010 e 2015. A comparação dos fatores de capacidades de inovação em 2010 e 2015 através de testes de inferência estatística (DEVORE, 2015) revelou se as perdas provenientes da deterioração do ambiente local sobrepuseram-se aos ganhos auferidos em sua exposição e aprendizado internacional. Análise de agrupamento permitiu reunir as BrMNEs conforme o perfil dos fatores representativos de capacidades de inovação. Os testes de inferência e as análises comparativas dos fatores de capacidades de inovação foram repetidos para cada agrupamento a fim de avaliar se e como esse processo se diferenciou em cada estratégia de internacionalização associada aos diferentes agrupamentos de empresas.

\subsection{ESTRUTURA DO DOCUMENTO}

Este documento está dividido em sete Capítulos, sendo o presente capítulo 1 a Introdução.

O capítulo 2 traz a revisão da literatura relevante para compreensão do problema de pesquisa e elaboração do quadro conceitual, com três seções principais. A seção 2.1 define as empresas multinacionais, descreve as teorias de gestão de operações internacionais, mostrando as diferenças entre as empresas multinacionais dos países desenvolvidos (DMNEs) e de países emergentes (EMNEs) e o papel dos efeitos do país de origem (COEs) nessas diferenças. Apresenta o argumento do escape, os estudos longitudinais das DMNEs com respeito a seus COEs e conclui com a primeira proposição deste trabalho. A seção 2.2 apresenta a firma como conjunto de competências e capacidades e discute como COEs levam à formação de capacidades de inovação usadas para definir estratégias de internacionalização. Encerra-se a seção $2.2 \mathrm{com}$ a segunda proposição. A seção 2.3 apresenta o modelo analítico utilizado na pesquisa, baseado no quadro teórico apresentado nas seções anteriores. O capítulo 3 explica a metodologia utilizada ao longo deste trabalho. Inicia-se com os motivos da escolha do caso brasileiro e descreve as fontes de dados para cada um dos construtos abordados no modelo analítico. Detalha as fontes de dados usadas na 
pesquisa, as escolhas metodológicas e os procedimentos executados em cada fase do trabalho, incluindo a amostragem utilizada, a operacionalização dos construtos, a coleta e análise dos dados.

O capítulo 4 traz os resultados da pesquisa. Inicia no nível país, com análise da evolução do ambiente institucional do país de origem que reflete as mudanças em COEs; a seguir, apresenta o nível firma e a evolução das capacidades de inovação das BrMNEs, identificando quatro agrupamentos de empresas associados a diferentes estratégias de internacionalização.

O capítulo 5 discute os resultados, aprofundando a análise dos níveis país e firma e revisando as proposições da pesquisa.

O capítulo 6 analisa a expansão internacional das BrMNEs no período avaliado, finalizando com "insights" adicionais

Finalmente, o capítulo 7 traz as considerações finais, com as implicações e contribuições dos resultados para a teoria, as limitações da pesquisa e oportunidades para futuros estudos. 


\section{REFERENCIAL TEÓRICO}

\subsection{AS EMPRESAS MULTINACIONAIS (MNES), MULTINACIONAIS DE PAÍSES EMERGENTES (EMNES) - TEORIAS, OS EFEITOS DO PAÍS DE ORIGEM (COES) E O ARGUMENTO DO ESCAPE}

Segundo Fleury e Fleury (2012 p. 35), "a primeira multinacional que se conhece é a Dutch East India Company, fundada em 1602". Empresas Multinacionais (MNEs) de relevância europeias (Saint-Gobain, Siemens entre outras) surgem a partir do final século XIX, enquanto a partir do início do século XX as MNEs norte-americanas entram em cena (Singer, GM e Ford) e têm seu auge a partir do final da II Guerra Mundial (FLEURY; FLEURY, 2007, 2012). A década de 1980 revela as MNEs japonesas (CHO; KIM; RHEE, 1998; CHANG, 1995) enquanto as da Coréia e Taiwan aparecem a partir da década de 1990 (CHO; KIM; RHEE, 1998; MATHEWS, 2002; YEUNG, 1999).

Os modelos que explicam a existência de MNEs originaram-se a partir dos anos 1970, portanto com base na experiência das multinacionais de países desenvolvidos (DMNEs). Basearam-se no pressuposto de que essas empresas se internacionalizam principalmente devido a capacidades inovação de Pesquisa e Desenvolvimento (P\&D) e de marketing. Nas teorias do ciclo do produto de Vernon (1966), da internalização de Buckley e Casson (1976, 2009) e no paradigma eclético de Dunning (1979, 1998), as MNEs teriam origem apenas nos países desenvolvidos a partir dessas capacidades, cabendo aos países menos desenvolvidos o papel de receber subsidiárias das DMNEs para reduzir o custo total de produção, seja por proximidade das fontes de recursos, seja pelo custo mais baixo da mão de obra ou pela proximidade do mercado consumidor. Conforme essas teorias, as empresas multinacionais de países emergentes (EMNEs) sequer existiriam "por falta de condições mínimas para internacionalizar, tais como propriedade de bens intangíveis que as diferenciariam" (DUNNING 1998) ou "teriam crescimento fortuito e pontual determinado por vantagens específicas de seus países de origem, tais como baixo custo de mão de obra" (RUGMAN E VERBEKE, 2001).

No final dos anos 1990 e início dos anos 2000, começam a chamar atenção as EMNEs, notadamente da China e da Índia (AWATE; LARSEN; MUDAMBI, 2012; DUNNING, 2006; KOTHARI; KOTABE; MURPHY, 2013; LUO; TUNG, 2007; 
MATHEWS, 2006), mas também de outros países incluindo o Brasil (ALMEIDA, 2007; FLEURY; FLEURY, 2007, 2012; JUNIOR; BOEHE; BORINI, 2009; JUNIOR, 2010; RAMAMURTI; SINGH, 2009; RUGMAN, 2009; WILLIAMSON et al., 2013). Embora as teorias tradicionais as desconsiderassem ou mesmo negassem sua existência, as EMNEs prosperaram e hoje competem em vários setores com as DMNEs conforme atestam Cuervo-Cazurra (2012), Cuervo-Cazurra e Ramamurti (2014), Fleury e Fleury (2007), Ramamurti e Singh (2009) e Williamson et al. (2013) entre outros.

A evidência da existência e sucesso das EMNEs forçou a uma revisão das teorias da internacionalização das empresas. A principal característica que diferencia as EMNEs das DMNEs é como cada grupo gera vantagem competitiva: enquanto as DMNEs se valem principalmente de inovações de produto e marca para se internacionalizar, as EMNEs baseiam-se em capacidades de inovação de processo e operações e de funções administrativas. Essas geralmente dependem dos Efeitos do País de Origem (COE), e resultam em inovações organizacionais ou de processos de produção (FLEURY; FLEURY, 2012; GUILLÉN; GARCÍA-CANAL, 2009; MATHEWS, 2006; WILLIAMSON et al. 2013). COEs diferem de país para país: a mão de obra barata na China e na Índia e a abundância de recursos naturais na Rússia e no Brasil possibilitaram o surgimento de grandes EMNEs nesses países; as MNEs chinesas contam com suporte governamental através da política chinesa de globalização, enquanto as instituições indianas e brasileiras possuem viés conservador quanto à importância da internacionalização de suas empresas (FLEURY et al., 2015; RAMAMURTI; SINGH, 2009; WILLIAMSON et al., 2013).

Sethi e Elango (1999, p.287, tradução nossa) definem Efeitos do País de Origem (COEs) como "os recursos físicos e humanos, instituições políticas e as características culturais de um país que poderiam prover suas firmas com vantagem competitiva superior em comparação a outras firmas de outros países". Ramamurti e Singh (2009) argumentam que COEs não fizeram parte das teorias originais das multinacionais porque as DMNEs já estavam em estágios avançados de internacionalização quando foram estudadas, enquanto a maioria das EMNEs ainda está em estágios inicial ou intermediário de internacionalização. Cuervo-Cazurra (2012), Lessard e Lucea (2008), Ramamurti e Singh (2009) e Rugman (2009) propõem que a influência em COEs na formação de vantagens competitivas é grande nos estágios iniciais de internacionalização, decaindo nos estágios mais avançados. Ao revisar a literatura de 
negócios internacionais e sua evolução com o surgimento das EMNEs, CuervoCazurra (2012, p. 162, tradução nossa) conclui que "a contribuição potencial à teoria através da análise de EMNEs como fenômeno distinto cai nos estágios mais avançados de internacionalização".

COEs característicos dos países emergentes, em particular seu ambiente institucional mais frágil que o dos países desenvolvidos, levou Cuervo-Cazurra, Narula e Un (2015) a elaborarem quatro motivos para a internacionalização das EMNEs: (a) vender mais, onde a firma explora os recursos do seu país de origem para obter vantagens competitivas no exterior; (b) comprar melhor, em que a firma melhora a qualidade das compras explorando recursos no exterior e fugindo das limitações do país de origem; (c) fazer upgrade através da incorporação de recursos no exterior inexistentes no país de origem; (d) escapar, em que a firma explora novos recursos e evita as condições desfavoráveis de seu país de origem. Exceto o primeiro motivo, os outros buscam reduzir ou anular a dependência em COEs, o que Cuervo-Cazurra, Narula e Un (2015) denominam motivos de escape para uma EMNE se internacionalizar e assim evitar as piores condições de seu país de origem com relação às dos países onde ela instala suas operações. Segundo esse raciocínio, muitas operações internacionais reduziriam a dependência do país de origem, igualando EMNEs a DMNEs do ponto de vista teórico (CUERVO-CAZURRA, 2012). No entanto, essa abordagem não leva em conta a diferente origem das vantagens competitivas das EMNEs e das DMNEs nem explica como as primeiras se igualariam às últimas somente por aumentar sua internacionalização. Explora-se esse problema com mais profundidade na próxima seção.

Um segundo problema com o argumento do escape é que mesmo as DMNEs com avançada internacionalização parecem sofrer influência de seus países de origem. Embora raros, os estudos empíricos longitudinais a respeito da influência de COEs nas empresas multinacionais oferecem evidência de sua persistência ao longo do tempo, como sugerem os trabalhos de Dimitratos (2002), Nachum, Jones e Dunning (2001) e Sull e Escobari (2004).

Nachum, Jones e Dunning (2001) analisam o caso do Reino Unido a partir da competitividade do país e de suas multinacionais ao longo do século XX. Utilizam o PIB e as exportações como indicadores de competitividade do país, e os investimentos diretos no exterior (IDE) como indicadores de competitividade das multinacionais. Comparam o Reino Unido aos países de Organização para 
Cooperação e Desenvolvimento Econômico (OCDE). Uma queda significativa de competitividade ocorreu entre os anos 1950 e 1970, período em que medidas governamentais afetaram 0 ambiente institucional do país, favorecendo baixa produtividade e dificultando adoção de novas tecnologias. O resultado foi a perda de competitividade do Reino Unido e de suas empresas. Nos anos 1950 o Reino Unido foi responsável por 25\% das exportações globais, enquanto em 1975 essa fatia caiu para apenas 7,5\%. Em contraste, o período seguinte apresentou duplicação das exportações entre 1975 e 1980, e nova duplicação entre 1980 e 1990. Além disso, nos anos 1980 o Reino Unido recuperou a segunda posição entre os países com maior IDE no mundo, representando $20 \%$ do total global. Nachum, Jones e Dunning (2001) associam essa reversão às políticas governamentais que incentivaram o aumento tanto da produtividade histórica como da produtividade em relação aos concorrentes do Reino Unido. Também sugerem que o aumento simultâneo das exportações e do IDE nos anos 1980 provocaram aumento de competitividade tanto para o Reino Unido como para suas multinacionais.

Dimitratos (2002) avalia fatores locacionais de pequenas multinacionais gregas, indicando que empresas de dois diferentes locais na Grécia, Tessalonia, próxima à fronteira com outros países do Mercado Comum Europeu, e Atenas, centro político e financeiro do país, possuem diferentes estratégias de internacionalização devido aos diferentes tipos de COEs que cada local oferece. No caso de Tessalonia, a proximidade das fronteiras, a existência de um grande porto, a existência de feiras e um ambiente competitivo e o fato de existirem diásporas gregas na Europa e nos Estados Unidos facilita a internacionalização das suas empresas com relação às suas concorrentes atenienses. No caso grego, localizar-se em Tessalonia é uma vantagem competitiva, enquanto localizar-se em Atenas é uma desvantagem, ambas COEs locacionais da Grécia que as diferenciaram ao longo do tempo.

Sull e Escobari (2004) descrevem o ambiente institucional do Brasil, um país emergente, como instável, que tem períodos de estabilidade, quando as empresas podem desenvolver suas competências e capacidades no que os autores chamam de preparação ativa, entremeados por períodos de grande turbulência, quando aparecem tanto desvantagens como vantagens intrínsecas do país, denominadas ameaças de morte súbita e oportunidades de ouro respectivamente. As empresas que não se preparam ativamente nos tempos de calmaria têm mais risco de sucumbir às ameaças 
de morte súbita, ou não terão condições de capturar as oportunidades de ouro e crescer. Sull e Escobari (2004) apresentam casos de empresas com diversos graus de internacionalização para comprovar seu modelo.

Os trabalhos de Dimitratos (2002), Nachum, Jones e Dunning (2001) e Sull e Escobari (2004) sugerem influência de COEs no desenvolvimento de suas multinacionais, tanto em países desenvolvidos como o Reino Unido e a Grécia como em países emergentes como o Brasil; e tanto em empresas recém internacionalizadas quanto aquelas já maduras em seu processo de internacionalização. Quando COEs favorecem as MNEs, promovem crescimento e internacionalização; quando COEs formam barreiras ao crescimento, podem prejudicar a evolução das MNEs se não puderem ser transformados em vantagens competitivas.

A constatação de que COEs interferem no desempenho de empresas de países emergentes e desenvolvidos, e a diferente origem das vantagens competitivas de DMNEs e EMNEs desafiam o argumento do escape de Cuervo-Cazurra, Narula e Un (2015), pois ele traz embutido o pressuposto de Cuervo-Cazurra (2012), Lessard e Lucea (2008), Ramamurti e Singh (2009) e Rugman (2009) de que o avanço da internacionalização das EMNEs reduziria os efeitos de seus países de origem em suas operações. Isto leva à proposição 1 deste estudo:

PROPOSIÇÃO 1: A INFLUÊNCIA DE COES PODE SE MANTER AO LONGO DO TEMPO NAS EMNES, AO CONTRÁRIO DO QUE PREVÊ A MOTIVAÇÃO DO ESCAPE.

\subsection{TRANSFORMANDO COES EM VANTAGENS COMPETITIVAS ATRAVÉS DE CAPACIDADES DE INOVAÇÃO; ESTRATÉGIAS DE INTERNACIONALIZAÇÃO}

Empresas Multinacionais (MNEs) podem ser definidas como "uma rede diferenciada de operações dispersas, com uma configuração de competências e capacidades que não podem ser totalmente controladas através de decisões hierárquicas tomadas pela matriz corporativa" (RUGMAN; VERBEKE, 2001, pág. 238, tradução nossa). As competências a que se referem Rugman e Verbeke (2001) têm origem na definição por Prahalad e Hamel (1990) de competências essenciais como recursos intangíveis que: (a) a concorrência tem dificuldades em imitar; (b) que proporcionam à empresa 
capacidade de gerar produtos e serviços diferenciados aos seus clientes; e (c) que possibilitam maior flexibilidade na exploração de diferentes mercados.

O domínio de competências por si só, no entanto, não assegura a manutenção de vantagem competitiva, segundo Eisenhardt e Martin (2000). Para tanto, as competências devem ser reorganizadas continuamente de forma rápida e flexível de forma a gerar e manter vantagem competitiva. A fonte dessa vantagem é chamada de capacidade dinâmica e enfatiza dois aspectos: primeiro, refere-se ao caráter mutante do ambiente; segundo, enfatiza o papel-chave da gestão estratégica em adaptar, integrar e reconfigurar apropriadamente habilidades organizacionais, recursos e competências funcionais em reação ao ambiente em mutação (EISENHARDT E MARTIN, 2000; TEECE; PISANO, 1994). Lawson e Samson (2001) definem a capacidade de inovação, um tipo particular de capacidade dinâmica, como "a habilidade de moldar e gerenciar diferentes competências organizacionais e recursos que estimulam as atividades de inovação com sucesso", definição utilizada neste estudo.

Fleury, Fleury e Borini (2013) descrevem quatro tipos de capacidades de inovação utilizadas pelas MNEs: (a) Tecnológica, que inclui desenvolvimento de tecnologia e P\&D; (b) Produção e Operações, que também inclui compras e cadeia de suprimento de materiais; (c) Marketing, que também inclui a cadeia de distribuição, vendas e serviços; e (d) Funções Administrativas, subdivididas em legais, financeiras e recursos humanos. Fleury e Fleury (2012) definem ainda as três primeiras - Tecnológica; Produção e Operações; e Marketing - como essenciais, terminologia utilizada mais adiante no estudo das capacidades de inovação relacionadas às competências da firma. As DMNEs utilizam-se principalmente de capacidades de inovação Tecnológica e de Marketing para obter produtos e marcas diferenciados, sua vantagem competitiva (BUCKLEY; CASSON, 1976, 2009; DUNNING, 1979, 1998), enquanto as EMNEs, deficientes em produtos e marcas, buscam outras alternativas de diferenciação.

Uma forma de adquirir capacidade de inovação Tecnológica é busca-la no exterior, processo utilizado por MNEs chinesas e denominado de efeito trampolim por Luo e Tung (2007). No Brasil, Almeida (2007), Fleury e Fleury (2007, 2012), Junior (2010) e Ramsey e Almeida (2010) descrevem empresas multinacionais brasileiras (BrMNEs) que buscaram parcerias para desenvolvimento de tecnologia no exterior destacando diversas origens e setores como Petrobrás (estatal), Vale do Rio Doce (mineradora 
privatizada), Embraer (aeronáutica privatizada), Votorantim (recursos naturais), Gerdau (siderurgia), Ambev (bens de consumo), Weg (componentes e subsistemas) e Natura (cosméticos). Almeida (2007) também destaca outra estratégia, a aquisição de empresas com capacidade de inovação tecnológica, exemplificada pela Sabó (autopeças), que adquiriu a KaKo alemã, detentora de competências de P\&D na indústria automotiva com o fim específico de se qualificar como fornecedora das grandes montadoras de automóveis. Este processo também é conhecido como inovação reversa, em que as capacidades adquiridas nas subsidiárias são replicadas em suas matrizes (GOVINDARAJAN E RAMAMURTI, 2011; BORINI et al., 2012). No entanto, a maioria das EMNEs se internacionaliza usando combinações de capacidades de inovação de Processos e Operação e de Funções Administrativas através de modelos organizacionais diferenciados que thes conferem vantagens competitivas no mercado internacional (FLEURY; FLEURY, 2012; MATHEWS, 2006; RAMAMURTI, 2012; WILLIAMSON et al., 2013). Guillén e García-Canal (2009) e Mathews (2006) destacam a capacidade de inovação com base em modelos organizacionais originais das EMNEs, derivada da vivência em ambientes institucionais instáveis, da necessidade de internacionalizar rapidamente tanto em países desenvolvidos como em outros países emergentes, e do uso de alianças e fusões como modo de entrada no exterior. Fleury e Fleury (2012) e Fleury, Fleury e Borini (2013), Ramamurti (2012) e Ramamurti e Singh (2009) descrevem a importância da capacidade de inovação em processos de produção para as EMNEs, especialmente no início de sua internacionalização. Nesse momento, elas replicam suas capacidades de inovação em Produção e Operações do país de origem nas suas subsidiárias até que elas se nivelem com as operações da matriz. Iniciam então um ciclo virtuoso de transferência de conhecimentos, especialmente nas indústrias chamadas de "sunsef", aquelas que perderam atratividade para as DMNEs, mas são interessantes para as EMNEs por seu potencial de expansão internacional.

Essa difusão de capacidades de operações através de modelos de inovação organizacional é ilustrada pelo "Gerdau Business System" (GBS), um modelo baseado em macroprocessos que capturam e reaplicam as melhores práticas em toda a empresa utilizando-se de uma plataforma de transmissão de conhecimento padronizada (RAMSEY; ALMEIDA, 2010). Um sistema parecido foi desenvolvido pela Votorantim Cimentos, o "Votorantim Cimentos Best Practices". Além do compartilhamento de melhores práticas, o sistema prevê intenso intercâmbio de 
executivos, visitas entre as unidades, além de proporcionar autonomia às subsidiárias para sua tomada de decisões (FLEURY; FLEURY, 2012). A Vale aliou a sua capacidade de inovação em processos de mineração a um modelo organizacional enfocado em Responsabilidade Social Corporativa (RSC) após dificuldades com a aquisição da Inco no Canadá (FLEURY; FLEURY, 2012). A Embraer adotou um modelo organizacional inovador de parcerias de risco com seus fornecedores, que incluiu a montagem de times integrados para coordenar o desenvolvimento de seus jatos comerciais (ARAUJO, 2012). Cuervo-Cazurra (2012), Fleury e Fleury (2012), Oliveira, Borini e Fleury (2013) e Ramamurti e Singh (2009) evidenciam ainda outros modelos organizacionais inovadores que EMNEs utilizam para organizar suas atividades internacionais, exemplificados por: Marcopolo, que a partir de 2003 aliou seu sistema de plataformas de produção, sua principal vantagem competitiva até então, ao desenvolvimento de sistemas de transporte customizados para atender às demandas locais de seus clientes, tais como o de Curitiba e o de Bogotá; o sistema "Ambev/Brahma de alta performance" com foco em excelência operacional não apenas em processos de produção, mas aplicado a todas as áreas da Ambev; e Tigre, cujo modelo de negócios permite atuação internacional em mercados altamente fragmentados como o da construção.

Os modelos e abordagens descritos acima representam vários caminhos possíveis de internacionalização com o uso de diferentes capacidades de inovação, geralmente associadas a uma condição do país de origem tal como o acesso a um recurso natural, a vivência em ambiente institucional instável ou a necessidade de atender a demandas tecnológicas do setor em que a empresa se encontra (GUILLEN; GARCÍACANAL, 2009; RAMAMURTI; SINGH, 2009). Ramamurti e Singh (2009) agruparam esses possíveis caminhos em cinco estratégias de internacionalização com base em casos de vários países emergentes dentre os quais se inclui o Brasil. Essas estratégias são apresentadas no Quadro 1 e descritas a seguir:

a) Integrador Vertical de Produtos Naturais (Natural Resource Vertical Integrator) - a EMNE que adota esta estratégia tem origem em um país rico em recursos naturais e/ou com um grande mercado consumidor desses recursos, que configuram COEs. O acesso privilegiado a essas fontes e/ou mercados constituem as vantagens dessas firmas. No primeiro caso, as EMNEs expandem-se internacionalmente para ganhar mercados consumidores no 
exterior, caso de empresas como a Gazpom, Lukoil e Norisk, da Rússia, e a Vale, do Brasil, que detêm a propriedade das fontes dos recursos que exploram em seus países de origem; já no segundo caso, as EMNEs buscam por fontes de recursos no exterior para sua conversão e uso no mercado doméstico a que têm acesso, que constituem suas vantagens, caso das indianas Oil and Gas Corporation e da Bharat Petroleum, das chinesas CNOOC e Chinalco e da brasileira Petrobrás. Ainda que a tendência em muitas indústrias seja de desintegração da cadeia produtiva, as firmas de recursos naturais seguem verticalmente integradas. A existência de empresas estatais e de forte regulação é comum, tanto nos países desenvolvidos como emergentes;

b) Otimizador Local (Local Optimizer) - esta é uma estratégia de internacionalização específica das firmas oriundas dos países emergentes. As vantagens dessas empresas são a capacidade de adaptar produtos, processos e serviços às condições específicas de seus mercados domésticos, caracterizados por consumidores de baixa renda e infraestrutura deficiente. Esses produtos, processos e serviços podem ser explorados em outros mercados emergentes, servindo de base para a internacionalização dessas EMNEs, como por exemplo a venda veículos robustos e baratos desenhados para as estradas precárias da Índia em outros países emergentes. Ramamurti e Singh (2009) consideram que os produtos dos otimizadores locais não servem para os mercados desenvolvidos, mas existe evidência em contrário, conforme demonstram Williamson e Yin (2013) ao discutir a inovação de custo e de aplicação das firmas chinesas e mostrar como seus produtos podem atender às populações de baixa renda dos países desenvolvidos;

c) Parceiro Global (Low Cost partner) - o baixo custo de mão de obra, tanto básica e qualificada (engenheiros, cientistas, etc.) em seu país de origem é o COE desse grupo. As vantagens são excelência de processos, gerenciamento de projetos e a capacidade de gerar alto desempenho nas condições adversas dos mercados emergentes a um custo mais baixo do que suas concorrentes, facilitando sua inserção em cadeias globais de valor definidas por Gereffi, Humphrey e Sturgeon (2005). Seu papel é tipicamente o de fornecedores das líderes dessas cadeias (FLEURY; FLEURY; BORINI, 2013). Segundo Ramamurti e Singh (2009), essa estratégia é muito comum na Índia, especialmente em serviços, e na China em produtos; menos comum em países 
emergentes de renda média tais como o Brasil e o México; e praticamente inexistente nos países com renda mais alta, como Israel. A estratégia de internacionalização dessas empresas consiste em entrar em países desenvolvidos através de cadeias globais de valor para buscar mercado, estarem próximas às líderes da cadeia e possivelmente incrementarem sua captura de valor na cadeia, fenômeno descrito como upgrade por Humphrey e Schmitz (2002), além de buscar menores custos localizando subsidiárias em outros países emergentes. Essas características diferenciam as estratégias de internacionalização dos Parceiros Globais daquela usada pelos Otimizadores Locais;

d) Consolidador Global (Global Consolidator) - COEs desse grupo são os clientes sensíveis a preço e seu grande mercado doméstico, que cresceu rapidamente, mas atrasado em relação aos mercados internacionais. Tipicamente pertencem a indústrias maduras com produtos e tecnologias estabelecidas, tais como cimento, aço, alumínio, autopeças, computadores pessoais, bebidas e bens de consumo. Suas vantagens são: a excelência de execução de projetos e produtos para ganho e manutenção em mercados competitivos que exigem preços menores; o fato de serem entrantes tardios, pois se desenvolveram depois das firmas tradicionais de seus setores, resultando em escala, tecnologia e processos organizacionais mais avançados, com posição forte nos mercados domésticos e fluxo de caixa sólido. Sua estratégia de internacionalização consiste em aquisições de empresas com fraco desempenho no exterior, tanto em outros países emergentes como em países desenvolvidos. Exemplos dessa estratégia são a compra da divisão de computadores da IBM pela Lenovo, a expansão da Haier em outros mercados emergentes e desenvolvidos, a compra de fábricas de cimento australianas, americanas e britanicas pela Cemex, todos mencionados por Ramamurti e Singh (2009), e a expansão internacional da Gerdau, inicialmente adquirindo produtores de aço no Canadá, Chile e Uruguai, e posteriormente nos Estados Unidos (Ameristeel, Callaway, Fargo, Sheffield e Chaparral ) e Espanha (Corporación Sidenor), conforme relatam Fleury e Fleury (2012). Algumas características dessas aquisições são: (a) as empresas adquiridas muitas vezes são maiores que as EMNEs adquirentes; (b) as operações adquiridas 
são mais antigas e menos produtivas que as existentes no país de origem das EMNEs, com vendas e lucros decrescentes, o que as torna um alvo atraente para aquisição; (c) as EMNEs que adotam a estratégia de Consolidador Global originam-se em grandes economias, como Brasil, Rússia, Índia, China, África do Sul e México;

Quadro 1 - Estratégias de Internacionalização Genéricas das EMNEs

\begin{tabular}{|c|c|c|c|c|}
\hline $\begin{array}{l}\text { Estratégia } \\
\text { Geral }\end{array}$ & COEs & Vantagens & $\begin{array}{c}\text { Processo de } \\
\text { Internacionalização }\end{array}$ & Exemplos \\
\hline $\begin{array}{l}\text { Integrador } \\
\text { Vertical de } \\
\text { Produtos } \\
\text { Naturais }\end{array}$ & $\begin{array}{l}\text { Abundância de } \\
\text { recursos naturais } \\
\text { ou } \\
\text { Forte demanda } \\
\text { doméstica por } \\
\text { esses recursos }\end{array}$ & $\begin{array}{l}\text { Acesso privilegiado } \\
\text { aos recursos } \\
\text { naturais ou } \\
\text { Acesso ao seu } \\
\text { fornecimento no } \\
\text { mercado doméstico }\end{array}$ & $\begin{array}{l}\text { Integração } \\
\text { internacional das } \\
\text { fontes de recursos } \\
\text { naturais ou } \\
\text { de mercados } \\
\text { consumidores }\end{array}$ & $\begin{array}{l}\text { Gazprom, } \\
\text { Lukoil, Norilsk, } \\
\text { VALE } \\
\text { PETROBRÁs, } \\
\text { Oil and Natural } \\
\text { Gas Corp, } \\
\text { CNOOC }\end{array}$ \\
\hline $\begin{array}{l}\text { Otimizador } \\
\text { Local }\end{array}$ & $\begin{array}{l}\text { Consumidores de } \\
\text { baixa renda } \\
\text { Infraestrutura } \\
\text { deficiente }\end{array}$ & $\begin{array}{l}\text { Capacidade de } \\
\text { otimizar e adaptar } \\
\text { produtos-processos } \\
\text { ao mercado local } \\
\text { Intimidade e } \\
\text { envolvimento com o } \\
\text { cliente local }\end{array}$ & $\begin{array}{l}\text { Mercados-alvo: } \\
\text { outros mercados } \\
\text { emergentes }\end{array}$ & $\begin{array}{l}\text { HiSense, } \\
\text { Mahindra \& } \\
\text { Mahindra, Tata } \\
\text { Motors, } \\
\text { Shoprite, } \\
\text { MARCOPOLO }\end{array}$ \\
\hline $\begin{array}{l}\text { Parceiro } \\
\text { Global }\end{array}$ & $\begin{array}{l}\text { Baixo custo de } \\
\text { mão de obra } \\
\text { Disponibilidade } \\
\text { de Engenheiros, } \\
\text { Cientistas }\end{array}$ & $\begin{array}{l}\text { Excelência em } \\
\text { processo } \\
\text { Gestão de projetos } \\
\text { Capacidade de } \\
\text { operar em } \\
\text { mercados adversos }\end{array}$ & $\begin{array}{l}\text { Mercados-alvo: } \\
\text { países } \\
\text { desenvolvidos } \\
\text { IDE para fazer } \\
\text { "upgrade" da } \\
\text { cadeia de valor e } \\
\text { para ganhar } \\
\text { mercados }\end{array}$ & $\begin{array}{l}\text { Wipro, Infosys, } \\
\text { TCS, Dr. Reddy, } \\
\text { WEG, SABÓ }\end{array}$ \\
\hline $\begin{array}{l}\text { Consolidador } \\
\text { Global }\end{array}$ & $\begin{array}{l}\text { Mercado } \\
\text { doméstico grande } \\
\text { e em expansão } \\
\text { rápida } \\
\text { Consumidores } \\
\text { sensíveis a } \\
\text { preços }\end{array}$ & $\begin{array}{l}\text { Excelência em } \\
\text { execução: projetos } \\
\text { e produção } \\
\text { Entrantes tardios } \\
\text { (escala, tecnologia } \\
\text { e organização) } \\
\text { Posição forte no } \\
\text { mercado doméstico, } \\
\text { forte fluxo de caixa }\end{array}$ & $\begin{array}{l}\text { Mercados-alvo: } \\
\text { Global } \\
\text { IDE enfocado na } \\
\text { aquisição de firmas } \\
\text { com desempenho } \\
\text { fraco }\end{array}$ & $\begin{array}{l}\text { Tata Steel, } \\
\text { Hindalco, South } \\
\text { African } \\
\text { Breweries, } \\
\text { Lenovo, } \\
\text { Wanxiang, } \\
\text { Cemex } \\
\text { AMBEV }\end{array}$ \\
\hline $\begin{array}{l}\text { Inovadores } \\
\text { Globais }\end{array}$ & $\begin{array}{l}\text { Demanda alta e } \\
\text { crescente em } \\
\text { nova indústria } \\
\text { Baixo custo } \\
\text { doméstico para } \\
\text { projeto, } \\
\text { engenharia e } \\
\text { produção }\end{array}$ & $\begin{array}{l}\text { Proximidade com } \\
\text { fronteiras } \\
\text { tecnológicas } \\
\text { Forte posição no } \\
\text { mercado doméstico, } \\
\text { possivelmente com } \\
\text { apoio estatal }\end{array}$ & $\begin{array}{l}\text { Mercados-alvo: } \\
\text { IDE para aquisição } \\
\text { de tecnologias, } \\
\text { competências e } \\
\text { acesso a clientes } \\
\text { IDE para ganhar } \\
\text { mercado e } \\
\text { diversificar a base } \\
\text { produtiva }\end{array}$ & $\begin{array}{l}\text { Huawei, Suzlon } \\
\text { Energy, Check } \\
\text { Point, Teva, } \\
\text { EMBRAER }\end{array}$ \\
\hline
\end{tabular}

Fonte: Adaptado de Ramamurti e Singh (2009) págs 410 e 411 
e) Inovadores Globais (Global First movers) - essa estratégia envolve EMNEs que operam em fronteiras tecnológicas e indústrias nascentes. Alguns exemplos são a Huawei chinesa em tecnologia e equipamentos para telefonia 3G; a brasileira Embraer em jatos regionais; as indianas Suzlon em geradores eólicos e Dr. Reddy na indústria farmacêutica; e a Teva israelense, também na indústria farmacêutica. Os mercados-alvo dessas EMNEs são outros países emergentes, onde iniciam novas operações (greenfield) e países desenvolvidos através de fusões e aquisições. Ao contrário das demais estratégias, baseadas em indústrias maduras com tecnologia básica a média, os inovadores globais atuam em indústrias nascentes com tecnologia de ponta. Conforme o Quadro 1 e as descrições acima, cada estratégia de internacionalização utiliza formas de capacidades de inovação que geram vantagens competitivas a partir de diferentes COEs. Se esses últimos sofrerem alguma alteração, é razoável supor que haverá impacto nas vantagens das EMNEs e que esse impacto será diferente conforme o COE que mudou. Por exemplo, a descoberta de uma nova jazida mineral importante afeta diretamente as empresas que exploram esse COE, eventualmente provocando o desenvolvimento de vantagens que permitam às empresas explorar a nova situação. A descoberta de jazidas de petróleo no pré-sal e a necessidade do desenvolvimento de novas tecnologias para sua exploração ilustram mudança de COE dessa natureza com grande impacto no setor petrolífero (GOUVEIA, 2010; LIMA, 2008; RICCOMINI, 2012). Já a erosão do ambiente institucional gerando incertezas do ponto de vista regulatório, político ou econômico afetam a operação das empresas em geral segundo Holmes et al. (2013).

Um exemplo de mudança de ambiente institucional ocorre no Brasil ao longo dos anos 2010, com reversão de um ambiente institucional positivo em 2010 para um ambiente de instabilidade econômica e política a partir de 2013. Os parágrafos seguintes especulam sobre como esta situação afetaria EMNEs que se utilizam de cada estratégia de internacionalização de Ramamurti e Singh (2009), partindo do pressuposto que em situações de mudanças rápidas e imprevisíveis, a fonte de vantagens competitivas é o uso de capacidades dinâmicas para reorganizar e reconfigurar competências rapidamente (EISENHARDT; MARTIN, 2000).

A estratégia do integrador vertical de recursos naturais tem duas vertentes -0 acesso privilegiado aos recursos e o acesso privilegiado ao mercado consumidor. No primeiro 
caso, a estratégia é de internacionalização em busca de mercados consumidores e, portanto, as EMNEs que se utilizam dessa estratégia ficam sujeitas ao preço dos seus produtos no mercado internacional, com pouca ou nenhuma influência pelo mercado local. Commodities como minérios, aço, cimento e papel e celulose ilustram alguns desses produtos. No segundo caso, do acesso privilegiado ao mercado consumidor, as EMNEs teriam problemas com a deterioração do ambiente econômico, uma vez que sua estratégia se baseia justamente na exploração desse ambiente. A Petrobrás e seu monopólio de refino e distribuição de derivados de petróleo ilustram esta situação.

A estratégia do Otimizador Local, baseada na adaptação de produtos e processos a mercados de baixa renda, infraestrutura deficiente e contando com intimidade com o cliente local, deve sofrer impacto direto da instabilidade institucional. Segundo Sull e Escobari (2004), esse seria o momento de "morte súbita", mas que também pode se reverter em "oportunidade de ouro". Assim, pode-se supor que as EMNEs que apresentam agilidade e capacidade de inovação conforme Eisenhardt e Martin (2000) descobrirão as "oportunidades de ouro" e irão beneficiar-se do ambiente instável, enquanto outras enfrentarão sérias dificuldades para superar o momento de "morte súbita".

A estratégia do Parceiro Global beneficia-se do COE de disponibilidade de mão de obra barata, sem ou com qualificação. Em tempos de turbulência, a tendência de altas taxas de desemprego e a desvalorização da moeda local podem ser benéficas para esse grupo de empresas, pois sua receita é ligada às cadeias globais de valor. Embora as vendas domésticas possam sofrer nesse ambiente, as internacionais dele se beneficiam, especialmente se as operações fizerem uso da mão de obra do país de origem.

As empresas que utilizam a estratégia do Consolidador Global, baseadas em grandes mercados domésticos, podem sofrer com a deterioração institucional, especialmente a econômica, pois ela afeta a receita doméstica, o fluxo de caixa e consequentemente a capacidade das empresas em investirem em sua expansão e aquisição de competências no exterior. Provavelmente essas empresas buscariam reduzir sua dependência do mercado interno internacionalizando suas operações, procurando novos mercado tal como prevê Cuervo-Cazurra (2012, 2015), o que também confirmaria o argumento de escape de Cuervo-Cazurra, Narula e Un (2015). 
Finalmente, os inovadores globais poderiam sofrer diferentes influências de uma instabilidade institucional em seu país de origem. Se por um lado, assim como os parceiros globais, essas empresas se beneficiariam da maior oferta de mão de obra no mercado doméstico e sofreriam um impacto menor por conta de sua exposição internacional em indústrias de ponta, por outro lado aquelas que contam com forte apoio estatal sofreriam com ambientes institucionais que reduzissem sua capacidade de investimento, seja por problemas econômicos, políticos ou regulatórios.

Considerando-se a especulação sobre capacidades de inovação de grupos de EMNEs que se valem das diferentes estratégias de internacionalização e as mudanças produzidas por uma instabilidade institucional nos seus COEs, enuncia-se a segunda proposição deste trabalho:

PROPOSIÇÃO 2 - OS IMPACTOS DE MUDANÇAS DE COES NAS CAPACIDADES DE INOVAÇÃO DAS EMNES DEPENDEM DA ESTRATÉGIA DE INTERNACIONALIZAÇÃO UTILIZADA.

\subsection{MODELO ANALÍTICO PROPOSTO}

Os Efeitos do País de Origem (COEs) permitem à Empresa Multinacional de País Emergente (EMNE) desenvolver suas competências essenciais e administrativas, que uma vez organizadas através de capacidades dinâmicas de inovação geram vantagens competitivas. A combinação de COEs e capacidades de inovação define a estratégia de internacionalização da EMNE. Mudanças posteriores em COEs causados por alterações nas instituições econômicas, regulatórias ou políticas podem gerar "ameaças de morte súbita" ou "oportunidades de ouro" que requerem rápida reorganização das competências através de agilidade e capacidade dinâmica de inovação (Proposição 1), com reflexos na competitividade da firma (BAUSCH; KRIST, 2007; CUERVO-CAZURRA; GENC, 2008; ELANGO; SETHY, 2007; MARANO et al., 2016). Podem haver diferentes impactos nas capacidades de inovação das EMNEs conforme a estratégia de internacionalização usada (Proposição 2). O modelo analítico é mostrado na Figura 1. 
Figura 1 - Modelo Analítico

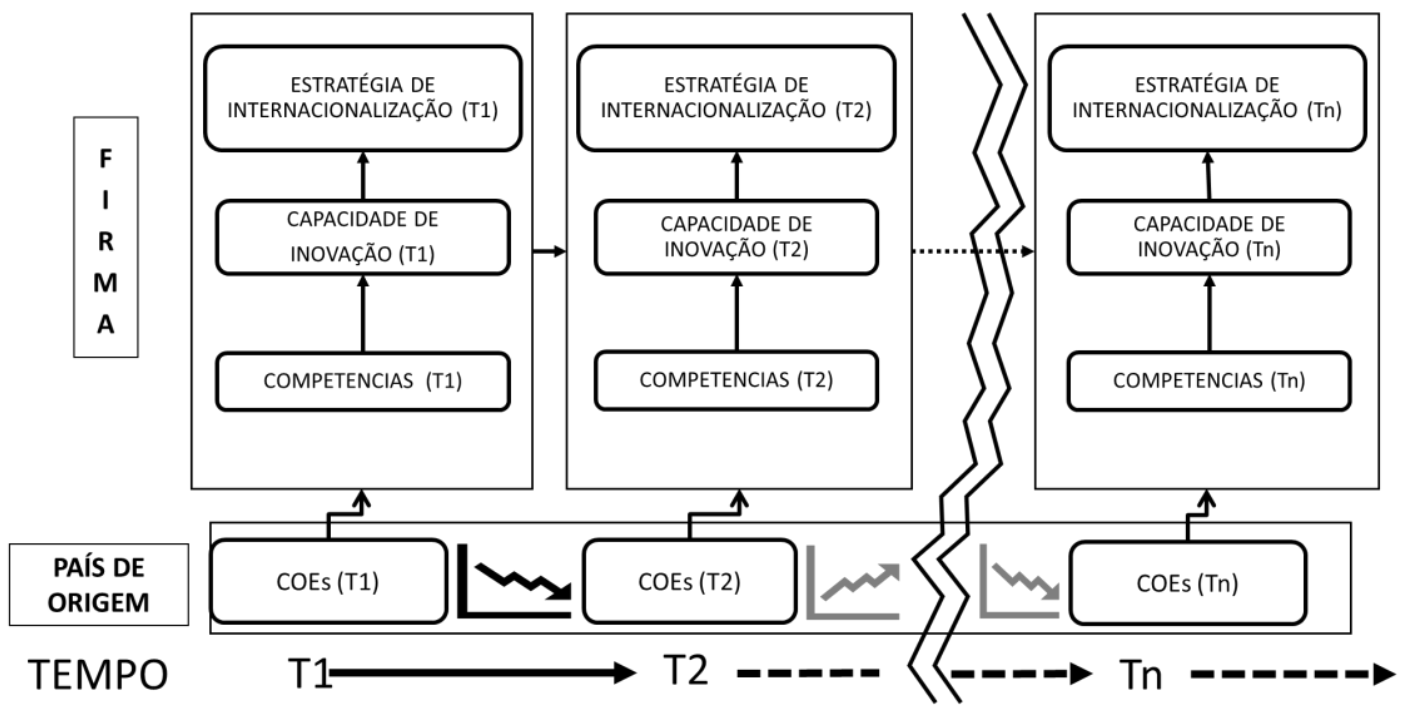

Fonte: Autor 


\section{METODOLOGIA}

\subsection{CONTEXTUALIZAÇÃO}

Alterações significativas nas condições institucionais representando mudanças nos efeitos do país de origem (COEs) que impactem as vantagens competitivas das suas multinacionais ocorrem em períodos de tempo relativamente longos. Nachum, Jones e Dunning (2001), por exemplo, estudam a Grã-Bretanha entre os anos de $1870 \mathrm{e}$ 1994 para extrair conclusões sobre a competitividade do país e o efeito nas suas multinacionais usando dois períodos que compreendem os anos de 1945 a 1964 e 1975 a 1990. O desenvolvimento do Japão e da Coréia após a II Guerra Mundial levou algumas décadas para ser notado (AMSDEN, 1991; WESTNEY, 2001), o mesmo ocorrendo com a China e a Índia mais recentemente (KOTHARI; KOTABE; MURPHY, 2013; LUO; TUNG, 2007).

O caso brasileiro é peculiar, pois o ambiente institucional gera períodos de relativa calmaria seguidos de tempos de turbulência institucional (SULL; ESCOBARI; 2004) que deflagram mudanças inesperadas nas suas instituições econômicas, políticas ou regulatórias em períodos relativamente curtos de tempo. O estudo de um desses períodos de instabilidade justifica o uso do Brasil e suas multinacionais (BrMNEs) com o objetivo de compreender como essas mudanças em COEs afetam as vantagens competitivas das BrMNEs e sua capacidade de inovação para lidar com essa turbulência.

Para estudar o nível empresa foram usados dados de dois surveys, um de 2010 executado pela Universidade de São Paulo (USP, 2010) e outro de 2015 executado em conjunto pela Fundação Getúlio Vargas com a USP (FGV; USP, 2015); e para avaliar o ambiente institucional no período compreendido entre 2008 e 2015, utilizaram-se dados secundários de relatórios e bancos de dados de competitividade global do Fórum Econômico Mundial (WEF) (WORLD ECONOMIC FORUM, 2008, 2009, 2010, 2011, 2012, 2013, 2014, 2015, 2016) e do Site da Federação Global de Conselhos de Competitividade (GFCC) (GLOBAL FEDERATION OF COMPETITIVITY COUNCIL, 2017) que extraem informação dos bancos de dados do Banco Mundial e do Fundo Monetário Internacional (FMI). 
O uso de anos imediatamente anteriores aos da execução dos surveys permitiu a avaliação do ambiente institucional e sua tendência no período em que os questionários foram submetidos e completados. Entre 2008 e 2010, o Brasil desfrutava de um ambiente institucional estável e positivo, mas entre 2013 e 2015 esse ambiente deteriorou-se política e econômicamente.

A avaliação da internacionalização das BrMNEs foi efetuada através do índice de transnacionalidade (TNI) publicado pela Fundação Dom Cabral (FDC) (FUNDAÇÃO DOM CABRAL, 2009, 2010, 2011, 2012, 2013, 2014, 2015, 2016). Dada a disponibilidade limitada destes dados, também foram utilizados casos individuais baseados no Site Observatório de Multinacionais Brasileiras da Escola Superior de Propaganda e Marketing (OBSERVATÓRIO MULTINACIONAIS BRASILEIRAS, 2017) e em dados secundários de Sites de BrMNEs.

\subsection{MÉTODO DE PESQUISA}

A presente pesquisa utiliza diversas técnicas para avaliar e comparar os diferentes construtos do modelo analítico da Figura 1. Dados de dois surveys (FGV; USP, 2015; USP, 2010) foram utilizados para avaliar a capacidade de inovação das EMNEs. As respostas aos questionários de ambos os surveys foram avaliadas através de técnicas de análise estatística multivariada exploratória (HAIR et al., 2006): a análise fatorial permitiu identificar fatores relacionados a diferentes capacidades de inovação; e a análise de agrupamento separou as BrMNEs conforme seu perfil de capacidades de inovação. A análise de fatoração foi executada de forma a extrair exatamente os mesmos fatores de ambos os surveys com o intuito de permitir posterior análise longitudinal, executada através da análise de inferência com o uso de testes $T$ de Student para comparação das duas amostras (DEVORE, 2015).

A evolução de COEs, representados por indicadores relacionados ao ambiente institucional do Brasil entre os anos de 2008 e 2016, foi estudada com análise gráfica e comparativa desses indicadores. A evolução do Grau de Internacionalização das empresas, medida através do seu TNI, foi avaliada através de análise gráfica e testes $\mathrm{T}$ de Student. Finalmente, análise comparativa foi utilizada para associar as capacidades de inovação das BrMNEs com as estratégias de internacionalização de Ramamurti e Singh (2009) e analisar sua evolução com a mudança de COEs de seu país de origem no mesmo período. 
Forza (2016) indica o uso de surveys quando o conhecimento sobre o fenômeno investigado é razoável, quando a generalização é uma contribuição importante, quando as variáveis do contexto podem ser detalhadas e quando se busca relações entre as variáveis. Entre os vários usos dos surveys, Forza (2016) menciona a pesquisa de survey para desenvolvimento de teorias, para a confirmação de teorias, e a descritiva, utilizada para entendimento da relevância de um fenômeno e a descrição da incidência ou distribuição desse fenômeno em uma população. A pesquisa de survey descritiva está em linha com o objetivo desta dissertação.

Forza (2016) descreve as várias etapas do processo de pesquisa por survey: (a) conexão do nível teórico e empírico, com as definições operacionais dos construtos, definição das proposições ou hipóteses e definição da unidade de análise e população; (b) desenho da pesquisa, considerando limitações, informações necessárias, tamanho de amostra, seleção de métodos de coleta de dados e desenvolvimento dos instrumentos de medição; (c) teste piloto, para avaliar a qualidade dos procedimentos, instrumentos e manuseio de dados faltantes; (d) coleta de dados, que inclui a aplicação do survey, manuseio de dados faltantes, compilação dos dados e verificação da sua qualidade; (e) análise dos dados, que consiste na análise preliminar, exploratória das proposições, ou confirmatória das hipóteses; (f) geração de relatório com as implicações teóricas e informações sobre reaplicação.

Ainda segundo Forza (2016), os surveys descritivos requerem: definição rigorosa dos construtos a serem medidos e um modelo que ajude na análise dos resultados; análise dos dados descritiva, embora algumas técnicas de redução de dados, tais como análise fatorial, possam ser utilizadas; e rigor na representação da população em estudo. Forza admite o uso de dados secundários, obtidos por outros surveys, como os utilizados na presente dissertação. No presente estudo, executaram-se somente as etapas (a), (e) e (f) acima, uma vez que as demais etapas ocorreram quando da obtenção dos dados primários.

\subsection{AMOSTRA E UNIDADE DE ANÁLISE}

Fleury et al. (2015b) analisam o survey FGV/USP de 2015, constatando que o número de BrMNEs existentes no Brasil saltou de 95 empresas em 2010 para 210 em 2015, um aumento de $120 \%$ conforme ilustra a Figura 2. Nela também é possível observar 
um aumento significativo no setor terciário, de serviços, que saltou de 27 para 79 empresas. No mesmo período, as empresas dos setores secundário e primário, que contavam com operações industriais de produção e extração, praticamente duplicaram, passando de 62 para 120 e 6 a 11 respectivamente.

Figura 2 - Evolução das BrMNEs por setor

\section{BrMNEs por setor em2010 e 2015}

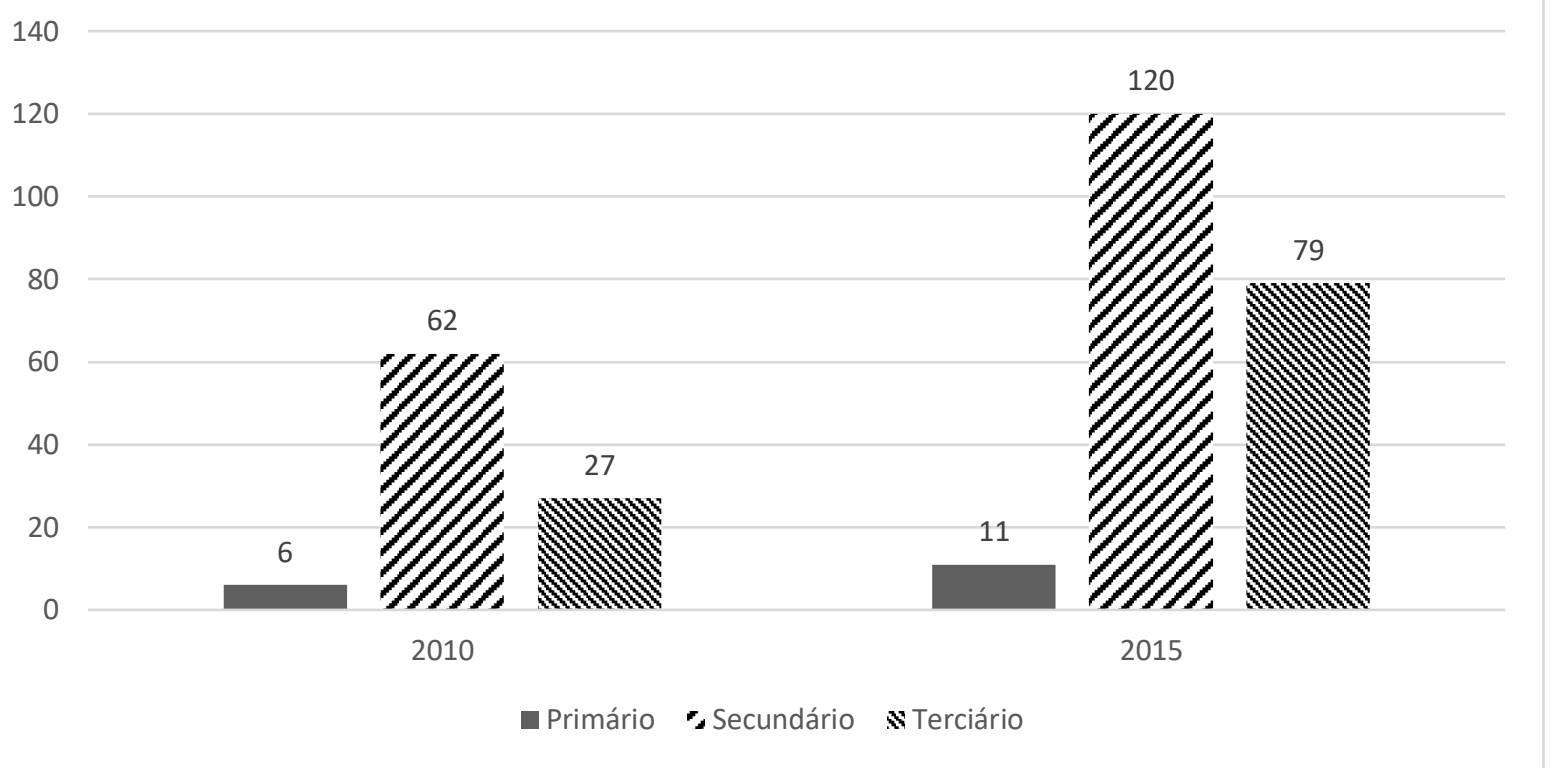

Fonte: Fleury et al. (2015b)

Ainda segundo Fleury et al. (2015b), o survey USP de 2010 enviou questionários às 95 BrMNEs e colheu 64 respostas, cobrindo $67 \%$ da população, sendo $69 \%$ do setor industrial e $31 \%$ do setor de serviços, próxima à proporção da população de BrMNEs; e o FGV/USP de 2015 contou com 60 respondentes das 210 BrMNEs de então, correspondentes a $29 \%$ da população total de BrMNEs, sendo $63 \%$ do setor industrial e os demais $37 \%$ do setor de serviços, também em linha com a proporção presente no total de BrMNEs. Ambos os surveys incluíram firmas de diferentes tamanhos, setores e graus de internacionalização. A amostra inicial, de 64 firmas para 2010 e 60 firmas para 2015, atende aos requerimentos mínimos para análise fatorial, de no mínimo 50 casos e 10 vezes o número de fatores extraídos (HAIR et al., 2006), mas por ser relativamente pequena, sua análise de agrupamento resultou em pequenos grupos de empresas, o que requereu cuidado no trato dos dados e extração das conclusões. 
Dados que refletem as mudanças institucionais que se refletem em COEs foram extraídos dos relatórios do Fórum Econômico Mundial (WORLD ECONOMIC FORUM, 2006, 2008, 2009, 2010, 2011, 2012, 2013, 2014, 2015, 2016); e das bases de dados do Banco Mundial e do Fundo Monetário Internacional através do Site do GFCC (GLOBAL FEDERATION OF COMPETITIVENESS CONCILS, 2017), que permite a construção de gráficos comparativos de diversos indicadores para um ou mais países. Análise gráfica foi utilizada para o estudo longitudinal dos indicadores que refletem o ambiente institucional no período avaliado. Anos anteriores e posteriores a cada survey foram utilizados para identificar tendências na evolução do ambiente institucional nesses períodos.

\subsection{COLETA DE DADOS}

A elaboração do survey USP de 2010 é descrita por Fleury, Fleury e Borini (2013), que explicam seu desenho conforme os passos propostos por Forza (2002) e sua estrutura que busca emular a abordagem desenvolvida por Knight e Kim (2009) com base em seu estudo das competências internacionais. O questionário original possuía vinte e uma questões, a maioria delas similar às de Knight e Kim (2009), com algumas modificações efetuadas para o propósito do survey USP de 2010, questões essas verificadas com experts da academia e representantes das BrMNEs para garantir coerência conceitual e compreensão apropriada das questões.

Os respondentes das firmas foram gestores com responsabilidades de operações internacionais localizados nas matrizes das empresas, principalmente a nível de diretoria, vice-presidência e presidência. A eles foi solicitado que avaliassem cada uma das afirmações utilizando uma escala com cinco opções: (a) discordo totalmente; (b) discordo parcialmente; (c) nem concordo nem discordo; (d) concordo parcialmente; (e) concordo totalmente. Uma escala Likert foi utilizada para tratamento das respostas, sendo 1 correspondente à resposta "discordo totalmente" e 5 à resposta "concordo totalmente".

O mesmo processo foi utilizado para o survey FGV/USP de 2015, que utilizou quinze questões para avaliação das competências e capacidade de inovação das BRMNEs ao invés das vinte e uma do survey USP de 2010. Nove questões que aparecem nos 
questionários de ambos os surveys foram utilizadas para o estudo longitudinal desta pesquisa.

\subsection{ANÁLISE DOS DADOS POR TRATAMENTO ESTATÍSTICO}

Os dados dos surveys USP de 2010 e FGV/USP de 2015 foram processados com auxílio do software de tratamento estatístico SPSS (Statistical Package for the Social Sciences), apropriado para análise multivariada. As técnicas de análise multivariada de dados permitem analisar múltiplas medidas de indivíduos simultaneamente. Duas técnicas exploratórias foram utilizadas: a fatoração das respostas aos questionários com vistas à representação de capacidades de inovação das BrMNEs; e uma análise de agrupamento das empresas participantes de cada survey, definindo comportamentos característicos que foram comparados às estratégias de internacionalização tipificadas por Ramamurti e Singh (2009). Ambas as técnicas são apresentadas em Hair et al. (2006), e sua execução no software SPSS é descrita por Fávero e Belfiore (2015).

Para a comparação longitudinal dos surveys foi utilizada uma análise de inferência com teste de hipótese, o teste T (DEVORE, 2015), que calcula a área comum de duas distribuições e permite identificar diferenças estatísticas na média de duas amostras, mesmo que o seu tamanho seja pequeno e sua variância desconhecida. Para um intervalo de confiança maior que 95\%, a área comum das duas distribuições deve ser menor que $5 \%$ da área total de cada distribuição. O software SPSS calcula o valor da área comum entre duas distribuições e a expressa através de uma grandeza chamada Sig (2-tailed). O teste foi utilizado para avaliar a diferença entre os resultados de 2010 e 2015 para cada fator representativo de capacidades de inovação, considerando-se a totalidade da amostra dos dois surveys e também um subconjunto composto pelas BrMNEs que participaram dos dois surveys para validação dos resultados. Posteriormente, o teste foi aplicado a cada agrupamento identificado na análise de agrupamentos considerando todas as BrMNEs de cada grupo em 2010 e 2015.

Análise gráfica foi utilizada para os índices representativos do ambiente institucional do Brasil entre 2010 e 2015, uma vez que a unidade de análise neste caso é o país, e não a firma. A comparação dos dois conjuntos de resultados permitiu a verificação das proposições 1 e 2 . Uma vez que o grau de internacionalização teoricamente depende da capacidade de inovação das BrMNEs sua evolução também foi avaliada com teste $\mathrm{T}$, mas devido à limitação de disponibilidade de dados, apenas o conjunto 
de BrMNEs que contam com dados foi avaliado. Para a discussão dos resultados gerais e de cada grupo, foram utilizados casos representativos já descritos na literatura ou que possuam dados públicos disponíveis em outras fontes de dados, tais como o Site Observatório de Multinacionais da Escola Superior de Propaganda e Marketing (OBSERVATÓRIO MULTINACIONAIS BRASILEIRAS, 2017), os relatórios Ranking das Transnacionais Brasileiras e Ranking das Multinacionais Brasileiras publicados pela FDC (FUNDAÇÃO DOM CABRAL, 2009, 2010, 2011, 2012, 2013, 2014, 2015, 2016), literatura (FLEURY; FLEURY; 2012; FLEURY; FLEURY; BORINI, 2013; JUNIOR, 2010; RAMAMURTI; SINGH, 2009; RAMSEY; ALMEIDA, 2010; SULL; ESCOBARI, 2004; WILLIAMSON ET AL, 2013;), portais das BrMNEs na Internet; jornais e revistas.

\subsection{OPERACIONALIZAÇÃO DOS CONSTRUTOS}

\subsubsection{Competências e Capacidade de Inovação}

As competências foram categorizadas na tipologia utilizada por Fleury, Fleury e Borini (2013), apresentada na Seção 2.3: (1) Tecnologia; (2) Produção e Operação; (3) Marketing; e (4) Funções Administrativas, subdivididas em finanças e recursos humanos. As quatro competências foram abordadas nos questionários dos dois surveys. A fatoração visou identificar os grupos de questões que caracterizam essas competências. Uma vez que as perguntas têm caráter qualitativo e refletem a opinião dos entrevistados, elas não medem diretamente competências, mas sim a percepção de capacidade de inovação e a rapidez para lidar com o ambiente existente, conforme descrito por Eisenhardt e Martin (2000).

\subsubsection{Efeitos do País de Origem (COEs)}

"Firmas originárias de diferentes países extraem vantagens competitivas únicas a partir de um conjunto diferente de dons, tratos culturais e infraestrutura sociopolítica, quando comparadas com firmas originárias de países que são menos hospitaleiros nessas áreas" (SETHI; ELANGO, 1999 p. 285). Assim, nações desenvolvem COEs através da combinação singular desses elementos existentes em seus países de 
origem e de opções políticas deliberadas. Neste contexto, esses fatores são relacionados a (1) recursos econômicos, físicos e capacidades industriais; (2) valores culturais e normas institucionais; e (3) políticas industriais e econômicas dos governos nacionais.

A dimensão institucional dos países é medida de diversas formas e a partir de diversas fontes segundo a literatura. O Investimento Direto no Exterior (IDE) e o volume de exportações são utilizados por Nachum, Jones e Dunning (2001); indicadores publicados pelo Banco Mundial, tais como o World Development Indicators (WDI) e Worldwide Governance Indicators, e os relatórios Doing Business Reports são usados por Holmes et al. (2013), Meyer et al (2009) e Deng e Yang (2014), e também na construção de outros índices globais tais como o Global Innovation Index da Universidade de Cornell (SOUMITRA; LANVIN; WUNSCH-VINCENT, 2015), e o Global Competitiveness Index (GCl) do WEF (WORLD ECONOMIC FORUM, 2016). A taxa de crescimento do Produto Interno Bruto (PIB) ou sua taxa de crescimento é usada por Nachum, Jones e Dunning (2001) e Elango e Sethi (2007). Os medidores que representam ambientes econômicos de negócios são em geral quantitativos, tais como o IDE, PIB, PIB per capita, taxas de inflação e de câmbio, índices de desemprego, saldo da balança de pagamentos entre outros, disponíveis em vários dos relatórios já mencionados. Já os medidores que representam ambientes políticos e regulatórios são qualitativos, baseados em surveys elaborados pelas instituições que os publicam, tais como os indicadores do relatório Doing Business e os indicadores presentes no Global Governance Index do Banco Mundial, o Índice de Liberdade Econômica, que contém medidores do ambiente regulatório, e os surveys da Freedom House sobre direitos políticos e liberdades civis.

O Relatório de Competitividade Global do WEF (WORLD ECONOMIC FUND, 2006, $2008,2009,2010,2011,2012,2013,2014,2015,2016)$ é utilizado como base para medição do ambiente institucional econômico e político do Brasil no período de estudo. Ele apresenta o $\mathrm{GCl}$ e sua construção a partir de dados públicos dos países, extraídos das bases de dados do Banco Mundial e do FMl, e resultados de um survey entitulado Executive Opinion Report (CORNELIUS; MCARTHUR, 2001), executado junto a executivos das nações listadas. O GCl, tal como definido por Blanke e LopezClaros (2004) e McArthur et al. (2001), envolve 114 indicadores em total, usados para construir índices representativos de doze pilares, por sua vez agrupados em três componentes conforme mostra a Figura 3: (a) requerimentos básicos, formados por 
quatro pilares; (b) promotores de eficiência, formados por seis pilares; (c) fatores de inovação e sofisticação de mercado, constituídos por dois pilares.

Figura 3 - Estrutura do GCl

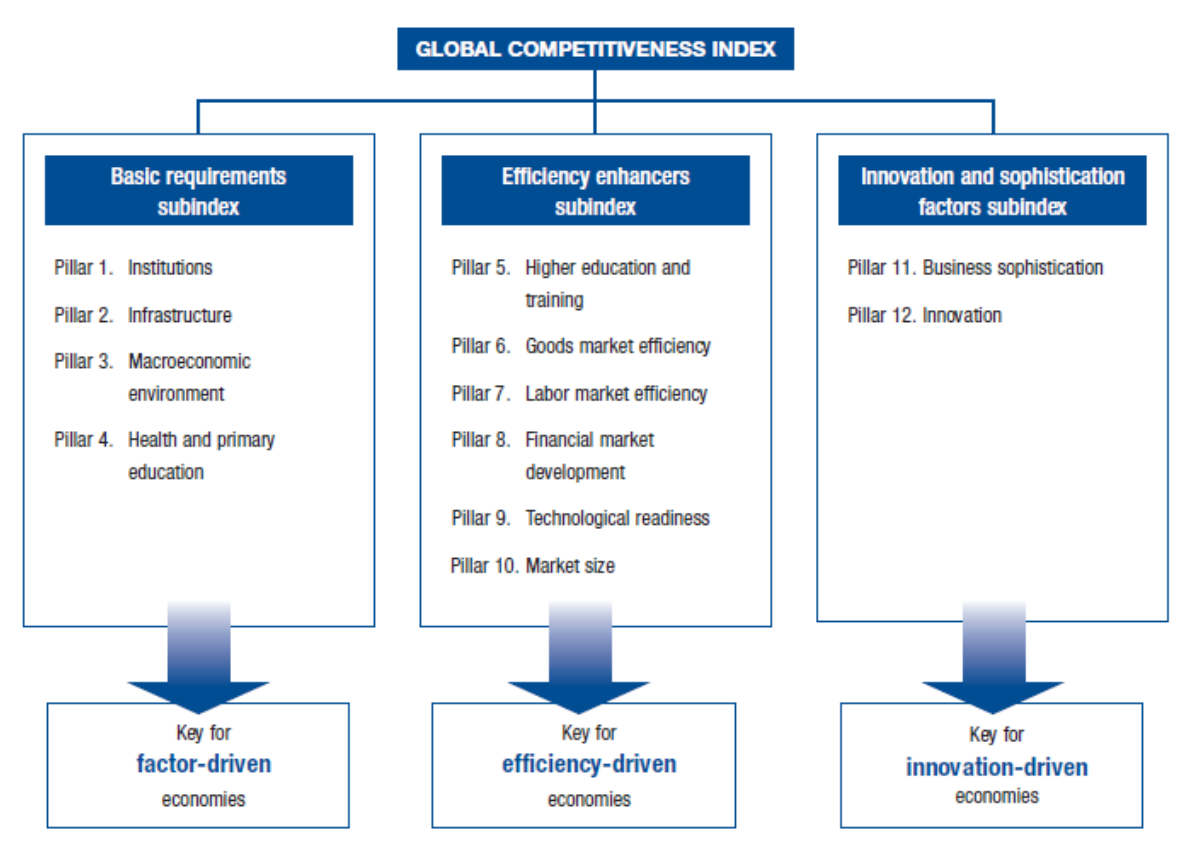

Fonte - The Global Competitiveness Report (WORLD ECONOMIC FORUM, 2016)

O GCl e seus três componentes principais são avaliados no período que antecede ao survey USP de 2010 ao ano posterior ao survey FGV/USP, ou seja, entre 2008 e 2016. Também são avaliados os pilares que refletem ambientes institucionais: (a) o ambiente macroeconômico é avaliado através do medidor do Pilar de Estabilidade Macroeconômica, formado principalmente por indicadores da base de dados World Economic Outlook do FMI como a dívida pública, a taxa de inflação, a taxa de juros, a dívida externa, o saldo do balanço de pagamentos; (b) a evolução do ambiente de negócios e suas regulações é avaliada pelos medidores do Pilar de Eficiência do Mercado de Bens e Serviços e do Pilar de Eficiência do Mercado de trabalho, que agregam indicadores extraídos da base de dados Doing Business do Banco Mundial, tais como o custo e tempo para iniciar um negócio, custos de processos de falência e custos redundantes de trabalho, e indicadores do survey Executive Opinion Report tais como a intensidade da competição local e a flexibilidade na determinação dos salários; (c) a evolução da conectividade e tecnologia é avaliada pelo medidor do Pilar de Disponibilidade Tecnológica, que inclui indicadores de assinaturas de telefones 
celulares, internet fixa e banda larga, além do número de usuários de internet a partir das bases de dados do Banco Mundial.

Complementam a análise os gráficos que refletem as taxas de crescimento do Produto Interno Bruto, taxas de inflação e índices de desemprego no mesmo período em que o $\mathrm{GCl}$ e seus componentes foram avaliados. Os dados foram extraídos do Site da GFCC (GLOBAL FEDERATION OF COMPETITIVENESS COUNCILS, 2017) para efeito da comparação do Brasil com outros países do bloco BRIC (Brasil, Rússia, India e China) e alguns países das Américas (Argentina, Chile e Estados Unidos). Os dados utilizados pela GFCC baseiam-se em informações do Banco Mundial. Tanto os resultados do $\mathrm{GCl}$ como aqueles da GFCC permitem avaliar se as mudanças institucionais ocorridas no período 2010-2015 se refletiram na alteração ou formação de novas COEs.

\subsubsection{Estratégias de Internacionalização}

O construto de estratégias de internacionalização segue o modelo proposto por Ramamurti e Singh (2009). Divide-se, portanto, nas cinco estratégias descritas em 2.2. Avaliam-se os grupos de empresas obtidos através da análise de cluster quanto a essas cinco estratégias, verificando-se a existência da predominância de uma ou mais em cada grupo. Para essa avaliação, utilizam-se dados primários do Survey FGV/USP quando disponíveis; fontes secundárias como estudos de caso e classificações obtidas na literatura (FLEURY; FLEURY; BORINI, 2013; RAMAMURTI; SINGH, 2009; WILLIAMSON et al., 2013); e análise do perfil das empresas através de suas páginas na internet, considerando sua área de atuação, tipo de produto ou serviço oferecido, dispersão geográfica, número e tamanho de subsidiárias.

\subsubsection{Grau de Internacionalização (GRI)}

A medição do grau de internacionalização (GRI) das empresas constitui um amplo debate. Uma descrição do desenvolvimento de índices de internacionalização encontra-se em Floriani (2010) e é resumida a seguir. Os medidores de referência mais utilizados dividem-se em dois grupos - unidimensionais e multidimensionais. Entre os primeiros, o mais utilizado é o FSTS (Foreign Sales / Total Sales ou Vendas 
no Exterior / Vendas Totais), desde os primeiros artigos que buscam avaliar o grau de internacionalização publicados nos anos 1970, tal como exposto por Sullivan (1994), e em particular nos artigos que tratam do desempenho das MNEs ou de empresas exportadoras, escritos nos anos 1990 e 2000 (MCDOUGALL; OVIATT, 1996; KAFOUROS et al., 2008; RIAHI; BELKAOUI, 1998), mas ainda utilizado até hoje (ARATA; SHENG; LORA, 2015; REN; EISINGERICH; TSAI, 2015), algumas vezes devido à indisponibilidade de outros medidores (GAUR; KUMAR, 2009).

Já os medidores multidimensionais baseiam-se principalmente em:

a) DOI (Degree of Internationalization) de Sullivan (1994), que agrupa medidores de desempenho, estrutura e comportamentais. Ele tem sido ajustado conforme a situação e disponibilidade de dados (REUBER; FISCHER 1997; SAPIENZA; DE CLERCQ; SANDBERG, 2005; SEGARO; LARIMO; JONES, 2014). A maior crítica a este índice vem de Ramaswami, Kroek e Renforth (1996), pois o índice agrupa indicadores que podem não ser covariantes, resultando em distorções ou em índices equivalentes para empresas muito diferentes;

b) TNI (Transnationality Index) de letto-Gillies (1998), usado pela UNCTAD, pela Fundação Dom Cabral na divulgação do seu índice anual e também utilizado na literatura (SILVA et al., 2015). Compreende a média de três índices: FSTS já descrito acima; FATA (Foreign Assets / Total Assets - Bens no estrangeiro / Bens Totais); e FETE (Foreign Employees / Total Employees Funcionários no Exterior/ Total de Funcionários). Sua maior deficiência é a falta de um indicador de dispersão territorial, incluído no próximo índice;

(c) Índice de extensão da rede, de letto-Gillies (2001), agrega uma medida de dispersão territorial ao TNI, embora criticado pelo próprio autor devido ao seu escopo limitado, mas também usado como tal por Oesterle, Richta e Fisch (2013) ou adaptado por Kaczmarek e Ruigrok (2013). É a multiplicação do TNI por um fator de dispersão territorial (Nsi) calculado pela razão entre o número de subsidiárias da MNE pelo número de países com comércio internacional.

Além do problema de definição e mensuração, há dificuldades de obtenção de dados para cálculo do GRI. Por exemplo, no caso brasileiro autores como Barcellos e Cyrino (2007) e Forte e Sette Júnior (2005) buscam adaptar os índices acima à realidade brasileira e servem como base para autores realizarem adaptações específicas a seus 
contextos (FLORIANI et al., 2012). Floriani (2010) justifica tais adaptações citando Hassel et al 2003, pois "a validade de medida de GRI depende de seu poder explicativo potencial. Os indicadores devem estar previstos dentro de um contexto de premissas teóricas utilizadas como base para seu cálculo". Considerando a citação a Hassel (2003), a facilidade de acesso, e seu uso na literatura (FLORIANI, 2010; SILVA et al., 2015), o presente trabalho utiliza dados secundários de TNI disponibilizados pela Fundação Dom Cabral em seus relatórios (FUNDAÇÃO DOM CABRAL, 2008, 2009, 2010, 2011, 2012, 2013, 2014, 2015, 2016 e 2017). 


\section{RESULTADOS}

\subsection{COMPORTAMENTO DAS COES ENTRE 2008 E 2016}

A Tabela 1 apresenta o $\mathrm{GCl}$, seus componentes principais e os indicadores dos pilares que refletem o ambiente institucional, conforme discutido em 3.6.2, no período compreendido entre 2008 e 2016. Os anos de 2008 a 2011 e 2013 a 2016 permitem avaliar a tendência dos indicadores no momento da aplicação dos surveys USP (2010) e FGV e USP (2015) respectivamente. Os indicadores revelam uma reversão de tendências das condições competitivas. O Brasil estava evoluindo no ranking global de competitividade, uma vez que estava na posição 64 ( $\mathrm{GCl}$ de 4,2) em 2008, chegou à posição 56 do ranking, com um GCl de 4,26 em 2010, evoluindo para sua melhor posição na série histórica do ranking, 48 ( $\mathrm{GCl}$ de 4,4) em 2012. Nos dois anos seguintes, 2013 e 2014 - houve ligeira deterioração na posição e 2015 apresentou uma retração significativa da posição do Brasil. Em 2016 houve nova queda para a posição atual, 81 ( $\mathrm{GCl}$ 4,06) entre 138 países, portanto, uma perda de 25 posições entre 2010 e 2016. A Figura 4 ilustra essa evolução.

Figura 4 - Evolução do GCl e componentes do Brasil entre 2008 e 2016

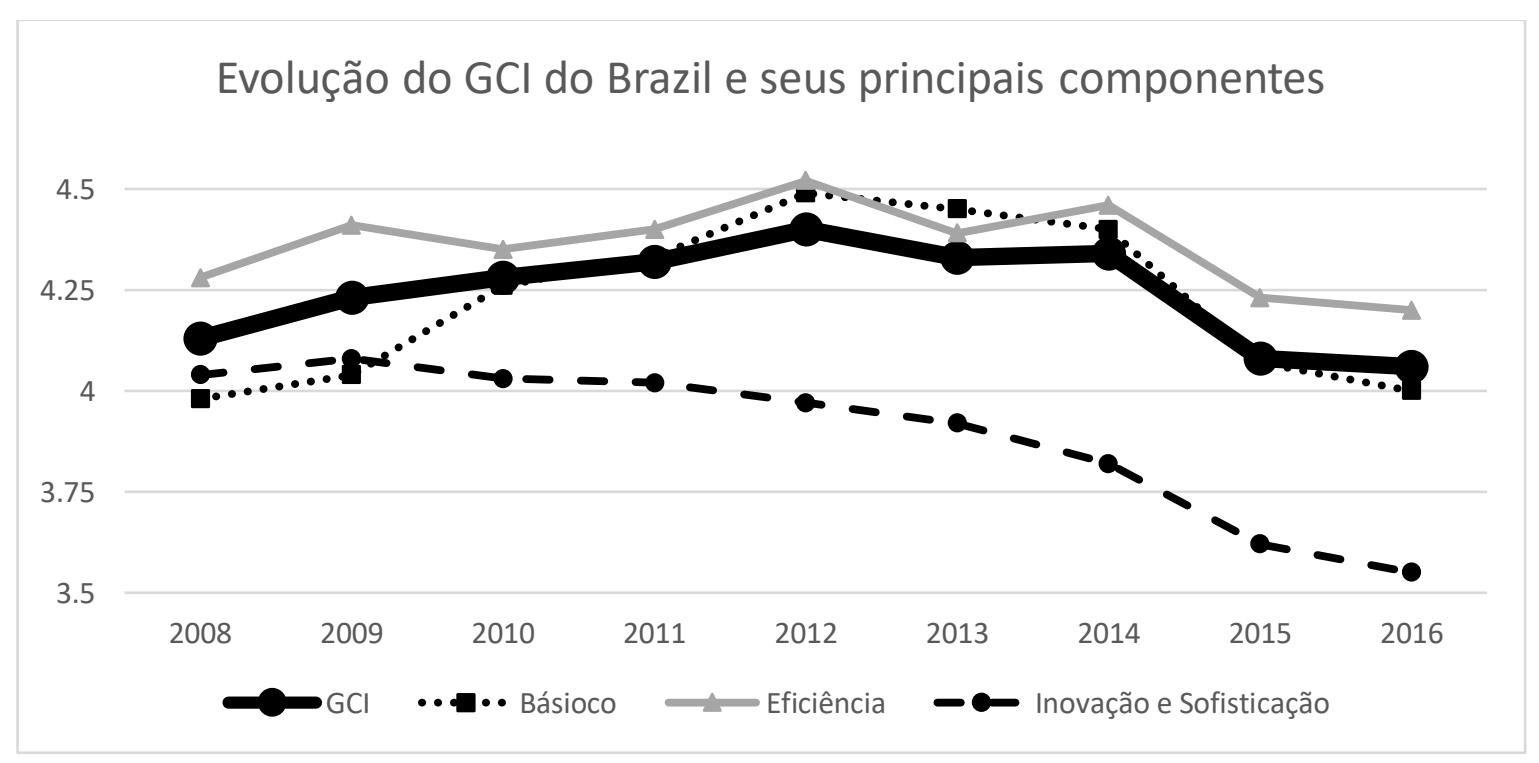

Fonte: Relatórios WEF 2008 a 2016

Os componentes principais sofreram redução, tanto no score quanto no ranking. Os relativos a Requerimentos Básicos e Promotores de Eficiência perderam 28 posições entre 2010 e 2016, conforme mostra a Tabela 1. Ambos evoluíram entre 2008 e 2013, 
mas regrediram a partir daí. Alguns dos pilares que formam esses componentes avaliam o ambiente institucional conforme descrito nos seguintes parágrafos. $O$ último Componente, de Inovação e Sofisticação dos Negócios, apresentou queda contínua no período estudado. Esse resultado é baseado principalmente no survey Executive Opinion Report e avalia principalmente o ambiente interno das empresas. Não reflete, portanto, mudanças institucionais de forma direta, embora reflita a percepção dos executivos das empresas com respeito ao ambiente de negócios e de inovação.

Dois pilares do Componente de Requerimentos Básicos foram analisados - o Pilar 1, referente às Instituições e o Pilar 3, que reflete o ambiente macroeconômico.

O Pilar de Instituições, que se apresentava estável entre 2008 e 2010 com GCl de 3,6 e posição no 93 no ranking de 2010, apresentou leve melhora nos anos seguintes, mas regrediu depois, chegando a um $\mathrm{GCl}$ de 3,1 em 2015, levando o Brasil à posição 121 no ranking global, uma perda de 18 posições. Contribuíram para esse resultado a piora na percepção de corrupção, procedimentos legais mais complexos e a perda de confiança nas instituições em geral, o que sugere uma piora nas instituições políticas.

Tabela 1 - Global Competitiveness Index (GCl)

Componentes Principais e Pilares indicadores de ambiente institucional (os números entre parêntesis referem-se à posição no ranking de nações)

\begin{tabular}{llllllllll}
\hline \multicolumn{1}{c}{ INDICADOR } & 2008 & 2009 & 2010 & 2011 & 2012 & 2013 & 2014 & 2015 & 2016 \\
\hline GCI & $\mathbf{4 , 1}$ & $\mathbf{4 , 2}$ & $\mathbf{4 , 3}$ & $\mathbf{4 , 3}$ & $\mathbf{4 , 4}$ & $\mathbf{4 , 3}$ & $\mathbf{4 , 3}$ & $\mathbf{4 , 1}$ & $\mathbf{4 , 1}$ \\
& $\mathbf{( 6 4 )}$ & $\mathbf{( 5 6 )}$ & $\mathbf{( 5 8 )}$ & $\mathbf{( 5 3 )}$ & $\mathbf{( 4 8 )}$ & $\mathbf{( 5 6 )}$ & $\mathbf{( 5 7 )}$ & $\mathbf{( 7 5 )}$ & $\mathbf{( 8 1 )}$ \\
\hline A: Requerimentos & $\mathbf{4 , 0}$ & $\mathbf{4 , 0}$ & $\mathbf{4 , 3}$ & $\mathbf{4 , 3}$ & $\mathbf{4 , 5}$ & $\mathbf{4 , 5}$ & $\mathbf{4 , 4}$ & $\mathbf{4 . 1}$ & $\mathbf{4 , 0}$ \\
Básicos & $\mathbf{( 9 6 )}$ & $\mathbf{( 9 1 )}$ & $\mathbf{( 8 6 )}$ & $\mathbf{( 8 3 )}$ & $\mathbf{( 7 3 )}$ & $\mathbf{( 7 9 )}$ & $\mathbf{( 8 3 )}$ & $(\mathbf{1 0 3})$ & $(\mathbf{1 0 3})$ \\
\hline Pilar 1: Instituições & 3,6 & 3,5 & 3,6 & 3,7 & 3,8 & 3,7 & 3,5 & 3,2 & 3,2 \\
& $(91)$ & $(93)$ & $(93)$ & $(77)$ & $(79)$ & $(80)$ & $(94)$ & $(121)$ & $(120)$ \\
\hline Pilar 3: Ambiente & 3,9 & 3,9 & 4,0 & 4,2 & 4,7 & 4,6 & 4,5 & 4,0 & 3,5 \\
Macroeconômico & $(122)$ & $(109)$ & $(111)$ & $(115)$ & $(62)$ & $(75)$ & $(85)$ & $(117)$ & $(126)$ \\
\hline B: Promotores de & $\mathbf{4 , 3}$ & $\mathbf{4 , 4}$ & $\mathbf{4 , 4}$ & $\mathbf{4 , 4}$ & $\mathbf{4 , 5}$ & $\mathbf{4 , 4}$ & $\mathbf{4 , 5}$ & $\mathbf{4 , 2}$ & $\mathbf{4 , 2}$ \\
Eficiência & $\mathbf{5 1 )}$ & $\mathbf{( 4 2 )}$ & $\mathbf{( 4 4 )}$ & $\mathbf{( 4 1 )}$ & $\mathbf{( 3 8 )}$ & $\mathbf{( 4 4 )}$ & $\mathbf{( 4 2 )}$ & $\mathbf{( 5 5 )}$ & $\mathbf{( 6 1 )}$ \\
\hline Pilar 6: Eficiência do & 3,9 & 3,9 & 3,7 & 3,8 & 3,9 & 3,8 & 3,8 & 3,7 & 3,7 \\
Mercado de & $(101)$ & $(99)$ & $(114)$ & $(113)$ & $(104)$ & $(123)$ & $(123)$ & $(128)$ & $(128)$ \\
Bens/Serviços & & & & & & & & & \\
\hline Pilar 7: Eficiência do & 4,2 & 4,3 & 4,1 & 4,2 & 4,4 & 4,1 & 3,8 & 3,7 & 3,7 \\
Mercado de Trabalho & $(91)$ & $(80)$ & $(96)$ & $(83)$ & $(69)$ & $(92)$ & $(109)$ & $(122)$ & $(117)$ \\
\hline Pilar 8: & 4,4 & 4,5 & 4,4 & 4,5 & 4,4 & 4,4 & 4,3 & 4,0 & 3.6 \\
Desenvolvimento do & $(64)$ & $(51)$ & $(50)$ & $(43)$ & $(46)$ & $(50)$ & $(53)$ & $(58)$ & $(93)$ \\
Mercado Financeiro & & & & & & & & & \\
\hline Pilar 9: Disponibilidade & 3,6 & 41 & 3,9 & 4,0 & 4,4 & 4,1 & 4,2 & 4,4 & 4,4 \\
Tecnológica & $(56)$ & $(46)$ & $(54)$ & $(54)$ & $(48)$ & $(55)$ & $(58)$ & $(54)$ & $(59)$ \\
\hline B: Inovação e & 4,0 & 4,1 & 4,0 & 4,0 & 4,0 & 3,9 & 3,8 & 3,6 & 3,6 \\
Sofisticação de & $(40)$ & $(38)$ & $(38)$ & $(35)$ & $(39)$ & $(46)$ & $(56)$ & $(64)$ & $(72)$ \\
Negócios & & & & & & & & & \\
\hline
\end{tabular}

Fonte WEF (2011 e 2016), editados pelo autor 
O ambiente macroeconômico (Pilar 3) foi o que apresentou a maior deterioração entre todos os pilares. De um viés estável a levemente positivo no período de 2008 ( $\mathrm{GCl}$ de 3,9 com a posição 122 no ranking) a 2010 ( $\mathrm{GCl}$ de 4,0 com posição 111 no ranking), apresentou evolução nos anos seguintes, chegando a um $\mathrm{GCl}$ de 4,7 ocupando a posição 62 no ranking, mas sofreu séria reversão em 2015 e 2016 com o agravamento do ambiente econômico, com o GCl regredindo a 3,5 e levando o Brasil à posição 126 no ranking de nações neste pilar. Influíram para esse resultado a inflação mais alta e a piora nos ratings de crédito, afetando particularmente firmas com maior dependência dos mercados locais e com maiores necessidades financeiras para desenvolver seus negócios.

O Componente Promotores de Eficiência tem quatro pilares que refletem o ambiente institucional: Eficiência de Mercado de Bens e Serviços, Eficiência do Mercado de Trabalho, Desenvolvimento do Mercado Financeiro e Disponibilidade Tecnológica.

O pilar de Eficiência do Mercado de bens e serviços manteve-se estável durante todo o período, indicando estabilidade no ambiente regulatório, pois o pilar é composto por medidores relacionados a práticas de abertura e fechamento de firmas, tarifas e impostos, e questões de importação e exportação. Houve perda de pontos em fatores como sofisticação do mercado e barreiras de comércio, mas ligeira melhora para iniciar novos negócios. Mesmo assim, o Brasil ainda amarga as últimas posições no ranking global na posição 128 entre 148 países avaliados.

O pilar que representa a Eficiência do Mercado de Trabalho, estável com nota de 4,1 a 4,3 entre 2008 e 2013, caiu para 3,7 em 2015 e 2016, um viés explicado pela queda de produtividade e o desemprego provocados pela deterioração do ambiente econômico a partir de 2013.

O mesmo comportamento é observado no Pilar de desenvolvimento do mercado financeiro, que apresentou notas entre 4,4 e 4,5 entre 2008 e 2013, caindo a 4,0 em 2015 e 3,6 em 2016, reflexo da alta da inflação e da taxa de juros que subiram neste período, dificultando o crédito e afugentando o capital de investimentos. A queda no ranking neste pilar foi de 43 posições entre os anos de 2010 (posição 50) e 2015 (posição 93), reflexo da piora no ambiente de negócios.

O último pilar avaliado dentre os promotores de eficiência, que reflete disponibilidade tecnológica, apresentou melhora constante em todo o período avaliado, de 2008, quando obteve nota 3,6, a 2015 com nota 4,4. Este aumento deve-se à maior 
disponibilidade de internet e telefonia celular no país, mas não se reflete em melhora no ranking global, o que sugere que outros países também melhoraram sua rede de comunicações. Não basta, portanto, melhorar os índices para aumentar competitividade. É necessário avançar mais rápido que outros países.

A queda nos scores e nos rankings indica uma reversão do ambiente institucional e de COEs do Brasil, confirmando a perda de competitividade do país em várias áreas em relação a outros países, o que pode ser observado na Figura 5. A mesma conclusão é obtida ao comparar indicadores de desempenho do Brasil e de outros países ilustrados pela Figura 6. A comparação executou-se com os países do BRIC Brasil, Rússia, Índia e China, além da Argentina, Chile e Estados Unidos. Os índices utilizados - a taxa de crescimento do Produto Interno Bruto, a taxa de inflação e o índice de desemprego, oferecem perspectiva sobre a dimensão da reversão do ambiente econômico. Nos três gráficos da Figura 6 é possível observar deterioração dos indicadores a partir de 2013. Os dados de variação do PIB $(-3,8 \%)$ e de desemprego $(8,5 \%)$ referentes a 2015 , não mostrados no gráfico, mas divulgados pelo Instituto Nacional de Geografia e Estatística (IBGE) e utilizados pelo Banco Mundial na formação do seu banco de dados, confirmam as tendências apresentadas até 2014.

Figura 5 - Evolução do GCl do Brasil e de países selecionados

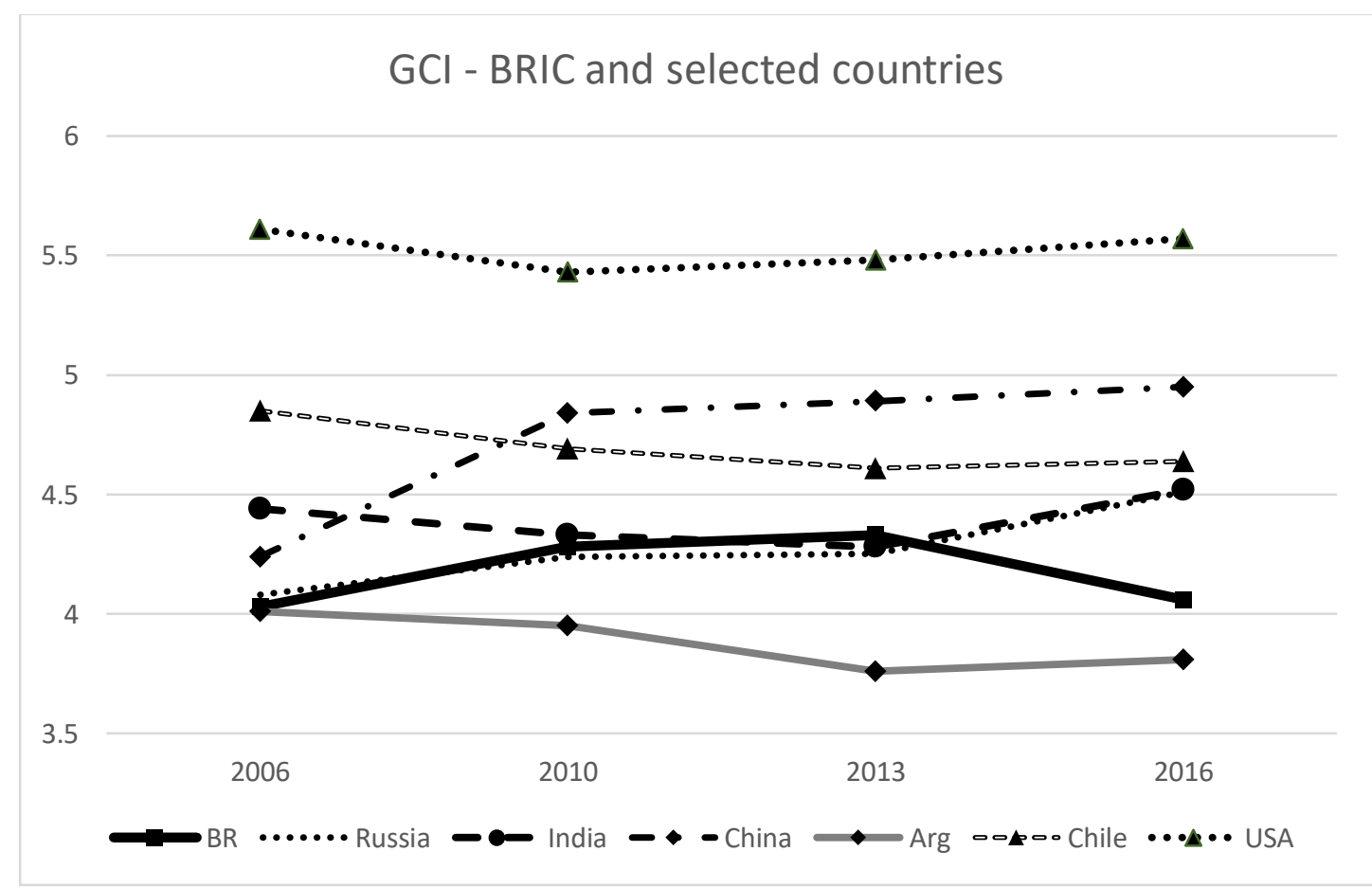

Fonte - Elaborado pelo autor com base em relatórios WEF 
Figura 6 - Comparação da taxa de crescimento do PIB, da taxa de inflação e da taxa de desemprego no Brasil e em outros países selecionados

Timeview: GDP growth index (\%)

Normalized (Base year index = 100) / Base year: 2005 / Period: $2005-2014$

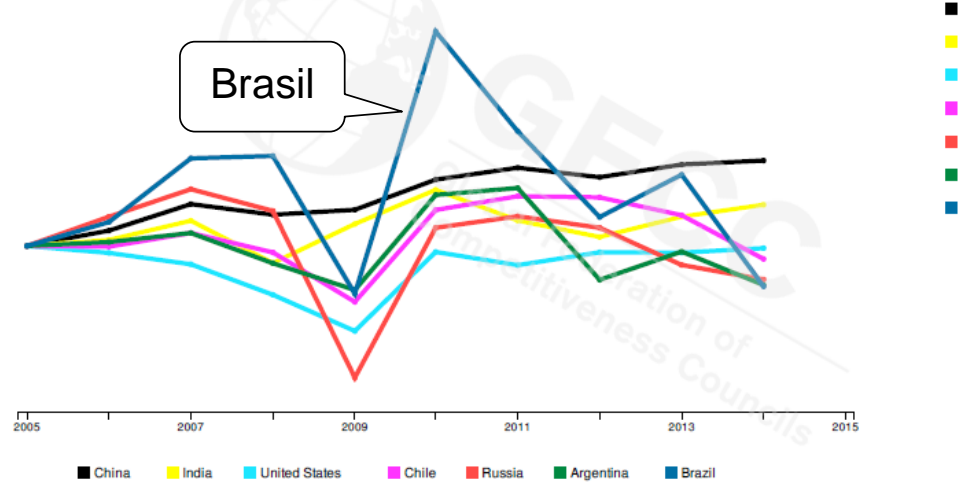

Timeview: Inflation, consumer prices (annual \%) Base year: 2005 / Period: 2005 - 2014

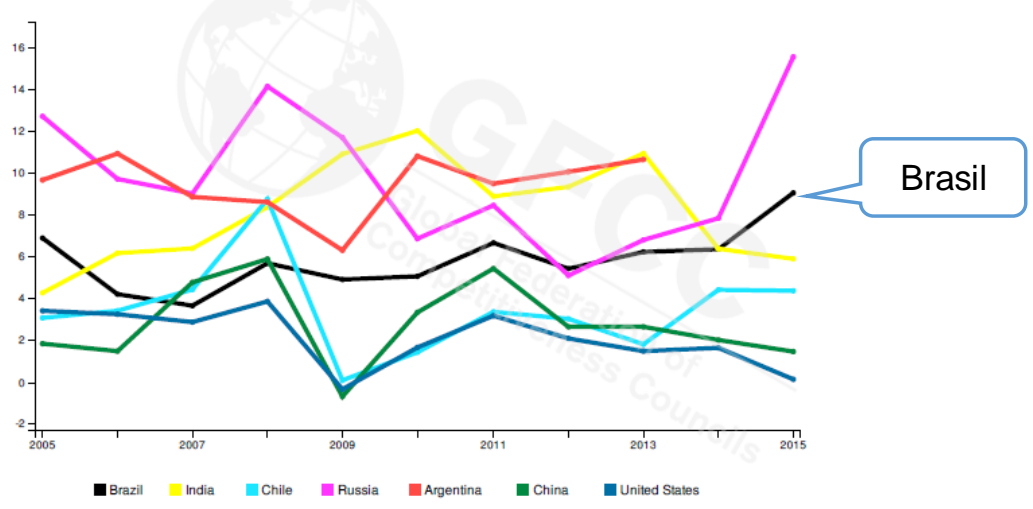

Timeview: Unemployment, total (\% of total labor force) Base year: 2005 / Period: 2005 - 2014

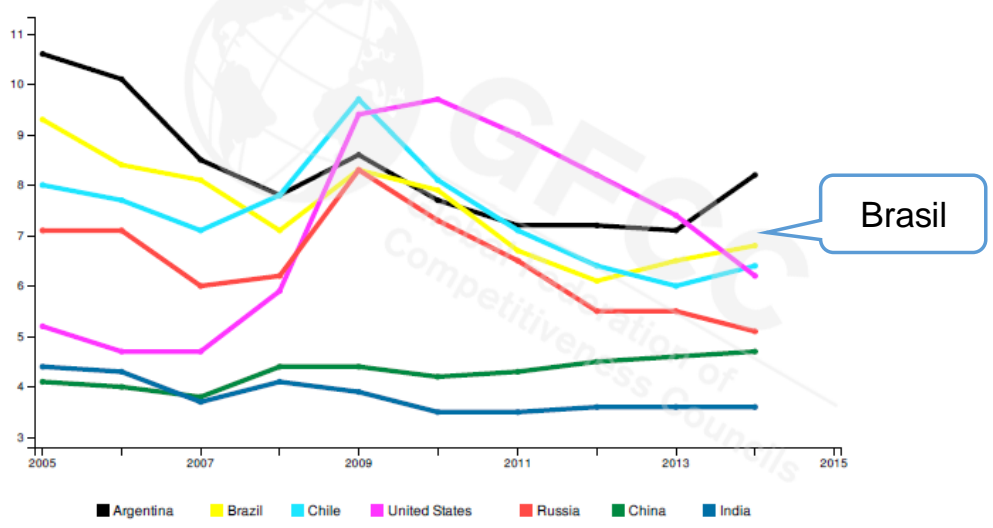

Fonte: Extraído de Global Federation of Competitiveness Councils (2017) 


\subsection{ANÁLISE DOS SURVEYS}

\subsubsection{Análise Fatorial}

A partir das nove perguntas repetidas nos questionários dos dois surveys, USP (2010) com 64 respostas e FGV/USP (2015) com 60 respostas, executou-se duas análises fatoriais das capacidades de inovação, uma para cada survey. As duas análises fatoriais seguiram o processo de decisão formulado por Hair et al. (2006) com sete estágios de execução, os cinco primeiros adequados à análise exploratória em questão. No primeiro estágio determinaram-se os objetivos da análise fatorial, que no presente caso visaram agrupar as perguntas dos questionários, consideradas como unidade de análise, em fatores que refletissem competências ou conjunto de competências, o que Hair et al. (2006) chamam de análise fatorial $\mathrm{R}$ e que serviram para descrever um número menor de conceitos do que as variáveis individuais originais. Neste caso, as variáveis foram as perguntas do questionário de cada um dos surveys. No segundo estágio, planejou-se a análise fatorial, que envolveu três decisões básicas: (a) o tipo de correlação buscado, entre variáveis (análise fatorial R) ou respondentes (análise fatorial $Q$ ) tendo-se definido a presente análise para a correlação de variáveis $(R)$; (b) seleção de variáveis e medidas, em que Hair et al. (2006) recomendam o uso de cinco ou mais para cada fator a identificar; no presente caso, houve limitação do número de questões repetidas nos surveys de 2010 e 2015, em número de nove para até quatro fatores representativos das quatro capacidades de inovação; e (c) tamanho da amostra, no presente caso limitada a 64 para o survey de 2010 e 60 para o de 2015, ainda assim acima do mínimo de 50 ou cinco vezes mais amostras que variáveis analisadas, no presente caso em número de 9.

O terceiro estágio compreendeu as suposições da análise, subdivididas em: (a) questões conceituais onde se determinaram grupos homogêneos para a análise, 0 que foi feito separando-se os surveys de 2010 e 2015, uma vez que representavam diferentes ambientes institucionais; (b) questões estatísticas, em que se verificou se a matriz de correlação podia apresentar fatorabilidades, tais como: a presença de um número substancial de valores maiores que 0,30; ausência de valores maiores que 0,30 na matriz anti-imagem, exceto na diagonal principal onde foram requeridos valores maiores que 0,5 ; o teste de esfericidade de Bartlett que foi aplicado utilizandose análise, cálculo de graus de liberdade e tabelas de Fávero e Belfiore (2015); a 
medida de adequação de amostra (MSA) também conhecida por teste de KaiserMeyer Olkin (KMO) maiores a 0,50, assim como as comunalidades das variáveis individuais, sendo que as que apresentaram valor menor a 0,50 foram descartadas uma por vez. Além dos critérios individuais, a análise requereu ainda que se encontrasse uma configuração de variáveis que atendesse a ambos os surveys, de forma que os fatores resultantes pudessem ser comparados. Para validação dos fatores extraídos utilizou-se o Alfa de Cronbach, que se recomenda ser maior que 0,6. O quarto estágio compreendeu a determinação de fatores a avaliação do ajuste geral. O método de extração de fatores escolhido foi o de análise fatorial de componentes, cujo objetivo é a redução de dados. A determinação do número de fatores foi efetuada utilizando-se o método de autovalores maiores que 1. Nos casos em que houvesse diferença de fatores extraídos entre os surveys por esse método, o que tivesse o maior número de fatores seria reavaliado considerando o menor número de fatores. O quinto estágio compreendeu a escolha do método rotacional para interpretação dos fatores. O método Varimax foi utilizado neste estudo seguindo a recomendação de Hair et al. (2006) por extrair estruturas mais simples e ortogonais quando comparado com outros métodos ortogonais e não-ortogonais. O resultado apresentou cargas fatoriais superiores a 0,6 no survey de 2010 e superiores a 0,7 no survey de 2015 , indicadores de estrutura bem definida para o número de casos de cada survey, conforme a tabela 3-2 em Hair et al. (2006, p.120).

Após execução da análise fatorial e remoção de duas questões, obteve-se um conjunto de sete questões que representam dois fatores, conforme a matriz rotacionada exibida na Tabela 2. Nota-se que as cargas dos fatores significativos $(\rho<0,05)$ foram todas maiores que 0,500 (praticamente significativos) com cinco variáveis maiores a 0,700 nos dois surveys, indicando fatores bem estruturados. A coluna de comunalidades apresentou valores maiores que 0,500 para todas as variáveis nos dois surveys, adequados para análise exploratória. Os alfas de Cronbach calculados para os dois fatores encontrados nos dois surveys apresentaram valores superiores a 0,7 e a variância total explicada pelos fatores foi maior que $60 \%$. 
Tabela 2 - Carga fatorial da Matriz de Componentes Rotacionada

\begin{tabular}{|c|c|c|c|c|c|c|}
\hline & \multicolumn{3}{|c|}{ SURVEY 2010} & \multicolumn{3}{|c|}{ SURVEY 2015} \\
\hline & CORE & ADM & Comon. & CORE & ADM & Comon \\
\hline $\begin{array}{l}\text { 1. A empresa responde aos eventos } \\
\text { inesperados, imprevistos, mais } \\
\text { rapidamente cque } \\
\text { competidores. }\end{array}$ & 0,78 & & 0,63 & 0,782 & & 0,61 \\
\hline $\begin{array}{l}\text { 2. Todos os nossos gestores } \\
\text { entendem como cada um dos } \\
\text { nossos colaboradores podem } \\
\text { contribuir para criar valor para os } \\
\text { mercados e clientes. }\end{array}$ & 0,67 & & 0,56 & 0,721 & & 0,52 \\
\hline $\begin{array}{l}\text { 3. A empresa tem padrões de } \\
\text { desempenho } \\
\text { (custo/preço, qualidade, entrega e } \\
\text { outros) que se igualam ou superam } \\
\text { os dos competidores } \\
\text { internacionais. } \\
\end{array}$ & 0,79 & & 0,63 & 0,693 & & 0,50 \\
\hline $\begin{array}{l}\text { 4. Nossa empresa se organiza e } \\
\text { mobiliza recursos rapidamente } \\
\text { quando temos informações de } \\
\text { clientes insatisfeitos. }\end{array}$ & 0,81 & & 0,67 & 0,721 & & 0,61 \\
\hline $\begin{array}{l}\text { 5. Na medida em que seja necessário, } \\
\text { a nossa empresa tem capacidade } \\
\text { de acessar diferentes mercados } \\
\text { para obter recursos financeiros. }\end{array}$ & & 0,87 & 0,76 & & 0,836 & 0,70 \\
\hline $\begin{array}{l}\text { 6. A nossa capacidade de montar } \\
\text { operações financeiras } \\
\text { internacionais é fator decisivo para } \\
\text { a boa performance internacional. }\end{array}$ & & 0,78 & 0,62 & & 0,844 & 0,72 \\
\hline $\begin{array}{l}\text { 7. Nossa empresa tem claramente } \\
\text { definidas as políticas de recursos } \\
\text { humanos que devem ser adotadas } \\
\text { em nossas subsidiárias no exterior. }\end{array}$ & & 0,61 & 0,57 & & 0,754 & 0,57 \\
\hline Alfa de Cronbach (mínimo 0,7) & 0,80 & 0,70 & & 0,71 & 0,75 & \\
\hline EXPLICAÇÃO DA VARIÂNCIA & $36,4 \%$ & $27,0 \%$ & & $30,5 \%$ & $29,9 \%$ & \\
\hline
\end{tabular}

Fonte: autor

A tabela 3 resume a análise fatorial final mostrando os indicadores que satisfazem os critérios elencados por Hair et al. (2006) descritos nos parágrafos anteriores. As matrizes de correlação e matrizes anti-imagem para análise dos três primeiros itens da tabela encontram-se no Apêndice A para o survey FGV/USP 2015 e no Apêndice B para o survey USP 2010. O fator 1, composto por quatro variáveis correspondentes às afirmações 1 a 4 da Tabela 2 , reflete capacidades de inovação relacionadas às competências de tecnologia, produção e operação e marketing, ou competências essenciais (core competences), e foi denominado "CORE", enquanto o fator 2 , representado pelas afirmações 5 a 7 , reflete capacidades de inovação da função administrativa e receberá a denominação de "ADM". 
Tabela 3 - Resumo dos resultados da análise fatorial contra critérios de aceitação

\begin{tabular}{|c|c|c|c|}
\hline & $\begin{array}{ll}\text { Critério } & \text { de } \\
\text { Sucesso } & \end{array}$ & Survey 2010 & Survey 2015 \\
\hline Matriz correlação & $\begin{array}{l}\text { Existência de valores } \\
\text { maiores que } 0,30\end{array}$ & Sim & Sim \\
\hline MSA segundo KMO & Mínimo 0,50 & 0,688 & 0,548 \\
\hline $\begin{array}{l}\text { MSA individual -Valor } \\
\text { mínimo na diagonal da } \\
\text { matriz anti-imagem }\end{array}$ & Mínimo 0,50 & 0,517 & 0,518 \\
\hline $\begin{array}{l}\text { Esfericidade de Bartlett } \\
- \\
\text { Graus de liberdade }= \\
\left(\mathrm{V}^{2}-\mathrm{V}\right) / 2^{*}\end{array}$ & $\begin{array}{l}\text { Valor crítico de } \text { Chi- } \\
\text { Quadrado para } 21 \\
\text { graus lib. }>32,671 \text { para } \\
\rho<0,05\end{array}$ & 146,514 & 111,706 \\
\hline Variáveis Utilizadas & & 7 & 7 \\
\hline Número de Amostras & Mínimo 50 & 64 & 60 \\
\hline Fatores Extraídos & & 2 & 2 \\
\hline $\begin{array}{l}\text { Explicação da variância } \\
\text { total }\end{array}$ & Maior que $60 \%$ & $63,4 \%$ & $60,4 \%$ \\
\hline
\end{tabular}

Fonte: autor, critérios baseados em Hair et al. (2006)

*V é o número de variáveis utilizadas na fatoração, representadas pelas sete afirmações da Tabela 3

4.2.2 Comparação e análise dos fatores de capacidades de inovação entre 2010 e 2015.

A comparação entre os fatores que representam capacidades de inovação - CORE e ADM - em 2010 e 2015 foi executada através do teste T (DEVORE, 2015). A Tabela 4 traz os resultados da aplicação do Teste $T$ considerando duas análises: (a) a totalidade das amostras (64 do survey de 2010 e 60 do survey de 2015); (b) o subconjunto formado pelas empresas que se repetem nos dois surveys, em um total de 19 BrMNEs. O fator que representa capacidades "CORE" resultou estatisticamente diferente para 2010 e 2015, apresentando Sig (2-tailed) < 0,05, ou seja, mais de $95 \%$ de confiança que as distribuições dos dois anos são diferentes com médias distintas, tanto para a totalidade da amostra como para o subconjunto composto pelas BrMNEs que estão presentes nos dois surveys. Nota-se, portanto, REDUÇÃO desse fator, já que a média das capacidades CORE para todas as BrMNEs foi menor em 2015 do que em 2010, conforme mostra a Tabela 4. Já o fator que representa capacidade de inovação para competências ADM sofreu leve redução, mas não apresentou diferenças significativas entre os dois surveys, uma vez que o Sig(2-tailed) de 0,506 aponta para uma grande similaridade entre as distribuições, com médias quase idênticas. Isso sugere que essas capacidades de inovação relativas à função 
administrativa (ADM) permaneceram estáveis entre 2010 e 2015, tanto para a totalidade da amostra como para o subconjunto de BrMNEs que participam dos dois surveys.

Tabela 4 - Comparação entre capacidades de inovação - surveys de 2010 e 2015

\begin{tabular}{|c|c|c|c|c|c|c|c|}
\hline \multirow[b]{2}{*}{$\begin{array}{l}\text { CAPACIDADES } \\
\text { INOVACÃO }\end{array}$} & \multirow[b]{2}{*}{ Survey } & \multicolumn{3}{|c|}{$\begin{array}{c}\text { TODAS AS EMPRESAS } \\
\text { dos surveys de } 2010 \text { e } 2015\end{array}$} & \multicolumn{3}{|c|}{$\begin{array}{l}\text { Subconjunto - } 19 \text { BrMNEs que aparecem } \\
\text { nos dois surveys - 2010 E } 2015\end{array}$} \\
\hline & & $\mathrm{N}$ & Média & Desvio Padrão & $\mathrm{N}$ & Média & $\begin{array}{l}\text { Desvio } \\
\text { Padrão }\end{array}$ \\
\hline \multirow{2}{*}{ Essenciais (CORE) } & 2010 & 64 & 4,1902 & 0,68626 & 19 & 4,3816 & 0,48138 \\
\hline & 2015 & 60 & 3,8190 & 0,50036 & 19 & 3,8795 & 0,50233 \\
\hline \multirow{3}{*}{$\begin{array}{l}\text { Funções } \\
\text { Administrativas (ADM) }\end{array}$} & 2010 & 64 & 3,7295 & 0,97018 & 19 & 3,8779 & 1,92636 \\
\hline & 2015 & 60 & 3,6172 & 0,90614 & 19 & 3,7905 & 0,88310 \\
\hline & TESTE T & \multicolumn{3}{|c|}{ Sig. (2-tailed) } & \multicolumn{3}{|c|}{ Sig. (2-tailed) } \\
\hline Essenciais (CORE) & & \multicolumn{3}{|c|}{0,001} & \multicolumn{3}{|c|}{0,003} \\
\hline $\begin{array}{l}\text { Funções } \\
\text { Administrativas (ADM) }\end{array}$ & & \multicolumn{3}{|c|}{0,506} & \multicolumn{3}{|c|}{0,780} \\
\hline
\end{tabular}

Fonte: autor

Esses resultados, juntamente com a discussão sobre a deterioração do ambiente institucional da seção 4.1, sugerem que a Proposição 1 tem suporte. Mudanças na situação institucional do país, com deterioração de COEs, impactaram as capacidades de inovação das BrMNEs entre 2010 e 2015. Os dois fatores estudados apresentaram redução, o fator CORE com relevância estatística, e o fator ADM sem relevância estatística.

\subsubsection{Análise de Agrupamentos das capacidades de inovação}

Para cada um dos dois surveys, executou-se análise de agrupamentos conforme processo decisório estabelecido por Hair et al. (2006), composto por seis estágios. O primeiro estágio consistiu em determinar o objetivo da análise, que em geral enquadra-se em um ou mais tipos: (a) determinação de uma taxonomia, seja exploratória, seja confirmatória; (b) simplificação de dados, agrupando observações através de características similares ou proximidade entre indivíduos; (c) identificação de relações de similaridade. No presente caso, pretendeu-se simplificar os dados através do seu agrupamento, possibilitando a comparação com a taxonomia de estratégias de internacionalização proposta por Ramamurti e Singh (2009). Em seguida, o segundo estágio consistiu na definição da análise de agrupamentos através de quatro atividades: (a) definição do tamanho de amostra; (b) detecção das 
observações atípicas; (c) determinação da forma de medição da similaridade entre objetos; (d) verificação da necessidade de padronizar dados. O tamanho da amostra, atividade (a), foi limitado pela quantidade de respostas obtidas em cada um dos surveys. Uma vez estabelecida a amostra, a seguinte atividade (b) foi a verificação de observações atípicas, pois elas poderiam interferir na análise distorcendo agrupamentos. Utilizou-se, para este fim, abordagem gráfica ilustrada pela Figura 7, que apresenta as capacidades CORE no eixo horizontal e as capacidades ADM no vertical para cada um dos surveys utilizados. As BrMNEs estão representadas no gráfico com os pontos isolados assinalados e as empresas de perfil semelhante identificadas com a mesma cor e forma. No survey de 2010 foram encontradas três observações atípicas que foram descartadas: uma empresa que explora recursos naturais, uma construtora e uma indústria de fabricação mecânica. No survey de 2015 foram duas as observações atípicas, ambas do setor industrial.

Figura 7 - Observações atípicas nos surveys de 2010 e 2015
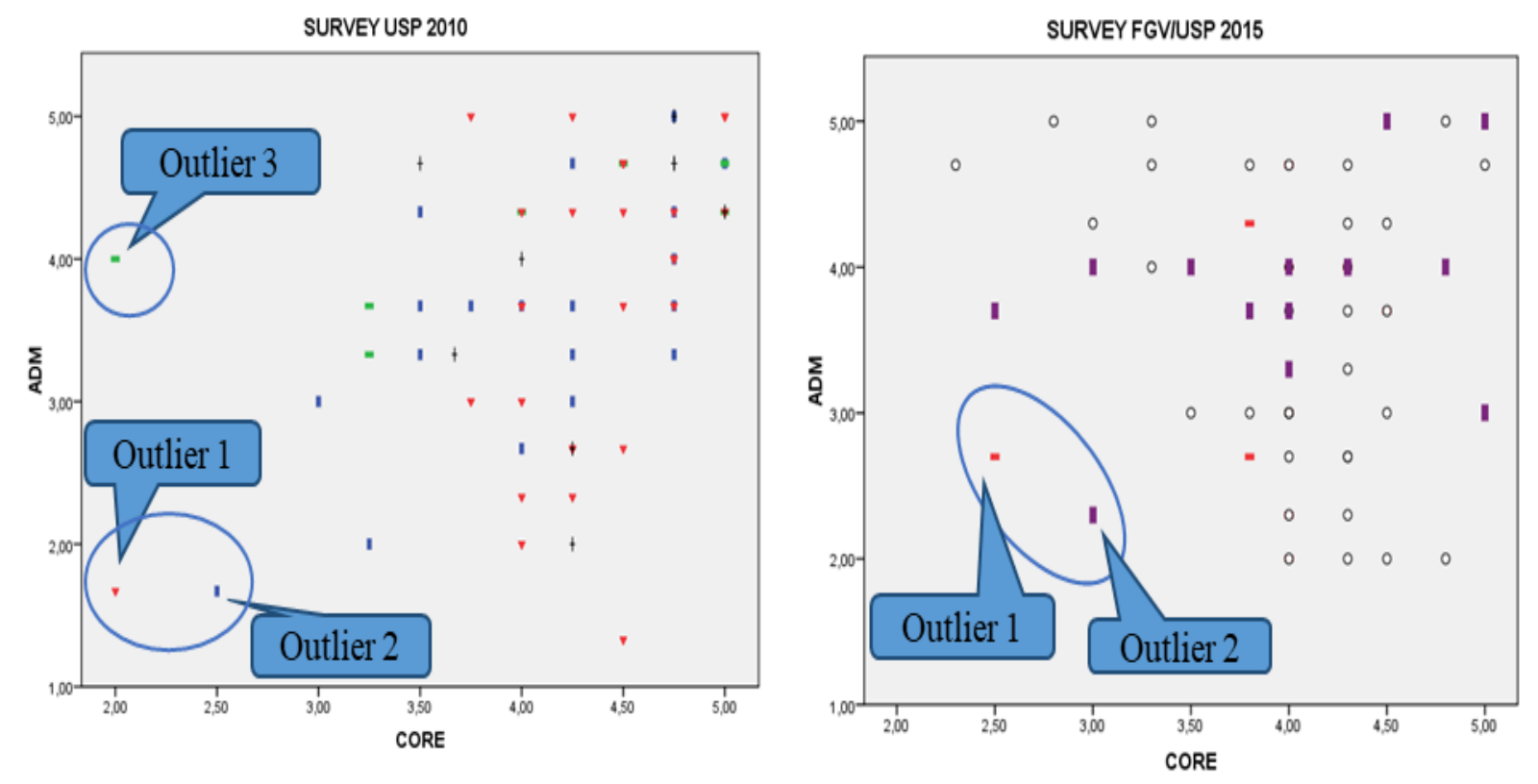

Fonte: Autor

As cinco observações atípicas encontravam-se distantes de suas concorrentes e similares. Uma vez removidas as observações atípicas, prosseguiu-se com a análise. $O$ apêndice $E$ repete os testes da Tabela 4, agora sem os outliers, comprovando que o resultado da comparação entre os surveys mantém-se inalterado. A similaridade entre as BrMNEs, atividade (c), foi medida através da distância euclidiana entre as 
firmas, calculada através das diferenças entre os dois fatores CORE e ADM entre cada par de firmas. Uma vez que ambos fatores se medem na mesma escala, os dados já estavam padronizados (d), sendo desnecessário qualquer tratamento adicional.

O terceiro estágio consistiu em estabelecer as suposições da análise de agrupamentos relacionadas à representatividade da amostra e o desenho estrutural das variáveis. A proporção de respondentes dos setores industrial e de serviços assemelha-se à população de BrMNEs. O número de BrMNEs que se utilizam de cada estratégia de internacionalização, mostrado na Tabela 5, foi estimado a partir de respostas a uma única pergunta do survey de FGV/USP de 2015 para os participantes desse survey, e a partir da literatura ou do perfil da firma para os participantes do survey USP 2010. A única empresa classificada como Inovadora Global foi associada à estratégia de Consolidadores Globais para efeito desta análise. A classificação da Tabela 5 foi utilizada para efeitos de estimação do perfil de distribuição das estratégias. A análise de agrupamentos, baseada nas variáveis fatoradas CORE e ADM, foi necessária para definir perfis de variação de capacidades de inovação e também para ajustar os casos de firmas que se declararam com uma estratégia, mas que de fato se utilizaram de outra para promover o avanço de sua internacionalização.

Tabela 5 - BrMNEs com cada estratégia nos surveys USP2010 e FGV/USP2015

\begin{tabular}{l|c|c}
\hline $\begin{array}{c}\text { ESTRATEGIA DE } \\
\text { INTERNACIONALIZAÇÃO }\end{array}$ & SURVEY USP 2010 & SURVEY FGV USP 2015 \\
\hline Otimizador Local & 19 & 11 \\
\hline $\begin{array}{l}\text { Integrador Vertical de Recursos } \\
\text { Naturais }\end{array}$ & 7 & 21 \\
\hline Parceiro de Global & 28 & 18 \\
\hline $\begin{array}{l}\text { Consolidador Global e Inovador } \\
\text { Global }\end{array}$ & 10 & \\
\hline
\end{tabular}

Fonte: Autor

O quarto estágio da análise consiste na determinação dos agrupamentos e avaliação do ajuste geral. Para este fim, executou-se inicialmente uma análise de agrupamentos hierárquica para estimativa do número de agrupamentos e posteriormente uma análise k-média não hierárquica para definição dos melhores agrupamentos. A análise hierárquica dos surveys USP 2010 e FGV/USP 2015 utilizou o método de ligação média, que combina as vantagens dos métodos de ligação simples (vizinho mais próximo) e completa (vizinho mais distante) com distância euclidiana quadrada que 
oferece melhor repartição dos grupos. Os dendogramas resultantes, apresentados no APÊNDICE C, sugerem a existência de 2 a 5 agrupamentos. A seguir, a análise de cluster não hierárquica k-média utilizando 3 , 4 e 5 agrupamentos foi executada, de forma a avaliar os agrupamentos resultantes. Escolheu-se a solução com quatro agrupamentos por apresentar os tamanhos de agrupamentos mais homogêneos nos dois surveys. A análise de variância utilizando o teste Tukey post hoc demonstra a diferença entre agrupamentos para os dois surveys, conforme tabela do APENDICE D. Cada agrupamento foi analisado considerando o perfil das empresas para que se pudessem associar os agrupamentos do survey USP $2010 \mathrm{com}$ os do survey FGV/USP 2015. A Tabela 6 apresenta as médias de cada agrupamento com respeito a suas competências CORE e ADM. A Figura 8 ilustra graficamente a situação de cada agrupamento em 2010 e 2015, permitindo uma comparação visual nesses dois anos. Cada ponto no gráfico pode representar mais de uma empresa.

Tabela 6 - Capacidades de inovação por agrupamento de BrMNEs - 2010 e 2015

Variação entre 2010 e 2015 e resultado do Teste T (mudança estatisticamente significativa quando o resultado é menor que 0,05 )

\begin{tabular}{l|l|l|l|l|l|l|l|l|l|l}
\hline & \multicolumn{3}{|c|}{ Survey USP 2010} & \multicolumn{3}{c|}{ Survey FGV/USP 2015 } & \multicolumn{2}{c|}{$\begin{array}{c}\text { Variação 2010- } \\
\text { 2015 }\end{array}$} & \multicolumn{2}{c}{ Teste - T } \\
\hline Cluster & $\begin{array}{l}\# \\
\text { EMNE }\end{array}$ & CORE & ADM & $\begin{array}{l}\text { \# } \\
\text { EMNE }\end{array}$ & CORE & ADM & CORE & ADM & CORE & ADM \\
\hline A & 26 & 4,59 & 4,63 & 21 & 4,16 & 3,86 & $-\mathbf{0 , 3 3} \downarrow$ & $\mathbf{- 0 , 4 7} \downarrow$ & 0,000 & 0,000 \\
\hline B & 10 & 3,52 & 3,43 & 8 & 2,94 & 4,43 & $-\mathbf{0 , 5 8} \downarrow$ & $\mathbf{+ 1 , 0 0 \uparrow}$ & 0,004 & 0,000 \\
\hline C & 11 & 4,14 & 2,30 & 29 & 4,16 & 2,56 & $+0,02$ & $+0,26$ & 0,841 & 0,127 \\
\hline D & 14 & 4,41 & 3,67 & 10 & 4,42 & 4,71 & $+0,01$ & $\mathbf{+ 1 , 0 4 \uparrow}$ & 0,955 & 0,000 \\
\hline Total & 61 & 4,29 & 3,79 & 58 & 4,04 & 3,66 & $\mathbf{- 0 , 2 5} \downarrow$ & $-0,13$ & 0,013 & 0,429 \\
\hline Fon
\end{tabular}

Fonte: autor

O agrupamento A possuía os maiores fatores CORE e ADM em 2010, mas apresentou redução significativa em ambos em 2015. A média do fator que representa capacidades de inovação essenciais (CORE) passou de 4,59 a 4,16 e a média do fator relacionado a funções administrativas (ADM) passou de 4,63 a 3,86. Os testes $T$ de ambos indicam que a variação é significativa estatisticamente com confiança maior que $95 \%$. Apesar da queda, o fator CORE segue alto quando comparado com outros agrupamentos. A estratégia que predomina neste agrupamento é a do "Consolidador Global". 
$\underline{\mathrm{O} \text { agrupamento } \mathrm{B}}$ apresentou um comportamento diferente, com a média do fator CORE caindo significativamente de 3,52 a 2,94 enquanto a média do fator ADM subiu de 3,43 a 4,43, ambas estatisticamente significativas conforme os testes $\mathrm{T}$ de 0,004 e 0,000 respectivamente. Esse agrupamento possuía os menores indicadores para capacidades CORE em 2010, mantendo-se assim em 2015. Já a subida das capacidades ADM levou este grupo a ultrapassar o grupo A nesse fator. A estratégia principal observada nas BrMNEs deste agrupamento é do "Integrador Vertical de Produtos Naturais".

Figura 8 - Agrupamentos de EMNEs em 2010 e 2015

Agrupamentos por perfil de capacidades de inovação
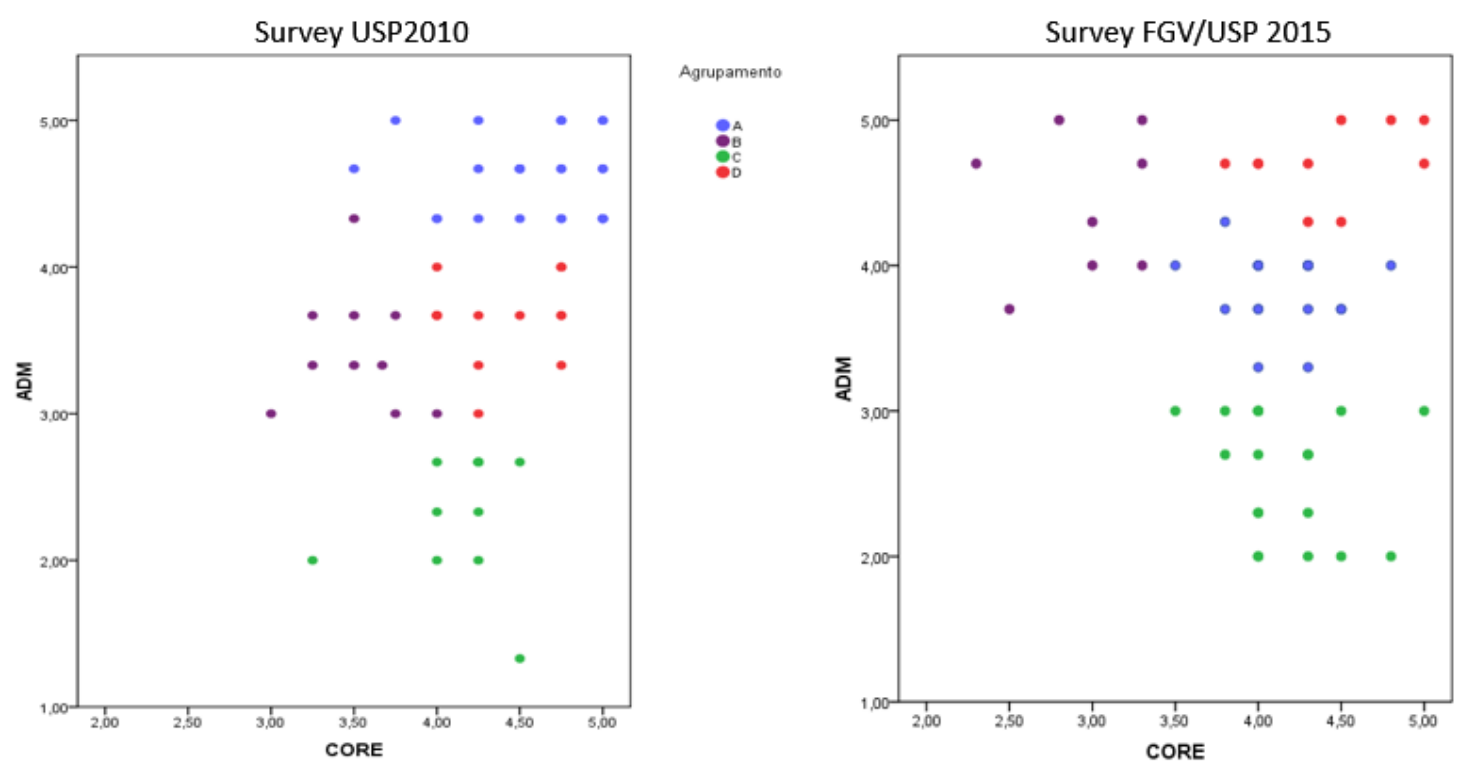

Fonte: Autor

O agrupamento $\mathrm{C}$ apresentou estabilidade estatística em ambos os indicadores de capacidades CORE e ADM conforme os resultados dos testes $T$, maiores que 0,05 $(0,841$ e 0,127 respectivamente). Em valores absolutos, houve estabilidade nas capacidades CORE, de 4,14 em 2010 a 4,16 em 2015 e leve aumento nas ADM, de 2,30 em 2010 para 2,56 em 2015. A estratégia de internacionalização predominante neste agrupamento é de "Parceiro Global".

O agrupamento $D$ apresentou estabilidade no fator CORE segundo o teste $T$ de 0,955 , com 4,41 em 2010 e 4,42 em 2015; e aumento no fator ADM de 3,67 em 2010 para 4,71 em 2015 estatisticamente relevante conforme o resultado do Teste $T$ de 0,000. Em 2015, este foi o agrupamento que apresentou os maiores indicadores de ambas as competências entre todos os agrupamentos. Graficamente, o agrupamento D 
moveu-se no sentido oposto ao agrupamento $A$, invertendo posições. A EMNE típica neste agrupamento utiliza a estratégia do "Otimizador Local".

Nas 19 BrMNEs que se repetem nos dois surveys, nota-se que dez delas se mantêm no mesmo agrupamento, enquanto nove aparentemente mudam de agrupamento. Uma análise caso a caso indica que as BrMNEs que mudaram de agrupamento entre um survey e outro encontravam-se em áreas fronteiriças entre dois agrupamentos, sendo que o tipo de alteração em seus indicadores de capacidades CORE e ADM seguiu o padrão e a estratégia de internacionalização do agrupamento para o qual elas migraram em 2015, confirmando a tendência geral apresentada por esses agrupamentos. As pequenas distâncias entre agrupamentos explicam porque inicialmente essas empresas foram classificadas em um agrupamento diferente do que realmente elas pertencem.

Os diferentes comportamentos de cada agrupamento sugerem que a Proposição 2 tem suporte. $\mathrm{O}$ uso de diferentes combinações de COEs utilizadas em diferentes estratégias de internacionalização parecem impactar as capacidades de inovação das firmas de forma diferenciada. Cada agrupamento da figura 8 apresenta um movimento diferenciado entre 2010 e 2015 quando se consideram os fatores indicadores de capacidades de inovação essenciais (CORE) e capacidades de inovação de funções administrativas (ADM) conforme a discussão sobre o comportamento de cada agrupamento acima. A próxima seção discute os resultados observados. 


\section{DISCUSSÃO}

A análise de agrupamentos revelou quatro conjuntos de BrMNEs com diferentes padrões de evolução nos fatores que representam suas capacidades de inovação. Cada grupo pôde ser associado a uma estratégia de internacionalização. $O$ agrupamento $A$ teve redução nos dois fatores CORE e ADM e as empresas pertencentes a esse agrupamento têm empresas com perfil compatível com a estratégia de Consolidador Global. $O$ agrupamento $B$ também apresentou redução em CORE, mas aumento estatisticamente significativo em ADM, sendo suas empresas associadas ao perfil de Integrador Vertical de Produtos Naturais. O grupamento C permaneceu estatisticamente estável em ambos os fatores e é formado por empresas compatíveis com a estratégia do Parceiro Global, enquanto o perfil das empresas do agrupamento $\mathrm{D}$, que também permaneceu estável no fator CORE, mas apresentou aumento no fator ADM, alinha-se à estratégia do Otimizador Local. A análise a seguir mostra como as COEs e as capacidades de inovação associadas explicam esses comportamentos. Os exemplos utilizados referem-se a empresas típicas de cada tipo de estratégia de internacionalização com base em informações públicas da literatura, dos websites das empresas e dos meios de comunicação.

\subsection{AGRUPAMENTO A - ESTRATÉGIA DO CONSOLIDADOR GLOBAL}

$\mathrm{O}$ agrupamento $\mathrm{A}$ é formado principalmente por BrMNEs que adotaram a estratégia do "Consolidador Global"; são firmas que apresentaram redução nos fatores que representam capacidades de inovação essenciais e de funções administrativas, o que confirma a especulação desenvolvida na seção 2.5 para este tipo de empresa, de que as capacidades de inovação seriam diretamente afetadas por mudanças no ambiente institucional do país de origem. Trata-se de empresas que contam com grandes operações e mercados consumidores no país de origem, e subsidiárias que algumas vezes ultrapassam suas matrizes em tamanho de operações. No modelo do Consolidador Global, o COE baseia-se em um mercado doméstico grande e em expansão, que tem um papel forte no estabelecimento de padrões de excelência na competência de produção e operação. Tal competência é reaplicada nas subsidiárias do exterior, caracterizando tendência centralizadora da matriz, pois o perfil de expansão internacional como entrantes tardios é a aquisição de empresas de fraco 
desempenho. Um ambiente econômico desfavorável no país de origem anula sua COE principal, ou seja, o mercado doméstico e o fluxo de caixa que ele gera. A importância desse mercado para a BrMNE, aliada à dependência das subsidiárias à matriz, faz as operações internacionais mais vulneráveis às condições enfrentadas no país de origem, pois agora elas não mais contam com um mercado em expansão nem com fluxo de caixa forte no mercado doméstico. Esses problemas, aliados ao porte dessas empresas, fazem mais difícil a adaptação às novas condições, refletindo-se em perda de capacidade de inovação e de agilidade na articulação de competências essenciais e de funções administrativas. As capacidades e competências que funcionaram tão bem enquanto o mercado se expandia já não suprem as necessidades do novo ambiente, e a capacidade de inovação dessas empresas ainda não conseguiu rearranjar suas competências de forma satisfatória, o que se reflete na diminuição de ambos os fatores CORE e ADM.

Uma tentativa de buscar melhores condições financeiras, em linha com o argumento do escape, tem sido a abertura de capital em bolsas de valores localizadas no exterior. Estão listadas em bolsas norte-americanas (FOREIGN ADRS LIST, 2017) empresas como a Ambev, BRF, Fibria, Gerdau e Ultrapar, todas com perfil que se enquadra na estratégia do Consolidador Global, e a Embraer, alinhada à estratégia do Inovador Global. Outra empresa que recentemente anunciou intenção de abrir seu capital em bolsa no exterior é a Votorantim Metais (PARRA-BERNAL; BAUTZER, 2017). Embora seja uma forma de abordar o problema de capacidade de inovação relacionada a competências financeiras, que são a parte mais afetada das funções administrativas nestas empresas, a solução não resolve o problema de perda de capacidade de inovação essenciais, algo que essas empresas aparentemente ainda não lograram equacionar.

A literatura sugere uma abordagem de escape para outros países, através do aumento da internacionalização para reduzir a sua dependência das instituições e do mercado do país de origem ou, em movimento radical, através da mudança da matriz dessas empresas para outros países para reduzir os laços com seu país original e atrelar sua imagem ao país da nova sede (CUERVO-CAZURRA,2015; FLEURY; FLEURY, 2014). O primeiro tipo de escape, de aumento de internacionalização, será discutido na seção 6 , enquanto a mudança de sede para o exterior foi tentada sem sucesso pela JBS em 2016 e está em avaliação pela Braskem (SCHELLER; PEREIRA, 2017). A Magnesita, 
que é discutida no agrupamento C, fez esse movimento em 2017, mas ainda é cedo para avaliar resultados de tal movimento.

\subsection{AGRUPAMENTO B - INTEGRADOR VERTICAL DE RECURSOS NATURAIS}

O agrupamento B compreende essencialmente firmas que adotam a estratégia do "Integrador Vertical de Recursos Naturais". Essas empresas tiveram uma redução considerável no fator CORE que representa suas capacidades de inovação essenciais, mas tiveram incremento estatisticamente significante no fator ADM que representa capacidades de inovação de funções administrativas. $O$ tamanho reduzido deste agrupamento não permite aprofundar a análise estatística, separando as empresas que se valem do acesso privilegiado às fontes de recursos naturais daquelas que priorizam o acesso privilegiado aos mercados consumidores que caracterizam as duas variantes do Integrador Vertical de Recursos Naturais. É possível, no entanto, revisar a evolução de alguns setores representados neste agrupamento, tais como petróleo, papel, cimento e minério de ferro. A análise desses setores possibilita entender o que ocorreu com cada um isoladamente e assim extrair conclusões alinhadas ao comportamento do agrupamento como um todo.

O setor de petróleo é caracterizado pela interferência do governo, que afeta 0 resultado das empresas não só do Brasil, mas também de outros países emergentes e desenvolvidos (RAMAMURTI; SINGH, 2009). Os governos influenciam os resultados das empresas do setor ao estabelecer políticas de preços, regulações e leis, casos em que o Brasil se enquadra ao restringir a exploração, refino e distribuição do petróleo e seus derivados. A Petrobrás, estatal brasileira beneficiada por tais restrições, teve um período de crescimento durante a década de 2000, período de alta nas cotações de petróleo, quando expandiu suas competências de exploração de petróleo em águas profundas. A descoberta do pré-sal nos anos 2000 e a mudança das regras de exploração dessa nova fonte resultaram em um desafio significativo para a empresa, tanto em termos de desenvolvimento de competências de exploração como de competências financeiras para suprir os investimentos necessários. Além disso, uma política de contenção de preços de derivados do petróleo em época de aumento dos preços internacionais do petróleo no início dos anos 2010 agravou a situação financeira da empresa, que importava petróleo a preços internacionais e revendia seus derivados a preços reduzidos, o que resultou em uma operação 
deficitária (PADUAN, 2017). Desta forma, a empresa viu-se em dificuldades para cumprir tanto objetivos operacionais como financeiros, o que se reflete na redução em capacidades de inovação essenciais e de funções administrativas, divergindo do que se observa no agrupamento $B$, embora explique o que ocorreu no setor específico de petróleo.

O setor de papel e celulose, por outro lado, se vale do acesso ao recurso natural, no caso a madeira, e busca integração internacional dessa fonte e acesso aos mercados consumidores globais. O setor passou por evolução considerável a partir da década de 1960, quando se formou a base florestal, para a consolidação do negócio florestal entre as décadas de 1980 e 2000 e finalmente para operações de classe mundial entre os anos de 2000 e 2010. Entre 2005 e 2015, a exportação de papel e celulose cresceu constantemente a uma taxa anual de cerca de 2,5\% ao ano (SILVA; BUENO; NEVES, 2016). O crescimento constante do mercado explica aumento das capacidades relacionadas às competências administrativas, em linha com a tendência observada pelos integradores verticais de recursos naturais. Um caso que ilustra o setor é o da Suzano Papel e Celulose (SUZANO, 2017), segundo maior produtor global de eucalipto comercializado em 30 países, e papel, em mais de 60 países, que integra verticalmente a produção de celulose, lignina e papéis para o setor de higiene, contando com operações no Brasil, Estados Unidos, Suíça, Inglaterra e Argentina, além de laboratórios de P\&D no Brasil, Israel e China implementados a partir de 2010. A oferta pública de ações em 2012 está em linha com o incremento de capacidades de inovação relacionadas a funções administrativas.

Processo similar vive o setor de cimento, com crescimento global constante nos últimos 20 anos. O Brasil passou de 13ª (2005) para a $5^{\text {a }}$ (2013) posição no ranking mundial de produtores (CIMENTO, 2017). A Votorantim Cimentos (VOTORANTIM CIMENTOS, 2017) é um expoente desse setor. Décima maior fabricante de cimentos global, atua em 14 países ao redor do mundo, ampliando operações continuamente desde 1997, quando efetuou sua primeira expansão internacional na Bolívia. Mesmo com o ambiente desfavorável no Brasil, inaugurou uma fábrica nova na Bahia em 2015 e no Pará em 2016, adquiriu participação na Cimpor o que abriu mercados na Espanha, Turquia, Tunísia, Marrocos, Índia e China. A maior complexidade das operações exigiu foco na expansão de suas capacidades relacionadas a funções administrativas e essenciais nesse período. Portanto, os setores de papel e celulose 
e de cimento apresentaram incremento de capacidades de inovação essenciais, divergindo do comportamento do agrupamento, e incremento das capacidades de inovação relacionadas às funções administrativas, em linha com o que o agrupamento apresentou.

O setor de minério de ferro, cuja maior empresa nacional é a Vale, sofreu com a queda de preços no mercado global de US $\$ 190$ a tonelada em 2011, para menos de US $\$ 40$ em 2015. Como outras grandes mineradoras do planeta, a Vale precisou enfocar-se no equilíbrio de suas contas durante o período para enfrentar essa desvalorização do seu produto. Para tanto, "a Vale vem reduzindo despesas administrativas, vendendo ativos que não sejam ligados às suas principais atividades, como embarcações de transporte, e modernizando minas antigas" (NAKAGAWA; NEDER, 2015). A CSN é outra empresa desse setor que se utiliza da estratégia de integração vertical de recursos naturais, conforme Fleury e Fleury (2009), também foi forçada a vender ativos para ajustar sua situação financeira (GUIMARÃES, 2015). Neste setor em particular, as empresas sofreram mais com a oscilação do preço do minério que com fatores relacionados ao seu país de origem. Portanto, as empresas do setor de minério de ferro precisaram enfocar-se em suas capacidades administrativas para fazer frente à ameaça de morte súbita relacionada à queda do preço do minério no mercado global, resultando em perda de algumas competências operacionais com a venda de ativos e a redução do seu portfólio de atividades.

As diferentes trajetórias das firmas relacionadas aos setores de aço, cimento, papel e celulose e petróleo acima descritas, todas adotando a estratégia de integradoras verticais de recursos naturais, mostra a dependência das firmas aos seus setores de atuação de forma relativamente independente do que acontece no país de origem para o grupo de empresas que explora os recursos naturais, e grande influência do ambiente institucional para aquelas que dependem do mercado interno ou do governo do país. O incremento no fator de capacidades de inovação das funções administrativas e a redução das essenciais parece ter pouca relação com as mudanças em COEs causados pela reversão do ambiente institucional do país de origem. As firmas que exploram os recursos naturais do país de origem têm como COE o acesso privilegiado a esses recursos. Mudanças institucionais políticas e econômicas parecem ter menos influência sobre essas firmas que os preços de seus produtos no mercado global. A princípio elas não teriam motivos para escapar dos seus COEs, em linha com as constatações de Ramamurti e Singh (2009) sobre a 
limitação ao acesso desse tipo de COE a todas as empresas e sobre a persistência de COEs na formação de capacidades de inovação das MNEs. Já para as BrMNEs cujo COE é o acesso privilegiado ao mercado local como no caso do setor de petróleo, a influência de COEs é importante, pois as mudanças no ambiente institucional afetaram diretamente suas operações no período estudado.

\subsection{AGRUPAMENTO C - PARCEIRO GLOBAL}

O Agrupamento C manteve ambos os fatores de capacidades de inovação relacionados às competências operacionais e administrativas, apesar da mudança no ambiente institucional do país no período estudado. Esse comportamento se explica pelo tipo de COE explorado por essas empresas que adotam a estratégia de internacionalização do tipo Parceiro Global, baseado no baixo custo de mão de obra ou na disponibilidade de engenheiros e cientistas. O Brasil é considerado um país de médio custo de mão de obra, portanto teria dificuldades de competir com países como a Índia e a China em setores que requerem mão de obra a baixo custo (RAMAMURTI, SINGH, 2009). No entanto, ao contar com boa disponibilidade de engenheiros e cientistas, desenvolvida desde a época das políticas de substituição de importações das décadas de 1950 a 1970, apresenta BrMNEs que se utilizam dessa disponibilidade como COE para formar suas vantagens competitivas.

As subsidiárias das empresas deste agrupamento são normalmente montadas para prestar serviços customizados a seus clientes, de forma que elas não envolvem investimentos substanciais e são "footloose" (FERDOWS, 2009) no sentido de serem capazes de abrir, fechar e realocar conforme a evolução do mercado. Tais habilidades requerem competências estratégicas e administrativas fortes das BrMNEs. Por outro lado, suas competências essenciais são, até certo ponto, dependentes de seus clientes e fornecedores. A deterioração dos ambientes econômico e político provoca a desvalorização da moeda local e o aumento das taxas de desemprego, que favorecem essas BrMNEs com base de operações no Brasil, mas que oferecem produtos e serviços a nível global, características dos "integradores de serviços" definidos por Fleury et al. $(2009,2015 a)$. Beneficiam-se da crescente infraestrutura de comunicações e do relativo baixo custo dos recursos humanos tecnicamente capacitados no Brasil para operar em nível global, o que lhes dá uma vantagem 
competitiva operacional. Seu relativo sucesso também as possibilitou a sustentar suas vantagens administrativas no período avaliado, pois seu faturamento vem do exterior. Seu modelo de negócio difere das EMNEs tradicionais, sendo algumas vezes descritas como "born globals", denominação conferida em Junior (2010) a quatro empresas estudadas por eles, Fujitec, Xseed, Ivia e Media Systems, e em Fleury e Fleury (2012) a outras duas, a Griaule e a Cl\&T, todas atuando globalmente em nichos do mercado de tecnologia. Essas e outras empresas similares localizam-se em polos tecnológicos como Campinas, São José dos Campos e São Carlos no Estado de São Paulo, Recife no Estado de Pernambuco, Florianópolis no Estado de Santa Catarina e Fortaleza no Estado do Ceará.

O agrupamento também inclui algumas BrMNEs tradicionais tais como a Magnesita, fabricante de refratários que expandiu suas operações internacionais através da aquisição da LBW alemã em 2008, da chinesa Dalian em 2013 e a britânica Holding Mag Intl. em 2016, movimentos que ampliaram seu mercado e competências internacionais (MAGNESITA, 2017b). Embora também explore minérios e possua um perfil que a princípio associe esta empresa à estratégia de integradores verticais de recursos naturais, a Magnesita parece comportar-se, para efeitos de internacionalização, como empresa que adotou a estratégia do Parceiro Global, crescendo através de fusões e aquisições. Outro movimento importante da Magnesita foi mover sua sede para a Holanda e listar suas ações na Bolsa de Valores de Londres para buscar melhores condições operacionais e financeiras (MAGNESITA, 2017a), em linha com o argumento de escape de Cuervo Cazurra (2015).

A estabilidade das capacidades de inovação das BrMNEs que adotaram a estratégia de internacionalização do "Parceiro Global" parece indicar que o ambiente institucional político e econômico tem pouco ou nenhum impacto em seu COE principal, a mão de obra qualificada a um custo relativamente baixo. O desempenho e a exposição dessas firmas no exterior contrabalancearam a reversão de ambiente institucional no país de origem, resultando na estabilidade das capacidades de inovação deste agrupamento. A persistência do COE no desempenho das BrMNEs deste agrupamento, principalmente das empresas integradoras de serviços, parece contradizer 0 argumento do escape, mesmo naquelas que já alcançaram escala global com seus produtos, serviços e operações. 


\subsection{AGRUPAMENTO D - OTIMIZADOR LOCAL}

As firmas do agrupamento D utilizam a estratégia do "Otimizador Local". Trata-se do menor grupo identificado no survey FGV/USP 2015, embora fosse o segundo mais numeroso no survey USP 2010, o que dificulta a análise estatística da evolução deste grupo. O que caracteriza este agrupamento é que eles não sofreram redução significativa nas capacidades de inovação relacionadas às suas competências essenciais e administrativas durante o período, logrando ao contrário incrementar ambas. Esse aumento surpreende, já que seu foco é o mercado brasileiro, embora essas firmas também estejam se expandindo para países vizinhos.

Algumas empresas desse agrupamento se parecem com as integradoras de serviços discutidas no agrupamento $C$ quanto ao aproveitamento de uma base de engenheiros e cientistas, mas se diferenciam por basear sua vantagem em amplo conhecimento do mercado local, além de atuar em âmbito regional. Elas operam principalmente no mercado latino americano ofertando serviços de tecnologia ao consumidor, e não a cadeias globais. Por sua recente internacionalização, vêm conquistando mercados que aparentemente compensam os efeitos negativos do ambiente econômico do Brasil. Exemplos deste tipo de empresa são a Movile, dona de aplicativos de comércio eletrônico como o iFood e Playkids, a Netshoes, e a PSafe, que desenvolve aplicativos de segurança, ambas com atuação na América Latina e Estados Unidos e candidatas a serem as primeiras representantes brasileiras a entrarem para o seleto grupo de "unicórnios", compostos por menos de duzentas start-ups com valor de mercado maior que US\$ 1 bilhão. Atualmente, apenas duas empresas da América Latina, a Decolar, site online de turismo da Argentina e a LifeMiles, programa de fidelidade da companhia aérea colombiana Avianca fazem parte desse grupo (CAPELAS; TOZETTO, 2016; MANZONI JR, 2017; SERRANO, 2017).

Outras BrMNEs deste agrupamento atuam em setores que apresentaram evolução no ambiente econômico brasileiro, notadamente no agronegócio, setor que pode ser considerado um COE brasileiro gerador de competitividade. A Camil Alimentos, que ilustra este tipo de empresa, iniciou seu processo de internacionalização em 2007 e hoje possui 27 plantas, sendo 12 no Brasil, 9 no Uruguai, 3 no Chile, 2 no Peru e 1 na Argentina todas estrategicamente localizadas próximas aos seus fornecedores (CAMIL, 2017). A Camil beneficia grãos, principalmente arroz e feijão, e também 
detém marcas como a União (açúcar) e Coqueiro (pescados enlatados), adquiridas entre 2011 e 2012. Abriu seu capital recentemente em 2017, seguindo seu processo de expansão. Sua principal vantagem competitiva está alinhada àquelas descritas por Ramamurti e Singh (2009), ou seja, na "capacidade de otimizar e adaptar seus processos e produtos ao mercado local, com o qual tem intimidade e envolvimento, e de reaplicar seu modelo de negócios nos países vizinhos". A Jacto, outra empresa ligada ao agronegócio, acaba de anunciar sua primeira fábrica fora do Brasil, prevista para iniciar operações na Argentina em 2018. (RABELLO, 2017). Embora o aproveitamento da vantagem relativa ao setor do agronegócio e intimidade com 0 mercado local comprovem a influência do país de origem no recente processo de internacionalização de empresas como a Camil e a Jacto, ainda não é possível avaliar a persistência desses COEs em seu sucesso a longo prazo. 


\section{A MUDANÇA NO AMBIENTE INSTITUCIONAL POLÍTICO E ECONÔMICO DO BRASIL AFETOU A EXPANSÃO INTERNACIONAL DAS BRMNES?}

O modelo analítico proposto e as Proposições 1 e 2 são o foco da dissertação e mostram a influência das mudanças em COEs devido à deterioração institucional econômica e política no período avaliado nas capacidades de inovação das BrMNEs, com as diferentes consequências conforme a estratégia de internacionalização utilizada. Dado que o argumento do escape pressupõe aumento de internacionalização e uma vez que as capacidades de inovação teoricamente influem na expansão do grau de internacionalização das firmas (FLEURY; FLEURY; BORINI, 2013; WILLIAMSON et al. 2013), a elaboração das conclusões requer a análise da evolução do grau de internacionalização das BrMNEs entre 2010 e 2015.

Conforme discutido na operacionalização de construtos, esta pesquisa utilizou os dados de TNI (Transnationality Index) de letto-Gillies (1998), disponíveis pela UNCTAD e pela FDC em seus relatórios anuais (FUNDAÇÃO DOM CABRAL 2009, 2010, 2011, 2012, 2013, 2014, 2015, 2016). Esse índice multidimensional cobre uma amostra relativamente ampla de BrMNEs.

A avaliação foi executada com as participantes dos relatórios da FDC de 2010, totalizando 40 firmas, e de 2015, totalizando 61; além disso, um subgrupo de validação composto somente pelas BrMNEs que participaram de ao menos um dos surveys USP2010 ou FGV/USP2015 e possuem TNI disponível em um ou nos dois anos também foi avaliado, com um total de 33 BrMNEs representando 2010 e 41 firmas representando o ano de 2015. Os dados originais de 2010 e 2015 foram complementados com informações de 2009 a 2011 e 2014 a 2016 respectivamente para aquelas BrMNEs que não apareceram em 2010 e 2015, mas foram listadas em anos adjacentes.

Tanto a análise do total dos participantes dos relatórios da FDC de 2010 e 2015 como a do subgrupo descrito acima apresentaram aumento em seu TNI entre 2010 e 2015, confirmado através de Testes T. A média do TNI evoluiu de aproximadamente 0,20 em 2010 para $0,30 \mathrm{em} 2015 \mathrm{em}$ ambos os casos. O resultado dos testes $T$ indicaram que o aumento foi estatisticamente significativo com um nível de confiança de $95 \%$. A Tabela 7 detalha os resultados e a Figura 9 a evolução do TNI entre 2010 e 2015 para as duas análises. 
Tabela 7 - Resultados de Testes T para TNI das BrMNEs entre 2010 e 2015

\begin{tabular}{c|c|c|c|c|c|c|c}
\hline \multicolumn{2}{c|}{} & \multicolumn{3}{c|}{ BASE - relatórios FDC - Todas as firmas } & \multicolumn{3}{c}{\begin{tabular}{c} 
BASE - relatórios FDC - \\
\multicolumn{2}{c|}{}
\end{tabular}} \\
\hline \multirow{2}{*}{ SNI participantes dos surveys USP e FGV/USP }
\end{tabular}

Fonte: autor

Figura 9 - TNI - evolução anual entre 2010 e 2015

\section{Evolução do TNI - 2010-2015}

35

30

25

20

15

10

2010

2011

2012

2013

2014

2015

Fonte: autor segundo relatórios FDC e para participantes dos surveys USP e USP/FGV

Informações adicionais dos relatórios da FDC validam os resultados observados na análise do TNI. Mais BrMNEs estão iniciando do que encerrando novas operações. A entrada de BrMNEs em novos países é de cerca de 25 a 30 por ano, enquanto a saída gira entre 3 e 8 países a cada ano, considerando o período de 2010 a 2015. Outro dado divulgado no relatório FDC (2016) é que 78\% das BrMNEs aumentaram suas operações no exterior no ano de 2015 contra 69\% em 2014. No mesmo período, aproximadamente $67 \%$ das empresas manteve ou ampliou suas operações no mercado brasileiro.

Esta análise confirma que o incremento do TNI ocorre por expansão internacional, objetivo do medidor, e não por redução das atividades no Brasil. Portanto, o grau de internacionalização das BrMNEs segue crescendo, apesar da redução observada nas capacidades de inovação essenciais e de funções administrativas no mesmo período. 


\section{CONSIDERAÇÕES FINAIS}

\subsection{CONTRIBUIÇÕES PARA A TEORIA}

O objetivo da presente pesquisa foi contribuir para o conhecimento sobre a evolução de capacidades de inovação das Empresas Multinacionais de Países Emergentes (EMNEs) em um período de mudanças institucionais em seu país de origem. Nortearam o desenvolvimento desta dissertação as perguntas de pesquisa: (a) "Como o ambiente institucional do país de origem afeta as multinacionais e suas capacidades de inovação ao longo do tempo?"; e (b) "A estratégia adotada para internacionalizar tem algum papel nesse processo, e caso afirmativo qual é esse papel?'. Os resultados apresentados ajudam a lançar luz sobre essas perguntas e permitem as seguintes conclusões:

a) A capacidade de inovação das EMNEs é afetada por mudanças nas Condições do País de Origem (COEs) causadas por alterações institucionais.

Os achados desta pesquisa confirmam o argumento de que mudanças no ambiente institucional do país de origem afetam as capacidades de inovação das EMNEs, tanto no início, mas também em estágios mais avançados de internacionalização. O período 2010-2015 foi marcado por uma virada no ambiente institucional político e econômico do Brasil, que passou de estável e positivo a politicamente turbulento e economicamente instável, conforme comprovam a evolução do índice de competitividade do Brasil, dos seus componentes e medidores associados a instituições econômicas e políticas nesse período, além dos resultados oficiais do país. Esse quadro criou um novo ambiente de operação para as multinacionais brasileiras, que tiveram que redirecionar seus recursos e competências para fazer face aos desafios dessa nova situação. Períodos de relativa estabilidade como o marcado pela primeira década dos anos 2000 em contraste com o período posterior a 2013, com deterioração do ambiente institucional, repetem o modelo apresentado por Sull e Escobari (2004), em que os períodos de turbulência apresentam ameaças de morte súbita bem como oportunidades de ouro para as empresas que operam no Brasil. 
A primeira ponderação gerada pelos achados desta pesquisa relaciona-se à proposição de que o estudo das multinacionais dos países emergentes (EMNEs) não pode abster-se do uso da dimensão institucional (PENG; WANG; JIANG, 2008). Essa última manifesta sua influência ao longo do tempo, conforme evidenciado pela alteração do ambiente institucional entre o período anterior e posterior a 2013 e seu reflexo nas capacidades de inovação das BrMNEs. Em linha com a primeira proposição deste trabalho, a reversão do ambiente institucional do Brasil causou uma redução no fator que mede capacidades de inovação essenciais entre 2010 e 2015 para a amostra de BrMNEs estudada, sugerindo maior dificuldade para elas organizarem suas competências essenciais e assim gerar, manter ou incrementar suas vantagens competitivas.

b) EMNEs que usam diferentes estratégias de internacionalização apresentam evolução distinta de suas capacidades de inovação quando há mudanças em COEs.

A segunda ponderação refere-se ao papel das estratégias de internacionalização na evolução das capacidades de inovação das EMNEs quando ocorrem mudanças em COEs. Quando a deterioração institucional econômica e política afeta um país, ela gera diferentes consequências para as MNEs locais, uma vez que cada estratégia de internacionalização tipificada por Ramamurti e Singh (2009) utiliza uma combinação específica de COEs e capacidades de inovação para geração de vantagens competitivas.

As estratégias baseadas no mercado doméstico parecem mais suscetíveis às suas mudanças, conforme apresentado na discussão dos resultados desta pesquisa. $O$ agrupamento que representa a estratégia de Consolidadores Globais, que normalmente possuem operações de porte no país de origem, perdem as vantagens desse COE quando há reversão de crescimento para contração no ambiente econômico doméstico. A maior dificuldade no mercado interno exige redirecionamento de foco que provoca redução das capacidades de inovação de competências essenciais e de suporte administrativo para se expandir no exterior, uma vez as subsidiárias dependem da matriz para seu próprio incremento de capacidades. Uma forma de adquirir capacidade financeira que essas firmas têm buscado é a abertura de capital no exterior, movimento que busca aumentar a capacidade financeira, mas 
não tem impacto na recuperação do mercado doméstico e na resolução do problema de desempenho das subsidiárias adquiridas no exterior. Outro agrupamento diretamente afetado por turbulências institucionais econômica e política no país de origem é o que utiliza a estratégia do Integrador Vertical de Recursos Naturais com base no acesso privilegiado ao mercado doméstico, tal como discutido no caso da Petrobrás.

Já as empresas que se valem do acesso às fontes de recursos naturais mostram relativa independência do ambiente doméstico, apresentando maior dependência da trajetória dos setores a que pertencem no mercado internacional, como observado para os setores de aço, que apresentou considerável queda de preços após 2008, levando empresas como a Vale e a CSN a desinvestirem no exterior, reduzindo suas competências essenciais e administrativas, e os setores de cimento e papel e celulose, que apresentaram valorização considerável no período estudado e permitiram a essas empresas aumentassem ambas as capacidades de inovação relacionadas a competências essenciais e de funções administrativas.

Empresas com estratégias associadas a COEs referentes à disponibilidade de mão de obra qualificada de engenheiros e cientistas a relativo baixo custo para atuar em cadeias globais de valor, como é o caso das empresas que se utilizam da estratégia do Parceiro Global, puderam sustentar suas capacidades de inovação de competências essenciais e de funções administrativas e assim compensar os problemas do ambiente institucional doméstico. Essas empresas têm como clientes os líderes das cadeias globais de valor em que atuam e, portanto, têm suas operações afetadas mais pelo comportamento dessas cadeias que pelo ambiente institucional no mercado doméstico. Os "Parceiros Globais" que puderam escolher um tipo "footloose" de internacionalização, geralmente associados ao fornecimento de serviços e sistemas de tecnologia, estão conectados a seus fornecedores e clientes e tendem a sofrer menos que aquelas multinacionais mais dependentes de suas matrizes, pois requerem pouco investimento para operar, contam com uma base de técnicos e engenheiros formados em polos tecnológicos do país e uma estrutura enxuta de operação no exterior, o que Ihes confere vantagem competitiva em competências de operação.

As empresas com estratégia de Otimizador Local associadas a setores específicos também são influenciadas pelo mercado doméstico. Neste caso, defrontam-se com 
ameaças de morte súbita ou com oportunidades de ouro. Empresas associadas ao agronegócio apresentaram crescimento em ambos os fatores associados a capacidades de inovação essenciais e administrativas influenciadas pelo sucesso desse setor, apesar da instabilidade econômica e política do Brasil no período estudado. Já os prestadores de serviços em países da América Latina e Estados Unidos utilizam-se do mesmo COE que os "Parceiros Globais" com respeito à mão de obra qualificada, mas se diferenciam por se valem um COE adicional, a intimidade com o mercado local e seu tamanho, para desenvolverem suas capacidades de inovação, apresentarem serviços inovadores no seu mercado local e se expandirem regionalmente, tal como o caso da Movile, Netshoes e PSafe.

Os resultados desta pesquisa confirmam a tipologia de Ramamurti e Singh (2009) e ajudam a compreender aspectos da efemeridade ou persistência de COEs na evolução das EMNEs. A resposta parece depender de COEs e do tipo de estratégia adotados, além da capacidade das EMNEs de identificarem oportunidades de ouro ou evitarem as ameaças de morte súbita para se expandir conforme discutido nos parágrafos anteriores.

c) As EMNEs seguem diferentes das DMNEs apesar do aumento de sua internacionalização. As origens diversas implicam em evoluções distintas

A terceira ponderação refere-se ao nivelamento de EMNEs e DMNEs em estágios maduros de internacionalização. A afirmação de Cuervo-Cazurra (2012) e Rugman (2009) de que EMNEs em estágios mais avançados de internacionalização se equiparariam às DMNEs devido à perda de importância de COEs revela-se apenas parcialmente correta à luz dos achados desta pesquisa. Contrariando a afirmação, em algumas estratégias de internacionalização COEs persistem mesmo em EMNEs com estágios mais avançados de internacionalização, como observado nas empresas com origem e atuação forte nos países com grandes mercados consumidores e naquelas que se utilizam da mão de obra qualificada de seus países de origem para se expandir. No caso das empresas com estratégia do Parceiro Global, COEs realmente perdem importância com o avanço da internacionalização das EMNEs, pois o desempenho dessas empresas está atrelado às cadeias globais a que pertencem. Finalmente, há empresas para as quais o aumento de internacionalização não modifica a dependência ou impacto de COEs, como discutido no caso dos Integradores Verticais 
de Produtos Naturais que buscam no exterior mercados adicionais para seus produtos e eventualmente novas fontes de recursos para seus mercados ampliados.

Os resultados desta pesquisa também divergem de Rugman (2009) ao demonstrar que alguns grupos de BrMNEs desenvolvem suas vantagens competitivas de fatores que não a mão de obra barata ou acesso a fontes de recursos naturais, mas sim a partir da disponibilidade de engenheiros e cientistas ou de setores que se beneficiam de vantagens únicas do país, tais como a sofisticação de sua agroindústria; e da afirmação de Lassard e Lucea (2009) de que COEs de um país estão disponíveis igualmente para todas as empresas que nele operam. COEs utilizados pelas BrMNEs variam conforme a estratégia de internacionalização utilizada e não parecem estar igualmente disponíveis a todas as firmas do país.

d) O argumento do escape é válido em algumas situações, mas não pode ser generalizado

A quarta ponderação desta pesquisa relaciona-se ao argumento do escape. Ele é válido em algumas situações onde se apresentem COEs como desvantagens, mas não em situações onde COEs formam vantagens competitivas. EMNEs que se valeram de COEs para manter ou ampliar suas capacidades de inovação e assim expandir-se fora das fronteiras de seus países de origem não têm motivos para escapar de seus COEs, pelo contrário os usam a seu favor. O acesso privilegiado a fontes de recursos naturais, o acesso a mão de obra qualificada a baixo custo ou a atuação em setores competitivos em expansão são alguns exemplos de situações onde as empresas não têm motivos para reduzir a influência de seus países de origem em suas operações. Já as empresas com grande dependência do mercado doméstico e que sofreram com as reversões institucionais política e econômica com redução nessas mesmas capacidades podem tentar minimizar a dependência de seus países de origem ao internacionalizar, conforme sugerem Cuervo-Cazurra (2015) e CuervoCazurra, Narula e Un (2015) na motivação do escape. A redução de capacidades de inovação, neste caso, pode estar associada à centralização das operações e à dificuldade experimentada pela matriz em lidar com o ambiente institucional desfavorável em seu país de origem ao mesmo tempo em que essas empresas 
buscam atuar em novos mercados com paradigmas diferentes do país de origem, que requerem novas competências de produção e operação, marketing e produto.

\subsection{LIMITAÇÕES DA PESQUISA}

Há limitações que requerem cuidado na generalização dos resultados deste trabalho. O tamanho de amostra relativamente pequeno devido à população reduzida de BrMNEs que toma parte nos surveys usados no estudo é a principal delas. Generalizações devem ser tratadas com o devido cuidado considerando este fato. Outra limitação é que os surveys foram executados nas sedes das BrMNEs, excluindo, portanto, suas subsidiárias, o que impede a avaliação da percepção destas em relação às capacidades de inovação e competências das empresas como uma rede internacional de operações. Futuros estudos incluindo subsidiárias podem oferecer uma perspectiva mais ampla sobre as BrMNEs. Os dados de competitividade do Brasil são secundários, limitando a análise às informações disponíveis nos relatórios pesquisados. Embora esta abordagem simplifique o processo de pesquisa, o acesso a fontes de dados primárias possibilitaria análise mais aprofundada dos dados. As diferenças entre os questionários dos surveys de 2010 e 2015 e entre as empresas participantes dos dois surveys limitam a comparação longitudinal. Finalmente, a pesquisa centra-se em apenas uma mudança em COEs, permitindo apenas avaliar esta mudança em particular.

\subsection{OPORTUNIDADES DE ESTUDOS FUTUROS}

Futuras pesquisas, caso o Brasil reverta seus problemas institucionais político e econômico, poderiam oferecer informação valiosa sobre o real impacto dos efeitos do país de origem no desempenho de suas multinacionais. A ampliação da amostra, incluindo mais BrMNEs, e a participação das subsidiárias nos surveys ampliaria a amostragem usada nos estudos, bem como adicionaria a perspectiva da rede das multinacionais. O uso do mesmo questionário em sucessivos surveys possibilitaria melhor comparação longitudinal dos fatores estudados, eventualmente possibilitando a fatoração das competências essenciais em seus elementos de tecnologia, produção e operação e marketing. Estudos similares em outras economias emergentes e 
complexas, tais como BRIC, África do Sul, México ou Turquia, ou mesmo mais próximas ao Brasil como Argentina, Chile e Colômbia, proporcionariam maior generalização aos achados deste estudo. O aprofundamento dos estudos sobre empresas de tecnologia merece atenção, pois algumas delas têm crescido rapidamente com potencial para se posicionarem entre as grandes BrMNEs em um futuro próximo. 


\section{REFERÊNCIAS}

ALMEIDA, André. Internacionalização de empresas brasileiras: perspectivas e riscos. Elsevier, 2007.

AMSDEN, Alice $\mathrm{H}$. Diffusion of development: The late-industrializing model and greater East Asia. The American Economic Review, v. 81, n. 2, p. 282-286, 1991.

ARAUJO, Claudiano Sales. Lessons learned on the planning and execution of technology innovation projects with academic partnership: aerospace industry case study. Product: Management \& Development, v. 10, p. 10, 2012.

ARATA, Newton; SHENG, Hsia Hua; LORA, Mayra Ivanoff. Internationalization and Corporate Cash Holdings: Evidence from Brazil and Mexico. Revista de Administração Contemporânea, v. 19, n. SPE, p. 1-19, 2015.

AWATE, Snehal; LARSEN, Marcus M.; MUDAMBI, Ram. EMNE catch-up strategies in the wind turbine industry: Is there a trade-off between output and innovation capabilities?. Global Strategy Journal, v. 2, n. 3, p. 205-223, 2012.

BARCELLOS, Erika Penido; CYRINO, Alvaro Bruno. Quão internacionalizadas são as nossas multinacionais? Proposta de metodologia e resultados da sua aplicação a empresas brasileiras com atuação no exterior. ENCONTRO DA ASSOCIAÇÃO NACIONAL DE PÓS-GRADUAÇÃO E PESQUISA EM ADMINISTRAÇÃO, v. 31, 2007.

BAUSCH, Andreas; KRIST, Mario. The effect of context-related moderators on the internationalization-performance relationship: Evidence from metaanalysis. Management international review, v. 47, n. 3, p. 319-347, 2007.

BLANKE, Jennifer; LOPEZ-CLAROS, Augusto. The growth competitiveness index: assessing countries' potential for sustained economic growth. The global competitiveness report, v. 2005, p. 3-18, 2004.

BORINI, Felipe Mendes et al. The reverse transfer of innovation of foreign subsidiaries of Brazilian multinationals. European Management Journal, v. 30, n. 3, p. 219-231, 2012.

BUCKLEY, P. J. Casson., M. 1976. The future of the multinational enterprise, v. 1, 1976.

BUCKLEY, Peter J.; CASSON, Mark C. The internalisation theory of the multinational enterprise: A review of the progress of a research agenda after 30 years. Journal of International Business Studies, v. 40, n. 9, p. 1563-1580, 2009.

CAMIL. História da Camil. Disponível em <http://camilalimentos.com.br/\#sobre>. Acesso em 13 ago. 2017

CAPELAS, B.; TOZETTO, C. Primeiro 'unicórnio' pode colocar Brasil no mapa global de startups. O Estado de S. Paulo. São Paulo. 16 out. 2016. Disponível em 
$<$ http://link.estadao.com.br/noticias/geral,primeiro-unicornio-pode-colocar-brasil-nomapa-global-de-startups, 10000082464>. Acesso em 24 ago. 2017.

CHANG, Sea Jin. International expansion strategy of Japanese firms: Capability building through sequential entry. Academy of Management journal, v. 38, n. 2, p. 383-407, 1995.

$\mathrm{CHO}$, Dong-Sung; KIM, Dong-Jae; RHEE, Dong Kee. Latecomer strategies: evidence from the semiconductor industry in Japan and Korea. Organization science, v. 9, n. 4, p. 489-505, 1998.

CIMENTO, O Mundo do. Site de divulgação da Indústria do Cimento. Disponível em: $<$ http://cimento.org/cimento-no-mundo/>. Acesso em 11 ago.2017

CORNELIUS, Peter K.; MCARTHUR, John W. The executive opinion survey. The Global Competitiveness Report, v. 2002, p. 166-177, 2001.

CUERVO-CAZURRA, Alvaro. Extending theory by analyzing developing country multinational companies: Solving the Goldilocks debate. Global Strategy Journal, v. 2, n. 3, p. 153-167, 2012.

CUERVO-CAZURRA, Alvaro. The co-evolution of pro-market reforms and emerging market multinationals. In: Emerging Economies and Multinational Enterprises. Emerald Group Publishing Limited, 2015. p. 71-94.

CUERVO-CAZURRA, Alvaro; GENC, Mehmet. Transforming disadvantages into advantages: developing-country MNEs in the least developed countries. journal of international Business Studies, v. 39, n. 6, p. 957-979, 2008.

CUERVO-CAZURRA, Alvaro; NARULA, Rajneesh; UN, C. Annique. Internationalization motives: sell more, buy better, upgrade and escape. The Multinational Business Review, v. 23, n. 1, p. 25-35, 2015.

CUERVO-CAZURRA, Alvaro; RAMAMURTI, Ravi (Ed.). Understanding multinationals from emerging markets. Cambridge University Press, 2014.

DENG, Ping; YANG, Monica. Cross-border mergers and acquisitions by emerging market firms: A comparative investigation. International Business Review, v. 24, n. 1, p. 157-172, 2015.

DEVORE, Jay L. Probability and Statistics for Engineering and the Sciences. Cengage Learning, 2015.

DIMITRATOS, Pavlos. The firm's location in the home country and internationalisation: some evidence from Greek smaller firms. Intereconomics, v. 37, n. 2, p. 91-100, 2002.

DUNNING, John $\mathrm{H}$. Explaining changing patterns of international production: in defence of the eclectic theory. Oxford bulletin of economics and statistics, v. 41, n. 4, p. 269-295, 1979. 
DUNNING, John $H$. Reappraising the eclectic paradigm in an age of alliance capitalism. The changing boundaries of the firm, p. 29-59, 1998.

DUNNING, John H. Comment on Dragon multinationals: New players in 21 st century globalization. Asia Pacific Journal of Management, v. 23, n. 2, p. 139-141, 2006.

EISENHARDT, Kathleen M.; MARTIN, Jeffrey A. Dynamic capabilities: what are they? Strategic management journal, p. 1105-1121, 2000.

ELANGO, Balasubramanian; SETHI, S. Prakash. An exploration of the relationship between country of origin (COE) and the internationalization-performance paradigm. Management International Review, v. 47, n. 3, p. 369-392, 2007.

FÁVERO, L. P.; BELFIORE, P. Análise de dados: técnicas multivariadas exploratórias com SPSS® e Stata $\AA^{\circ} .2015$.

FERDOWS, Kasra. Shaping Global Operations. GCG: Revista de Globalización, Competitividad \& Gobernabilidad, v. 3, n. 1, 2009.

FGV; USP. Pesquisa - Multinacionais Brasileiras. São Paulo: 2015.

FLEURY, Afonso; FLEURY, Maria Tereza Leme. Internacionalização e os países emergentes. São Paulo: Atlas, v. 84, 2007.

FLEURY, Afonso Carlos Corrêa; FLEURY, Maria Tereza Leme. Multinacionais brasileiras: competências para a internacionalização. FGV Editora, 2012.

FLEURY, Afonso; TEREZA, Maria; FLEURY, Leme. 12 Country of origin effects on internationalization: insights from Brazil. Understanding Multinationals from Emerging Markets, p. 242, 2014.

FLEURY, Afonso; FLEURY, Maria Tereza Leme; BORINI, Felipe Mendes. The Brazilian multinationals' approaches to innovation. Journal of International Management, v. 19, n. 3, p. 260-275, 2013.

FLEURY, A. et al. Developing an analytical framework for study of emerging country multinationals' operations management. International Journal of Production Research, v. 53, n. 18, p. 5418-5436, $2015 a$.

FLEURY, A. et al. Gestão estratégica das multinacionais brasileiras. São Paulo: Universidade de São Paulo/Fundação Getúlio Vargas, 2015b.

FLORIANI, Dinorá Eliete. O grau de internacionalização, as competências e o desempenho da PME brasileira. 2010. Tese de Doutorado. Universidade de São Paulo.

FLORIANI, Dinorá Elite et al. O efeito do grau de internacionalização nas competências internacionais e no desempenho financeiro da PME brasileira. Revista de Administração Contemporânea, v. 16, n. 3, p. 438-458, 2012. 
FOREIGN ADRS LIST. Lista de empresas brasileiras listadas nas bolsas de Nova York (NYSE, NASDAQ) disponível em <http://topforeignstocks.com/foreign-adrslist/the-full-list-of-brazilian-adrs/>. Acesso em 23 ago. 2017.

FORTE, S. H. A. C.; SETTE JÚNIOR, E. L. M. Grau de internacionalização de empresas: um estudo no setor de rochas ornamentais e de revestimento no Estado do Ceará. Encontro da Associação Nacional de Pós-Graduação e Pesquisa em Administração, v. 29, 2005.

FORZA, Cipriano. Survey research in operations management: a process-based perspective. International journal of operations \& production management, v. 22, n. 2, p. 152-194, 2002.

FORZA, Cipriano. 4 Surveys. Research Methods for Operations Management, p. 79, 2016.

FUNDAÇÃO DOM CABRAL. Ranking das Transnacionais Brasileiras 2009: Investimentos no exterior crescem, apesar da crise mundial. Belo Horizonte: Fundação Dom Cabral, 2009.

Ranking das Transnacionais Brasileiras 2010: Repensando as estratégias globais. Belo Horizonte: Fundação Dom Cabral, 2010.

Ranking das Transnacionais Brasileiras 2011: Crescimento e gestão sustentável no exterior. Belo Horizonte: Fundação Dom Cabral, 2011.

- Ranking das Transnacionais Brasileiras 2012: Os benefícios da internacionalização. Belo Horizonte: Fundação Dom Cabral, 2012.

Ranking FDC das Multinacionais Brasileiras 2013: Os impactos da política externa na internacionalização de empresas brasileiras. Belo Horizonte: Fundação Dom Cabral, 2013.

. Ranking FDC das Multinacionais Brasileiras 2014: A força da marca Brasil na criação de valor internacional. Belo Horizonte: Fundação Dom Cabral, 2014.

- Ranking FDC das Multinacionais Brasileiras 2015: A capacidade de adaptação cultural das empresas brasileiras no mundo. Belo Horizonte: Fundação Dom Cabral, 2015.

Ranking FDC das Multinacionais Brasileiras 2016. 11를 Edição - 2016. Belo Horizonte: Fundação Dom Cabral, 2016.

GAUR, Ajai S.; KUMAR, Vikas. International diversification, business group affiliation and firm performance: Empirical evidence from India. British Journal of Management, v. 20, n. 2, p. 172-186, 2009.

GEREFFI, Gary; HUMPHREY, John; STURGEON, Timothy. The governance of global value chains. Review of international political economy, v. 12, n. 1, p. 78-104, 2005. 
GLOBAL FEDERATION OF COMPETITIVENESS COUNCILS. Ferramenta Competitiveness Decoder ${ }^{\mathrm{TM}}$. Disponível em < http://decoder.thegfcc.org/>. Acesso em 10 ago. 2017

GOUVEIA, Flávia. Tecnologia nacional para extrair petróleo e gás do présal. Conhecimento \& Inovação, v. 6, n. 1, p. 30-35, 2010.

GOVINDARAJAN, Vijay; RAMAMURTI, Ravi. Reverse innovation, emerging markets, and global strategy. Global Strategy Journal, v. 1, n. 3- 4, p. 191-205, 2011.

GUILLÉN, Mauro F.; GARCÍA-CANAL, Esteban. The American model of the multinational firm and the "new" multinationals from emerging economies. The Academy of Management Perspectives, v. 23, n. 2, p. 23-35, 2009.

GUIMARÃES, F. Endividada, CSN coloca vários ativos à venda. $\mathbf{O}$ Estado de $\mathbf{S}$. Paulo. São Paulo. Disponível em: $<$ http://economia.estadao.com.br/noticias/geral,endividada--csn-coloca-varios-ativosa-venda--imp-,1743827>. Acesso em 12 ago. 2017.

HAIR, J.F. et al. Multivariate data analysis 6th Edition. New Jersey: Pearson Education, 2006.

HASSEL, Anke et al. Two dimensions of the internationalization of firms. Journal of Management Studies, v. 40, n. 3, p. 705-723, 2003.

HOLMES JR, R. Michael et al. The interrelationships among informal institutions, formal institutions, and inward foreign direct investment. Journal of Management, $v$. 39, n. 2, p. 531-566, 2013.

HUMPHREY, John; SCHMITZ, Hubert. How does insertion in global value chains affect upgrading in industrial clusters? Regional studies, v. 36, n. 9, p. 1017-1027, 2002.

IETTO-GILLIES, Grazia. Different conceptual frameworks for the assessment of the degree of internationalization: an empirical analysis of various indices for the top 100 transnational corporations. Transnational corporations, v. 7, p. 17-40, 1998.

IETTO-GILLIES, Grazia. Assessing the degree of internationalization. Some conceptual issues. In: Workshop paper, Workshop MIUR-ITG, Torino. 2001.

JUNIOR, Moacir de Miranda Oliveira. Multinacionais brasileiras: internacionalização, inovação e estratégia global. Bookman Editora, 2010.

JUNIOR, Moacir de Miranda Oliveira; BOEHE, Dirk Michael; BORINI, Felipe Mendes. Estratégia e inovação em corporações multinacionais: a transformação das subsidiárias brasileiras. Saraiva, 2009.

KACZMAREK, Szymon; RUIGROK, Winfried. In at the deep end of firm internationalization. Management International Review, v. 53, n. 4, p. 513-534, 2013.

KAFOUROS, Mario I. et al. The role of internationalization in explaining innovation performance. Technovation, v. 28, n. 1, p. 63-74, 2008. 
KNIGHT, Gary A.; KIM, Daekwan. International business competence and the contemporary firm. Journal of International Business Studies, v. 40, n. 2, p. 255273, 2009.

KOTHARI, Tanvi; KOTABE, Masaaki; MURPHY, Priscilla. Rules of the game for emerging market multinational companies from China and India. Journal of International Management, v. 19, n. 3, p. 276-299, 2013.

LAWSON, Benn; SAMSON, Danny. Developing innovation capability in organisations: a dynamic capabilities approach. International journal of innovation management, v. 5 , n. 03 , p. 377-400, 2001.

LESSARD, D.; LUCEA, R. Mexican Multinationals: Lessons from Cemex. Emerging multinationals from emerging markets, 2008.

LIMA, Paulo César Ribeiro. Os desafios, os impactos e a gestão da exploração do pré-sal. Audiência Pública no Senado Federal. Nov, 2008.

LUO, Yadong; TUNG, Rosalie L. International expansion of emerging market enterprises: A springboard perspective. Journal of international business studies, v. 38, n. 4, p. 481-498, 2007.

MAGNESITA. Fato relevante. Disponível em: http://ri.magnesita.com/list.aspx?idCanal=WLIhRu0PniZASO04QJI57A==\&pagina=2.

Acesso em 23 out. 2017 a.

MAGNESITA. Nossa História. Disponível em: <http://magnesita.com/amagnesita/nossa-historia/>. Acesso em 23 out 2017b.

MANZONI JR, RALPHE. As startups mais promissoras do Brasil. Istoé Dinheiro. São Paulo. Disponível em: <http://www.istoedinheiro.com.br/startups-mais-promissorasbrasil/>. Acesso em 25 ago. 2017

MARANO, Valentina et al. Home country institutions and the internationalizationperformance relationship: A meta-analytic review. Journal of Management, v. 42, n. 5, p. 1075-1110, 2016.

MATHEWS, John A. Competitive advantages of the latecomer firm: A resource-based account of industrial catch-up strategies. Asia Pacific journal of management, v. 19, n. 4, p. 467-488, 2002.

MATHEWS, John A. Dragon multinationals: New players in 21st century globalization. Asia Pacific J Manage, v. 23, p. 5-27, 2006.

MCARTHUR, John W. et al. The growth competitiveness index: measuring technological advancement and the stages of development. The global competitiveness report, v. 2002, p. 28-51, 2001.

MCDOUGALL, Patricia Phillips; OVIATT, Benjamin M. New venture internationalization, strategic change, and performance: A follow-up study. Journal of business venturing, v. 11, n. 1, p. 23-40, 1996. 
MEYER, Klaus E. et al. Institutions, resources, and entry strategies in emerging economies. Strategic management journal, v. 30, n. 1, p. 61-80, 2009.

NACHUM, L.; JONES, G. G.; DUNNING, J. H. The international competitiveness of the UK and its multinational enterprises. Structural Change and Economic Dynamics, v. 12, n. 3, p. 277-294, 2001.

NAKAGAWA, F.; NEDER, V. Preço do minério cai 80\% desde 2011 e Vale perde $\mathrm{R} \$$ 247 bilhões em negócios na Bolsa. O Estado de S. Paulo, São Paulo, 08 dez. 2015. Disponível em: <http://economia.estadao.com.br/noticias/geral,preco-do-minerio-cai80-desde-2011-e-vale-perde-r-247-bilhoes-na-bolsa,10000004268> . Acesso em 12 ago. 2017

OBSERVATÓRIO MULTINACIONAIS BRASILEIRAS: banco de dados de empresas multinacionais brasileiras. Disponível em: <http://observatorio.espm.br/>. Acesso em 23/ago. 2017.

OESTERLE, Michael-Jörg; RICHTA, Hannah Noriko; FISCH, Jan Hendrik. The influence of ownership structure on internationalization. International Business Review, v. 22, n. 1, p. 187-201, 2013.

OLIVEIRA, M.; BORINI, F.; FLEURY, A. Innovation by Brazilian EMNEs. The Competitive Advantage of Emerging Market Multinationals, p. 11-28, 2013.

PADUAN, R. Como a Petrobras pode emergir do mar de lama. REVISTA ÉPOCA NEGÓCIOS, São Paulo, 08 mar. 2017. Disponível em $<$ http://epocanegocios.globo.com/Empresa/noticia/2017/03/como-petrobras-podeemergir-do-mar-de-lama.html>. Acesso em 29 out. 2017.

PARRA-BERNAL, Guillermo; BAUTZER, Tatiana. Votorantim Metais considera IPO, dizem fontes. REUTERS, São Paulo, 10 abr. 2017. Disponível em $<$ http://br.reuters.com/article/businessNews/idBRKBN17C1EL-OBRBS>. Acesso em: 23 ago. 2017.

PENG, Mike W. Institutional transitions and strategic choices. Academy of management review, v. 28, n. 2, p. 275-296, 2003.

PENG, Mike W.; WANG, Denis YL; JIANG, Yi. An institution-based view of international business strategy: $A$ focus on emerging economies. Journal of international business studies, v. 39, n. 5, p. 920-936, 2008.

PORTER, Michael E. The Competitive Advantage of Nations. Macmillan, London, 1990

PRAHALAD, C. K.; HAMEL, Gary. The core competence of the corporation. Harvard Business Review, v. 26, p. 2000, 1990.

RABELLO, T. Jacto expande operações com fábrica na Argentina. O Estado de S. Paulo, São Paulo, 23 out 2017. Disponível em: <http://digital.estadao.com.br/oestado-de-s-paulo/20171023/textview> . Acesso em 23 out. 2017 
RAMAMURTI, Ravi. What is really different about emerging market multinationals?. Global Strategy Journal, v. 2, n. 1, p. 41-47, 2012.

RAMAMURTI, Ravi; SINGH, Jitendra V. (Ed.). Emerging multinationals in emerging markets. Cambridge University Press, 2009.

RAMASWAMY, Kannan; KROECK, K. Galen; RENFORTH, William. Measuring the degree of internationalization of a firm: A comment. Journal of International Business Studies, p. 167-177, 1996.

RAMSEY, Jase; ALMEIDA, André. A ascensão das multinacionais brasileiras. Rio de Janeiro: Campus, 2010.

REN, Shengce; EISINGERICH, Andreas B.; TSAI, Huei-Ting. How do marketing, research and development capabilities, and degree of internationalization synergistically affect the innovation performance of small and medium-sized enterprises (SMEs)? A panel data study of Chinese SMEs. International Business Review, v. 24, n. 4, p. 642-651, 2015.

REUBER, A. Rebecca; FISCHER, Eileen. The influence of the management team's international experience on the internationalization behaviors of SMEs. Journal of International Business Studies, p. 807-825, 1997.

RIAHI-BELKAOUI, Ahmed. The effects of the degree of internationalization on firm performance. International Business Review, v. 7, n. 3, p. 315-321, 1998.

RICCOMINI, Claudio et al. Pré-sal: geologia e exploração. Revista USP, n. 95, p. 3342, 2012.

RUGMAN, Alan M. Theoretical aspects of MNEs from emerging economies. Emerging multinationals in emerging markets, p. 42-63, 2009.

RUGMAN, Alan M.; VERBEKE, Alain. Subsidiary- specific advantages in multinational enterprises. Strategic Management Journal, v. 22, n. 3, p. 237-250, 2001.

SAPIENZA, Harry J.; DE CLERCQ, Dirk; SANDBERG, William R. Antecedents of international and domestic learning effort. Journal of Business Venturing, v. 20, n. 4, p. 437-457, 2005.

SCHELER, F.; PEREIRA, R. Braskem avalia mudar sua sede para os EUA. O Estado de S. Paulo, São Paulo, 04 ago. 2017. Disponível em: $<$ http://economia.estadao.com.br/noticias/geral,braskem-estuda-mudar-sua-sedepara-os-eua,70001923605>. Acesso em 04 ago. 2017.

SEGARO, Ethiopia L.; LARIMO, Jorma; JONES, Marian V. Internationalisation of family small and medium sized enterprises: The role of stewardship orientation, family commitment culture and top management team. International business review, $v$. 23, n. 2, p. 381-395, 2014.

SERRANO, F. Perto de faturar R $\$ 1$ bilhão, a Movile quer mais. Revista Exame. São Paulo. 30 jun. 2017. Acesso em 24 ago. 2017. 
SETHI, S. Prakash; ELANGO, Balasubramanian. The influence of "country of origin" on multinational corporation global strategy: A conceptual framework. Journal of International Management, v. 5, n. 4, p. 285-298, 1999.

SILVA, Bárbara Queiroz et al. OS EFEITOS DA INTERNACIONALIZAÇÃO NO DESEMPENHO FINANCEIRO DE EMPRESAS MULTINACIONAIS DE PAÍSES DESENVOLVIDOS E EM DESENVOLVIMENTO. Revista de Administração da Unimep-Unimep Business Journal-B2, v. 13, n. 2, p. 213-239, 2015.

SILVA, Carlos Alberto Farinha; BUENO, Jefferson Mendes; NEVES, Manoel Rodrigues. A indústria de celulose e papel no Brasil. Guia ABTCP Fornecedores \& Fabricantes Celulose e papel, p. 16-28, 2016

SOUMITRA, Dutta; LANVIN, Bruno; WUNSCH-VINCENT, Sachs. The Global Innovation Index 2015. Effective Innovation Policies for Development. Johnson Cornell University, 2015.

SULL, Donald Norman; ESCOBARI, Martin E. Sucesso made in Brasil: os segredos das empresas brasileiras que dão certo. El Sevier, 2004.

SULLIVAN, Daniel. Measuring the degree of internationalization of a firm. Journal of international business studies, v. 25, n. 2, p. 325-342, 1994.

SUZANO Papel e Celulose. Perfil da empresa. Informações disponíveis em <http://www.suzano.com.br/institucional/perfil/>. Acesso em 11 ago. 2017

TEECE, David; PISANO, Gary. The dynamic capabilities of firms: an introduction. Industrial and corporate change, v. 3, n. 3, p. 537-556, 1994.

USP. Pesquisa sobre Gestão Empresarial para Internacionalização. São Paulo: 2010.

VERNON, Raymond. International investment and international trade in the product cycle. The quarterly journal of economics, p. 190-207, 1966.

VOTORANTIM CIMENTOS. Histórico. Disponível em $<$ http://vcimentos.mzweb.com.br/votorantimcimentos/web/conteudo pt.asp?idioma=0 \&conta=28\&tipo=46490 $>$. Acesso em: 11 ago. 2017.

WESTNEY, E. (2001) Japan in Alan Rugman and Thomas Brewer (Eds): The Oxford Handbook of International Business. Oxford: Oxford University Press pp 623-651

WILLIAMSON, Peter J. et al. (Ed.). The competitive advantage of emerging market multinationals. Cambridge University Press, 2013.

WILLIAMSON, P. J.; YIN, E. Innovation by Chinese EMNEs. The Competitive Advantage of Emerging Market Multinationals, p. 64-80, 2013.

WORLD ECONOMIC FORUM. The Global Competitiveness Report 2006-2007. Geneva: World Economic Forum. 2006 
Forum. 2008

. The Global Competitiveness Report 2008-2009. Geneva: World Economic . The Global Competitiveness Report 2009-2010. Geneva: World Economic Forum. 2009

. The Global Competitiveness Report 2010-2011. Geneva: World Economic Forum. 2010

. The Global Competitiveness Report 2011-2012. Geneva: World Economic Forum. 2011

. The Global Competitiveness Report 2012-2013. Geneva: World Economic Forum. 2012

. The Global Competitiveness Report 2013-2014. Geneva: World Economic Forum. 2013

. The Global Competitiveness Report 2014-2015. Geneva: World Economic Forum. 2014

. The Global Competitiveness Report 2015-2016. Geneva: World Economic Forum. 2015

. The Global Competitiveness Report 2016-2017. Geneva: World Economic Forum. 2016

YEUNG, Henry Wai-Chung. The internationalization of ethnic Chinese business firms from Southeast Asia: Strategies, processes and competitive advantage. International Journal of Urban and Regional Research, v. 23, n. 1, p. 88-102, 1999. 


\section{APÊNDICE A - MATRIZES DE CORRELAÇÃO E ANTI-IMAGEM SURVEY FGV/USP 2015}

\begin{tabular}{|c|c|c|c|c|c|c|c|c|}
\hline \multicolumn{9}{|c|}{ Correlation Matrix ${ }^{a}$} \\
\hline & & $\begin{array}{c}\text { A empresa } \\
\text { responde aos } \\
\text { eventos } \\
\text { inesperados, } \\
\text { imprevistos, } \\
\text { mais } \\
\text { rapidamente } \\
\text { que seus } \\
\text { competidores }\end{array}$ & $\begin{array}{l}\text { Todos os } \\
\text { nossos } \\
\text { gestores } \\
\text { entendem } \\
\text { como cada } \\
\text { um pode } \\
\text { contribuir } \\
\text { para a criação } \\
\text { de valor para } \\
\text { os clientes }\end{array}$ & $\begin{array}{c}\text { A empresa } \\
\text { tem padrões } \\
\text { de } \\
\text { desempenho } \\
\text { operacional } \\
\text { (custo/preço, } \\
\text { qualidade, } \\
\text { entrega,...) } \\
\text { que superam } \\
\text { os dos } \\
\text { competidores } \\
\text { internacionais }\end{array}$ & $\begin{array}{c}\text { Nossa } \\
\text { empresa } \\
\text { responde } \\
\text { rapidamente } \\
\text { a } \\
\text { informações } \\
\text { sobre clientes } \\
\text { insatisfeitos }\end{array}$ & $\begin{array}{c}\text { A nossa } \\
\text { empresa tem } \\
\text { capacidade } \\
\text { de acessar a } \\
\text { recursos } \\
\text { financeiros } \\
\text { diferentes, } \\
\text { nos } \\
\text { diferentes } \\
\text { mercados, de } \\
\text { maneira } \\
\text { eficiente }\end{array}$ & $\begin{array}{c}\text { A nossa } \\
\text { capacidade } \\
\text { de montar } \\
\text { operaçóes } \\
\text { financeiras } \\
\text { internacionais } \\
\text { é fator } \\
\text { decisivo para } \\
\text { a boa } \\
\text { performance } \\
\text { internacional }\end{array}$ & $\begin{array}{c}\text { Nossa } \\
\text { empresa tem } \\
\text { claramente } \\
\text { definidas as } \\
\text { políticas e } \\
\text { práticas de } \\
\mathrm{RH} \text { que } \\
\text { devem ser } \\
\text { adotadas em } \\
\text { nossas } \\
\text { subsidiárias } \\
\text { no exterior }\end{array}$ \\
\hline \multirow[t]{7}{*}{ Correlation } & $\begin{array}{l}\text { Aempresa responde aos } \\
\text { eventos inesperados, } \\
\text { imprevistos, mais } \\
\text { rapidamente que seus } \\
\text { competidores }\end{array}$ & 1,000 & 343 & 286 & .483 &,- 161 &,- 012 &,- 159 \\
\hline & $\begin{array}{l}\text { Todos os nossos } \\
\text { gestores entendem como } \\
\text { cada um pode contribuir } \\
\text { para a criação de valor } \\
\text { para os clientes }\end{array}$ &, 343 & 1,000 & ,302 & ,388 &,- 039 &,- 205 & , 153 \\
\hline & $\begin{array}{l}\text { A empresa tem padrões } \\
\text { de desempenho } \\
\text { operacional (custo/preço, } \\
\text { qualidade, entrega, ...) } \\
\text { que superam os dos } \\
\text { competidores } \\
\text { internacionais }\end{array}$ & ,286 & ,302 & 1,000 & ,275 & ,181 &,- 070 &,- 139 \\
\hline & $\begin{array}{l}\text { Nossa empresa } \\
\text { responde rapidamente a } \\
\text { informaçóes sobre } \\
\text { clientes insatisfeitos }\end{array}$ & ,483 & ,388 & ,275 & 1,000 &,- 173 &,- 267 &,- 306 \\
\hline & $\begin{array}{l}\text { A nossa empresa tem } \\
\text { capacidade de acessar a } \\
\text { recursos financeiros } \\
\text { diferentes, nos diferentes } \\
\text { mercados, de maneira } \\
\text { eficiente }\end{array}$ &,- 161 &,- 039 & 181 &,- 173 & 1,000 & ,621 & ,428 \\
\hline & $\begin{array}{l}\text { A nossa capacidade de } \\
\text { montar operacóes } \\
\text { financeiras internacionais } \\
\text { é fator decisivo para a } \\
\text { boa performance } \\
\text { internacional }\end{array}$ &,- 012 &,- 205 &,- 070 &,- 267 &, 621 & 1,000 & ,431 \\
\hline & $\begin{array}{l}\text { Nossa empresa tem } \\
\text { claramente definidas as } \\
\text { políticas e práticas de RH } \\
\text { que devem ser adotadas } \\
\text { em nossas subsidiárias } \\
\text { no exterior }\end{array}$ &,- 159 & ,153 &,- 139 &,- 306 & ,428 &, 431 & 1,000 \\
\hline
\end{tabular}

a. Determinant $=, 144$ 
APÊNDICE A - MATRIZES DE CORRELAÇÃO E ANTI-IMAGEM SURVEY FGV/USP 2015 (CONTINUAÇÃO)

\begin{tabular}{|c|c|c|c|c|c|c|c|c|}
\hline \multicolumn{9}{|c|}{ Anti-image Matrices } \\
\hline & & $\begin{array}{c}\text { A empresa } \\
\text { responde aos } \\
\text { eventos } \\
\text { inesperados, } \\
\text { imprevistos, } \\
\text { mais } \\
\text { rapidamente } \\
\text { que seus } \\
\text { competidores } \\
\end{array}$ & $\begin{array}{l}\text { Todos os } \\
\text { nossos } \\
\text { gestores } \\
\text { entendem } \\
\text { como cada } \\
\text { um pode } \\
\text { contribuir } \\
\text { para a criação } \\
\text { de valor para } \\
\text { os clientes } \\
\end{array}$ & $\begin{array}{c}\text { Aempresa } \\
\text { tem padrões } \\
\text { de } \\
\text { desempenho } \\
\text { operacional } \\
\text { (custo/preço, } \\
\text { qualidade, } \\
\text { entrega,...) } \\
\text { que superam } \\
\text { os dos } \\
\text { competidores } \\
\text { internacionais } \\
\end{array}$ & $\begin{array}{l}\text { Nossa } \\
\text { empresa } \\
\text { responde } \\
\text { rapidamente } \\
\text { a } \\
\text { informações } \\
\text { sobre clientes } \\
\text { insatisfeitos } \\
\end{array}$ & $\begin{array}{c}\text { A nossa } \\
\text { empresa tem } \\
\text { capacidade } \\
\text { de acessar a } \\
\text { recursos } \\
\text { financeiros } \\
\text { diferentes, } \\
\text { nos } \\
\text { diferentes } \\
\text { mercados, de } \\
\text { maneira } \\
\text { eficiente } \\
\end{array}$ & $\begin{array}{c}\text { Anossa } \\
\text { capacidade } \\
\text { de montar } \\
\text { operaçóes } \\
\text { financeiras } \\
\text { internacionais } \\
\text { éfator } \\
\text { decisivo para } \\
\text { a boa } \\
\text { performance } \\
\text { internacional } \\
\end{array}$ & $\begin{array}{c}\text { Nossa } \\
\text { empresa tem } \\
\text { claramente } \\
\text { definidas as } \\
\text { políticas e } \\
\text { práticas de } \\
R H \text { que } \\
\text { devem ser } \\
\text { adotadas em } \\
\text { nossas } \\
\text { subsidiárias } \\
\text { no exterior } \\
\end{array}$ \\
\hline \multirow[t]{7}{*}{ Anti-image Covariance } & $\begin{array}{l}\text { A empresa responde aos } \\
\text { eventos inesperados, } \\
\text { imprevistos, mais } \\
\text { rapidamente que seus } \\
\text { competidores }\end{array}$ & ,632 &,- 138 &,- 141 &,- 224 & 156 &,- 180 & ,046 \\
\hline & $\begin{array}{l}\text { Todos os nossos } \\
\text { gestores entendem como } \\
\text { cada um pode contribuir } \\
\text { para a criação de valor } \\
\text { para os clientes }\end{array}$ &,- 138 & 629 &,- 144 &,- 171 &,- 009 & ,145 &,- 253 \\
\hline & $\begin{array}{l}\text { A empresa tem padrões } \\
\text { de desempenho } \\
\text { operacional (custo/preço, } \\
\text { qualidade, entrega,...) } \\
\text { que superam os dos } \\
\text { competidores } \\
\text { internacionais }\end{array}$ &,- 141 &,- 144 &, 729 &,- 020 &,- 215 &, 089 & ,143 \\
\hline & $\begin{array}{l}\text { Nossa empresa } \\
\text { responde rapidamente a } \\
\text { informaçóes sobre } \\
\text { clientes insatisfeitos }\end{array}$ &,- 224 &,- 171 &,- 020 & 612 &,- 046 & ,072 & 156 \\
\hline & $\begin{array}{l}\text { A nossa empresa tem } \\
\text { capacidade de acessar a } \\
\text { recursos financeiros } \\
\text { diferentes, nos diferentes } \\
\text { mercados, de maneira } \\
\text { eficiente }\end{array}$ & ,156 &,- 009 &,- 215 &,- 046 & ,476 &,- 270 &,- 121 \\
\hline & $\begin{array}{l}\text { A nossa capacidade de } \\
\text { montar operacões } \\
\text { financeiras internacionais } \\
\text { é fator decisivo para a } \\
\text { boa performance } \\
\text { internacional }\end{array}$ &,- 180 &, 145 &, 089 &, 072 &,- 270 & ,471 &,- 129 \\
\hline & $\begin{array}{l}\text { Nossa empresa tem } \\
\text { claramente definidas as } \\
\text { políticas e práticas de RH } \\
\text { que devem ser adotadas } \\
\text { em nossas subsidiárias } \\
\text { no exterior }\end{array}$ &, 046 &,- 253 & ,143 & ,156 &,- 121 &,- 129 &, 595 \\
\hline \multirow[t]{7}{*}{ Anti-image Correlation } & $\begin{array}{l}\text { Aempresa responde aos } \\
\text { eventos inesperados, } \\
\text { imprevistos, mais } \\
\text { rapidamente que seus } \\
\text { competidores }\end{array}$ &, $538^{\mathrm{a}}$ &,- 219 &,- 208 &,- 360 & 285 &,- 329 & ,075 \\
\hline & $\begin{array}{l}\text { Todos os nossos } \\
\text { gestores entendem como } \\
\text { cada um pode contribuir } \\
\text { para a criação de valor } \\
\text { para os clientes }\end{array}$ &,- 219 &, $509^{\mathrm{a}}$ &,- 213 &,- 275 &,- 016 & ,267 &,- 414 \\
\hline & $\begin{array}{l}\text { A empresa tem padrões } \\
\text { de desempenho } \\
\text { operacional (custo/preço, } \\
\text { qualidade, entrega,...) } \\
\text { que superam os dos } \\
\text { competidores } \\
\text { internacionais }\end{array}$ &,- 208 &,- 213 &, $511^{\mathrm{a}}$ &,- 030 &,- 365 & ,151 & ,218 \\
\hline & $\begin{array}{l}\text { Nossa empresa } \\
\text { responde rapidamente a } \\
\text { informaçôes sobre } \\
\text { clientes insatisfeitos }\end{array}$ &,- 360 &,- 275 &,- 030 &, $687^{\mathrm{a}}$ &,- 085 & ,133 & ,259 \\
\hline & $\begin{array}{l}\text { Anossa empresa tem } \\
\text { capacidade de acessar a } \\
\text { recursos financeiros } \\
\text { diferentes, nos diferentes } \\
\text { mercados, de maneira } \\
\text { eficiente }\end{array}$ &, 285 &,- 016 &,- 365 &,- 085 &, $524^{a}$ &,- 571 &,- 226 \\
\hline & $\begin{array}{l}\text { A nossa capacidade de } \\
\text { montar operaçóes } \\
\text { financeiras internacionais } \\
\text { é fator decisivo para a } \\
\text { boa performance } \\
\text { internacional }\end{array}$ &,- 329 & 267 & 151 & 133 &,- 571 &, $533^{\mathrm{a}}$ &,- 243 \\
\hline & $\begin{array}{l}\text { Nossa empresa tem } \\
\text { claramente definidas as } \\
\text { políticas e práticas de RH } \\
\text { que devem ser adotadas } \\
\text { em nossas subsidiárias } \\
\text { no exterior }\end{array}$ &, 075 &,- 414 & ,218 & ,259 &,- 226 &,- 243 &, $569^{a}$ \\
\hline
\end{tabular}

a. Measures of Sampling Adequacy(MSA) 


\section{APÊNDICE B - MATRIZES DE CORRELAÇÃO E ANTI-IMAGEM SURVEY USP 2010}

\begin{tabular}{|c|c|c|c|c|c|c|c|c|}
\hline \multicolumn{9}{|c|}{ Correlation Matrix ${ }^{a}$} \\
\hline & & $\begin{array}{l}\text { Aempresa } \\
\text { responde aos } \\
\text { eventos } \\
\text { inesperados, } \\
\text { imprevistos, } \\
\text { mais } \\
\text { rapidamente } \\
\text { que seus } \\
\text { competidores }\end{array}$ & $\begin{array}{l}\text { Todos os } \\
\text { nossos } \\
\text { gestores } \\
\text { entendem } \\
\text { como cada } \\
\text { um dos } \\
\text { nossos } \\
\text { colaboradore } \\
\text { s podem } \\
\text { contribuir } \\
\text { para criar } \\
\text { valor para os } \\
\text { mercados e } \\
\text { clientes. }\end{array}$ & $\begin{array}{c}\text { Aempresa } \\
\text { tem padrões } \\
\text { de } \\
\text { desempenho } \\
\text { operacional } \\
\text { (custo/preço, } \\
\text { qualidade, } \\
\text { entrega e } \\
\text { outros) que } \\
\text { se igualam } \\
\text { ou superam } \\
\text { os dos } \\
\text { competidores } \\
\text { internacionais }\end{array}$ & $\begin{array}{c}\text { Nossa } \\
\text { empresa se } \\
\text { organiza e } \\
\text { mobiliza } \\
\text { recursos } \\
\text { rapidamente } \\
\text { quando } \\
\text { temos } \\
\text { informacoóes } \\
\text { de clientes } \\
\text { insatisfeitos. }\end{array}$ & $\begin{array}{c}\text { Na medida } \\
\text { em que seja } \\
\text { necessário, a } \\
\text { nossa } \\
\text { empresa tem } \\
\text { capacidade } \\
\text { de acessar } \\
\text { diferentes } \\
\text { mercados } \\
\text { para obter } \\
\text { recursos } \\
\text { financeiros. }\end{array}$ & $\begin{array}{c}\text { A nossa } \\
\text { capacidade } \\
\text { de montar } \\
\text { operaçóes } \\
\text { financeiras } \\
\text { internacionais } \\
\text { é fator } \\
\text { decisivo para } \\
\text { a boa } \\
\text { performance } \\
\text { internacional. }\end{array}$ & $\begin{array}{c}\text { Nossa } \\
\text { empresa tem } \\
\text { claramente } \\
\text { definidas as } \\
\text { políticas de } \\
\text { recursos } \\
\text { humanos que } \\
\text { devem ser } \\
\text { adotadas em } \\
\text { nossas } \\
\text { subsidiárias } \\
\text { no exterior. }\end{array}$ \\
\hline \multirow[t]{7}{*}{ Correlation } & $\begin{array}{l}\text { Aempresa responde aos } \\
\text { eventos inesperados, } \\
\text { imprevistos, mais } \\
\text { rapidamente que seus } \\
\text { competidores. }\end{array}$ & 1,000 & ,452 & ,636 & ,459 & ,328 & 208 & 303 \\
\hline & $\begin{array}{l}\text { Todos os nossos } \\
\text { gestores entendem como } \\
\text { cada um dos nossos } \\
\text { colaboradores podem } \\
\text { contribuir para criar valor } \\
\text { para os mercados e } \\
\text { clientes. }\end{array}$ & ,452 & 1,000 & ,367 & ,580 & 311 & ,311 & ,418 \\
\hline & $\begin{array}{l}\text { A empresa tem padrões } \\
\text { de desempenho } \\
\text { operacional (custo/preço, } \\
\text { qualidade, entrega e } \\
\text { outros) que se igualam } \\
\text { ou superam os dos } \\
\text { competidores } \\
\text { internacionais. }\end{array}$ & ,636 & ,367 & 1,000 & ,459 & , 177 & ,257 & ,317 \\
\hline & $\begin{array}{l}\text { Nossa empresa se } \\
\text { organiza e mobiliza } \\
\text { recursos rapidamente } \\
\text { quando temos } \\
\text { informacões de clientes } \\
\text { insatisfeitos. }\end{array}$ & ,459 &, 580 & ,459 & 1,000 & 083 &, 264 &, 530 \\
\hline & $\begin{array}{l}\text { Na medida em que seja } \\
\text { necessário, a nossa } \\
\text { empresa tem capacidade } \\
\text { de acessar diferentes } \\
\text { mercados para obter } \\
\text { recursos financeiros. }\end{array}$ & ,328 & 311, & ,177 & 083, & 1,000 & ,482 & 467, \\
\hline & $\begin{array}{l}\text { A nossa capacidade de } \\
\text { montar operaçōes } \\
\text { financeiras internacionais } \\
\text { é fator decisivo para a } \\
\text { boa performance } \\
\text { internacional. }\end{array}$ & ,208 & ,311 & ,257 & ,264 & ,482 & 1,000 & ,365 \\
\hline & $\begin{array}{l}\text { Nossa empresa tem } \\
\text { claramente definidas as } \\
\text { políticas de recursos } \\
\text { humanos que devem ser } \\
\text { adotadas em nossas } \\
\text { subsidiárias no exterior. }\end{array}$ & ,303 &, 418 &, 317 &, 530 & ,467 & ,365 & 1,000 \\
\hline
\end{tabular}

a. Determinant $=, 083$ 
APÊNDICE B - MATRIZES DE CORRELAÇÃO E ANTI-IMAGEM

SURVEY USP 2010 (CONTINUAÇÃO)

\begin{tabular}{|c|c|c|c|c|c|c|c|c|}
\hline \multicolumn{9}{|c|}{ Anti-image Matrices } \\
\hline & & $\begin{array}{l}\text { Aempresa } \\
\text { responde aos } \\
\text { eventos } \\
\text { inesperados, } \\
\text { imprevistos, } \\
\text { mais } \\
\text { rapidamente } \\
\text { que seus } \\
\text { competidores }\end{array}$ & $\begin{array}{l}\text { Todos os } \\
\text { nossos } \\
\text { gestores } \\
\text { entendem } \\
\text { como cada } \\
\text { um dos } \\
\text { nossos } \\
\text { colaboradore } \\
\text { s podem } \\
\text { contribuir } \\
\text { para criar } \\
\text { valor para os } \\
\text { mercados e } \\
\text { clientes. }\end{array}$ & $\begin{array}{c}\text { Aempresa } \\
\text { tem padrões } \\
\text { de } \\
\text { desempenho } \\
\text { operacional } \\
\text { (custo/preço, } \\
\text { qualidade, } \\
\text { entrega e } \\
\text { outros) que } \\
\text { se igualam } \\
\text { ou superam } \\
\text { os dos } \\
\text { competidores } \\
\text { internacionais }\end{array}$ & $\begin{array}{l}\text { Nossa } \\
\text { empresa se } \\
\text { organiza e } \\
\text { mobiliza } \\
\text { recursos } \\
\text { rapidamente } \\
\text { quando } \\
\text { temos } \\
\text { informações } \\
\text { de clientes } \\
\text { insatisfeitos. }\end{array}$ & $\begin{array}{c}\text { Na medida } \\
\text { em que seja } \\
\text { necessário, a } \\
\text { nossa } \\
\text { empresa tem } \\
\text { capacidade } \\
\text { de acessar } \\
\text { diferentes } \\
\text { mercados } \\
\text { para obter } \\
\text { recursos } \\
\text { financeiros. }\end{array}$ & $\begin{array}{c}\text { A nossa } \\
\text { capacidade } \\
\text { de montar } \\
\text { operaçóes } \\
\text { financeiras } \\
\text { internacionais } \\
\text { é fator } \\
\text { decisivo para } \\
\text { a boa } \\
\text { performance } \\
\text { internacional. }\end{array}$ & $\begin{array}{l}\text { Nossa } \\
\text { empresa tem } \\
\text { claramente } \\
\text { definidas as } \\
\text { políticas de } \\
\text { recursos } \\
\text { humanos que } \\
\text { devem ser } \\
\text { adotadas em } \\
\text { nossas } \\
\text { subsidiárias } \\
\text { no exterior. }\end{array}$ \\
\hline \multirow[t]{7}{*}{ Anti-image Covariance } & $\begin{array}{l}\text { A empresa responde aos } \\
\text { eventos inesperados, } \\
\text { imprevistos, mais } \\
\text { rapidamente que seus } \\
\text { competidores. }\end{array}$ & ,483, &,- 078 &,- 272 &,- 097 & -,155 & ,082 & ,066 \\
\hline & $\begin{array}{l}\text { Todos os nossos } \\
\text { gestores entendem como } \\
\text { cada um dos nossos } \\
\text { colaboradores podem } \\
\text { contribuir para criar valor } \\
\text { para os mercados e } \\
\text { clientes. }\end{array}$ &,- 078 &, 574 & ,002 &,- 204 &,- 097 &,- 042 &,- 007 \\
\hline & $\begin{array}{l}\text { A empresa tem padrões } \\
\text { de desempenho } \\
\text { operacional (custo/preço, } \\
\text { qualidade, entrega e } \\
\text { outros) que se igualam } \\
\text { ou superam os dos } \\
\text { competidores } \\
\text { internacionais. }\end{array}$ &,- 272 & 002 &, 543 &,- 057 & ,064 &,- 092 &,- 046 \\
\hline & $\begin{array}{l}\text { Nossa empresa se } \\
\text { organiza e mobiliza } \\
\text { recursos rapidamente } \\
\text { quando temos } \\
\text { informacónes de clientes } \\
\text { insatisfeitos. }\end{array}$ &,- 097 &,- 204 &,- 057 &, 435 & , 188 &,- 073 &,- 220 \\
\hline & $\begin{array}{l}\text { Na medida em que seja } \\
\text { necessáario, a nossa } \\
\text { empresa tem capacidade } \\
\text { de acessar diferentes } \\
\text { mercados para obter } \\
\text { recursos financeiros. }\end{array}$ &,- 155 &,- 097 & 064 & , 188 &, 527 &,- 241 &,- 232 \\
\hline & $\begin{array}{l}\text { A nossa capacidade de } \\
\text { montar operacões } \\
\text { financeiras internacionais } \\
\text { é fator decisivo para a } \\
\text { boa performance } \\
\text { internacional. }\end{array}$ &, 082 &,- 042 &,- 092 &,- 073 &,- 241 &, 694 &,- 015 \\
\hline & $\begin{array}{l}\text { Nossa empresa tem } \\
\text { claramente definidas as } \\
\text { políticas de recursos } \\
\text { humanos que devem ser } \\
\text { adotadas em nossas } \\
\text { subsidiárias no exterior. }\end{array}$ &, 066 &,- 007 &,- 046 &,- 220 &,- 232 &,- 015 &, 528 \\
\hline \multirow[t]{7}{*}{ Anti-image Correlation } & $\begin{array}{l}\text { Aempresa responde aos } \\
\text { eventos inesperados, } \\
\text { imprevistos, mais } \\
\text { rapidamente que seus } \\
\text { competidores. }\end{array}$ &, $688^{\mathrm{a}}$ &,- 148 &,- 531 &,- 212 &,- 306 & , 141 & ,132 \\
\hline & $\begin{array}{l}\text { Todos os nossos } \\
\text { gestores entendem como } \\
\text { cada um dos nossos } \\
\text { colaboradores podem } \\
\text { contribuir para criar valor } \\
\text { para os mercados e } \\
\text { clientes. }\end{array}$ &,- 148 &, $823^{a}$ & ,003 &,- 408 &,- 177 &,- 067 &,- 013 \\
\hline & $\begin{array}{l}\text { Aempresa tem padrões } \\
\text { de desempenho } \\
\text { operacional (custo/preço, } \\
\text { qualidade, entrega e } \\
\text { outros) que se igualam } \\
\text { ou superam os dos } \\
\text { competidores } \\
\text { internacionais. }\end{array}$ &,- 531 & ,003 &, $736^{\mathrm{a}}$ &,- 117 & 120 &,- 150 &,- 086 \\
\hline & $\begin{array}{l}\text { Nossa empresa se } \\
\text { organiza e mobiliza } \\
\text { recursos rapidamente } \\
\text { quando temos } \\
\text { informacóes de clientes } \\
\text { insatisfeitos. }\end{array}$ &,- 212 &,- 408 &,- 117 &, $647^{\mathrm{a}}$ & ,394 &,- 133 &,- 458 \\
\hline & $\begin{array}{l}\text { Na medida em que seja } \\
\text { necessário, a nossa } \\
\text { empresa tem capacidade } \\
\text { de acessar diferentes } \\
\text { mercados para obter } \\
\text { recursos financeiros. }\end{array}$ &,- 306 & -177 & 120, & ,394 &, $517^{\mathrm{a}}$ &,- 398 &,- 440 \\
\hline & $\begin{array}{l}\text { A nossa capacidade de } \\
\text { montar operacões } \\
\text { financeiras internacionais } \\
\dot{e} \text { fator decisivo para a } \\
\text { boa performance } \\
\text { internacional. }\end{array}$ &, 141 &,- 067 &,- 150 &,- 133 &,- 398 &, $741^{\mathrm{a}}$ &,- 025 \\
\hline & $\begin{array}{l}\text { Nossa empresa tem } \\
\text { claramente definidas as } \\
\text { políticas de recursos } \\
\text { humanos que devem ser } \\
\text { adotadas em nossas } \\
\text { subsidiárias no exterior. }\end{array}$ & ,132 &,- 013 &,- 086 &,- 458 &,- 440 &,- 025 &, $699^{a}$ \\
\hline
\end{tabular}

a. Measures of Sampling Adequacy(MSA) 
APÊNDICE C - DENDOGRAMAS

SURVEY FGV USP 2015

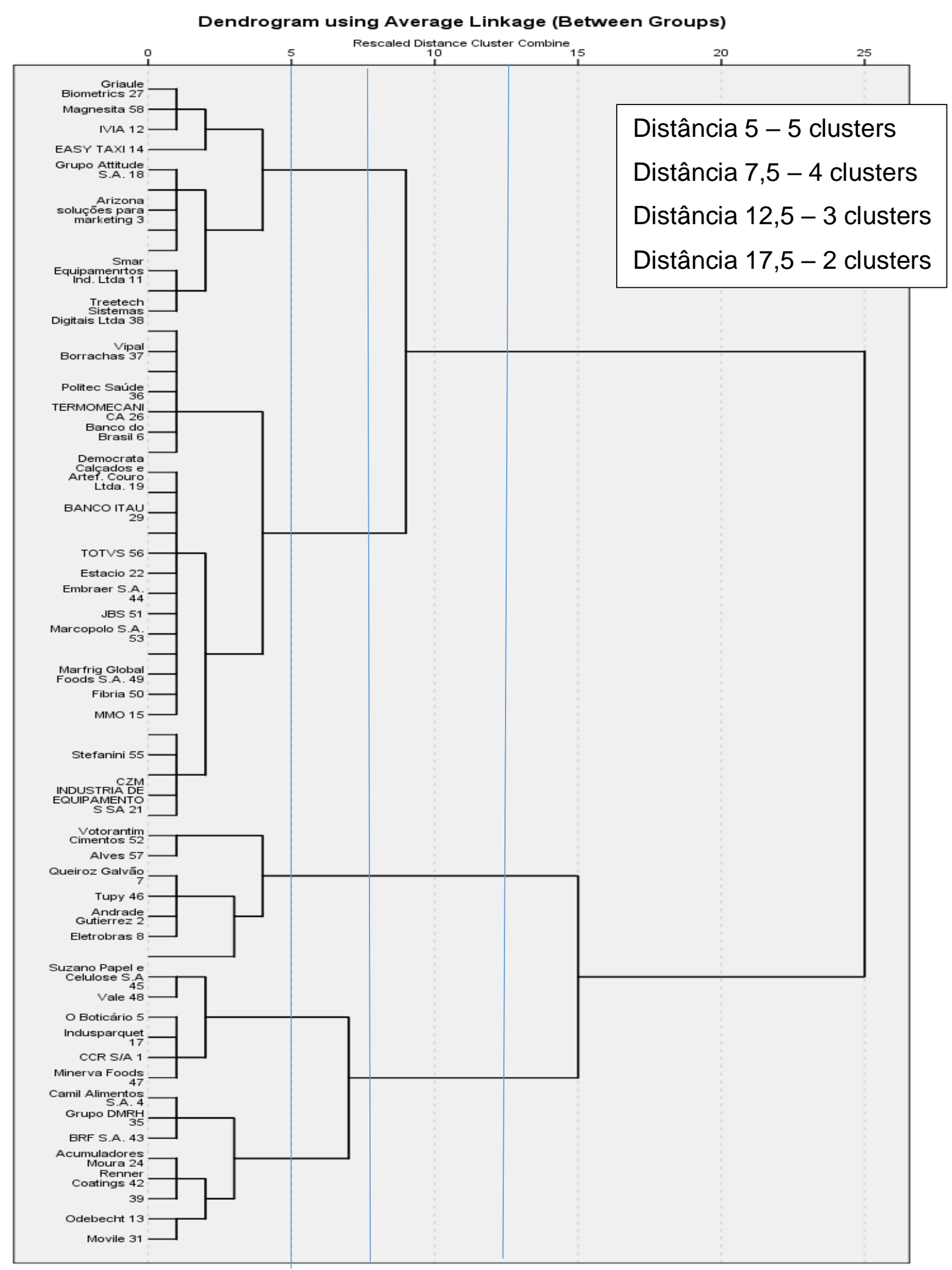


APÊNDICE C - DENDOGRAMAS (CONTINUAÇÃO) SURVEYS USP 2010

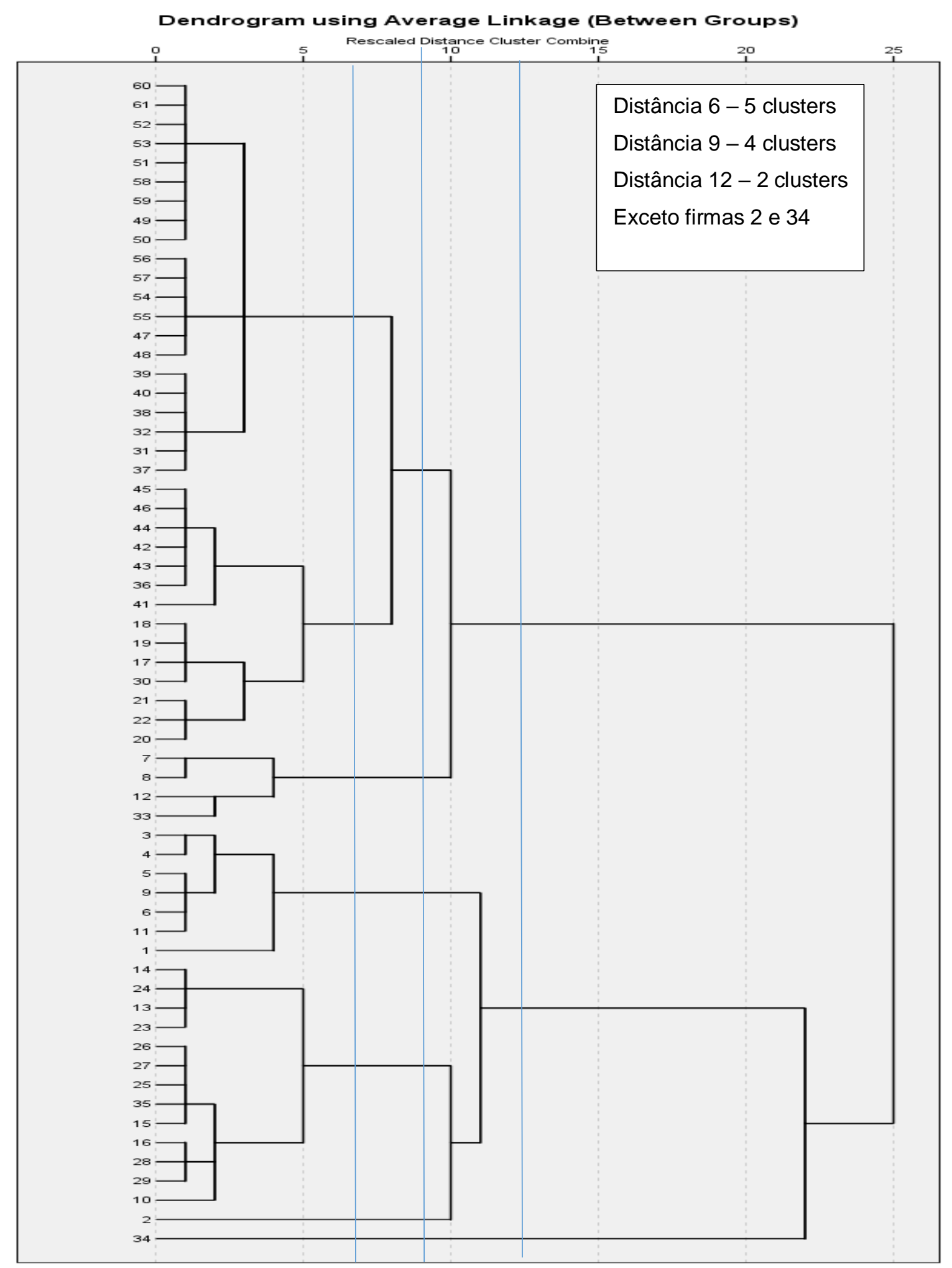




\section{APÊNDICE D - TESTE POST HOC - TUKEY \\ SURVEY USP 2010}

Multiple Comparisons

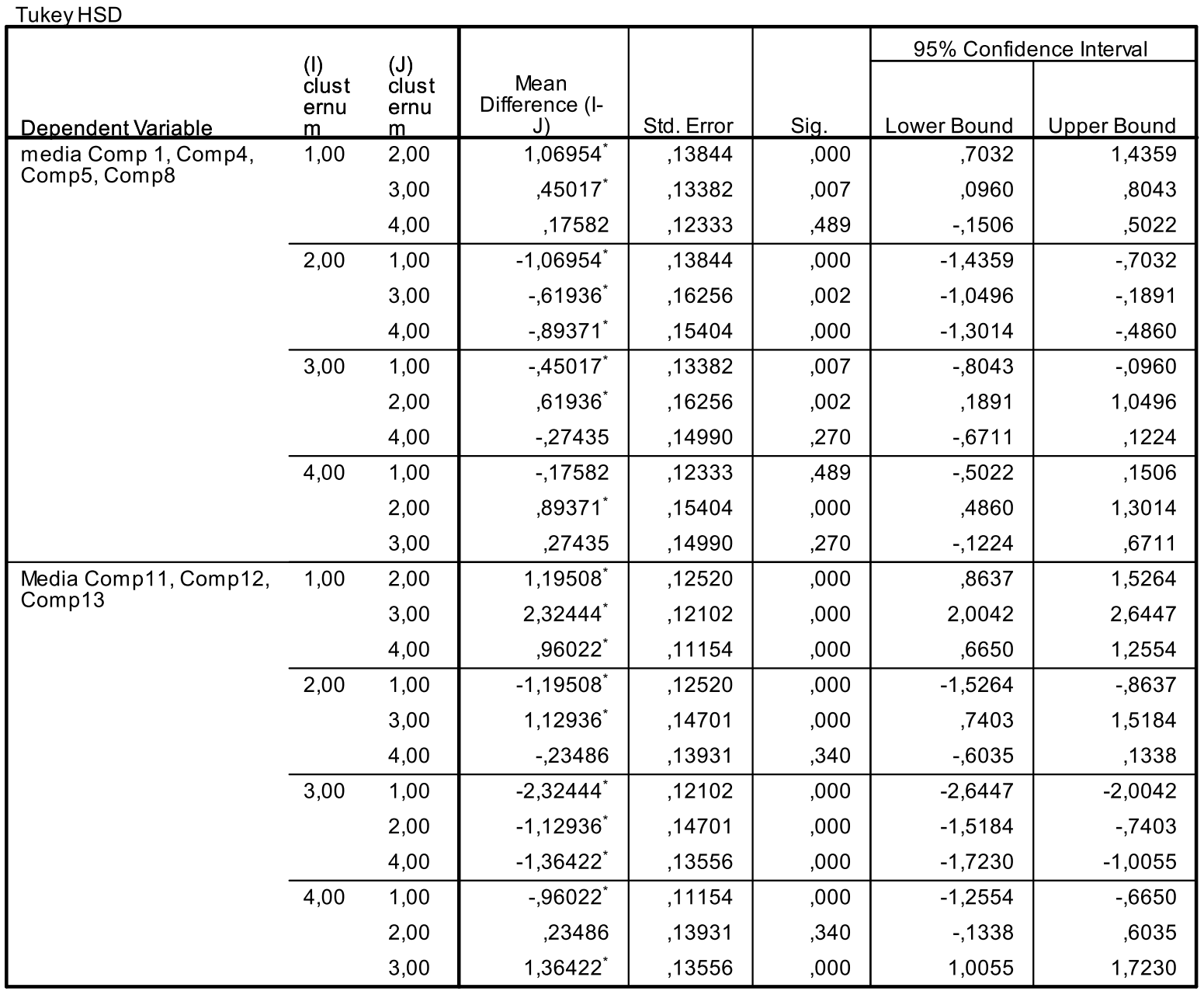

*. The mean difference is significant at the 0.05 level. 


\section{APÊNDICE D - TESTE POST HOC - TUKEY (CONTINUAÇÃO) SURVEY FGV USP 2015}

Multiple Comparisons

\begin{tabular}{|c|c|c|c|c|c|c|c|}
\hline \multirow[b]{2}{*}{ Dependent Variable } & \multirow{2}{*}{$\begin{array}{l}\text { (I) } \\
\text { clust } \\
\text { ernu } \\
\text { m }\end{array}$} & \multirow{2}{*}{$\begin{array}{l}\text { (J) } \\
\text { clust } \\
\text { ernu } \\
\text { m }\end{array}$} & \multirow[b]{2}{*}{$\begin{array}{c}\text { Mean } \\
\text { Difference (I- } \\
J)\end{array}$} & \multirow[b]{2}{*}{ Std. Error } & \multirow[b]{2}{*}{ Sig. } & \multicolumn{2}{|c|}{$95 \%$ Confidence Interval } \\
\hline & & & & & & Lower Bound & Upper Bound \\
\hline \multirow{12}{*}{$\begin{array}{l}\text { media Comp 1, Comp4, } \\
\text { Comp5, Comp8 }\end{array}$} & 1,00 & 2,00 & $1,21964^{*}$ & ,14537 & 000 & 8343 & 1,6050 \\
\hline & & 3,00 &,- 00602 & , 11078 & 1,000 &,- 2997 & ,2876 \\
\hline & & 4,00 &,- 26286 & ,13443 & ,218 &,- 6192 & 0935 \\
\hline & 2,00 & 1,00 & $-1,21964^{*}$ & , 14537 & 000 & $-1,6050$ &,- 8343 \\
\hline & & 3,00 & $-1,22566^{*}$ & 14746 & 000 & $-1,6166$ &,- 8348 \\
\hline & & 4,00 & $-1,48250^{*}$ & ,16596 & 000 & $-1,9224$ & $-1,0426$ \\
\hline & 3,00 & 1,00 & ,00602 & ,11078 & 1,000 &,- 2876 & ,2997 \\
\hline & & 2,00 & $1,22566^{*}$ & , 14746 & 000 & ,8348 & 1,6166 \\
\hline & & 4,00 &,- 25684 & , 13669 & ,249 &,- 6192 & , 1055 \\
\hline & 4,00 & 1,00 & ,26286 & ,13443 & ,218 &,- 0935 & ,6192 \\
\hline & & 2,00 & $1,48250^{*}$ & , 16596 & 000 & 1,0426 & 1,9224 \\
\hline & & 3,00 & ,25684 & 13669 & 249 &,- 1055 & ,6192 \\
\hline \multirow{12}{*}{$\begin{array}{l}\text { Media Comp11, Comp12, } \\
\text { Comp13 }\end{array}$} & 1,00 & 2,00 &,$- 55988^{\star}$ & ,14563 & 002 &,- 9459 &,- 1738 \\
\hline & & 3,00 & $1,29604^{*}$ & ,11098 & ,000 & 1,0019 & 1,5902 \\
\hline & & 4,00 &,$- 84338^{*}$ & , 13467 & 000 & $-1,2004$ &,- 4864 \\
\hline & 2,00 & 1,00 &, $55988^{*}$ & ,14563 & ,002 & ,1738 & 9459 \\
\hline & & 3,00 & $1,85592^{*}$ & 14772 & ,000 & 1,4643 & 2,2475 \\
\hline & & 4,00 &,- 28350 & ,16626 & ,331 &,- 7242 & 1572 \\
\hline & 3,00 & 1,00 & $-1,29604^{*}$ & ,11098 & ,000 & $-1,5902$ & $-1,0019$ \\
\hline & & 2,00 & $-1,85592^{*}$ & 14772 & ,000 & $-2,2475$ & $-1,4643$ \\
\hline & & 4,00 & $-2,13942^{*}$ & 13694 & ,000 & $-2,5024$ & $-1,7764$ \\
\hline & 4,00 & 1,00 &, $84338^{*}$ & ,13467 & ,000 & ,4864 & 1,2004 \\
\hline & & 2,00 & 28350 & , 16626 & ,331 &,- 1572 & ,7242 \\
\hline & & 3,00 & $2,13942^{*}$ & 13694 & ,000 & 1,7764 & 2,5024 \\
\hline
\end{tabular}

*. The mean difference is significant at the 0.05 level. 


\section{APÊNDICE E - COMPARAÇÃO DAS CAPACIDADES DE INOVAÇÃO SEM OS OUTLIERS PARA CONFIRMAÇÃO DO TESTE T \\ Surveys USP 2010 e FGV/USP 2015}

\begin{tabular}{|c|c|c|c|c|c|c|c|}
\hline & & \multicolumn{3}{|c|}{$\begin{array}{l}\text { TODAS AS EMPRESAS } \\
\text { dos surveys de } 2010 \text { e } 2015\end{array}$} & \multicolumn{3}{|c|}{$\begin{array}{c}\text { Subconjunto - } 19 \text { BrMNEs que aparecem } \\
\text { nos dois surveys - 2010 E } 2015\end{array}$} \\
\hline $\begin{array}{l}\text { CAPACIDADES DE } \\
\text { INOVAÇÃO }\end{array}$ & Survey & $\mathrm{N}$ & Média & Desvio Padrão & $\mathrm{N}$ & Média & $\begin{array}{l}\text { Desvio } \\
\text { Padrão }\end{array}$ \\
\hline \multirow[t]{2}{*}{ Essenciais (CORE) } & 2010 & 61 & 4,29 & 0,53 & 18 & 4,39 & 0,49 \\
\hline & 2015 & 58 & 4,04 & 0,57 & 18 & 4,95 & 0,49 \\
\hline \multirow{3}{*}{$\begin{array}{l}\text { Funções } \\
\text { Administrativas (ADM) }\end{array}$} & 2010 & 61 & 3,79 & 0,92 & 18 & 3,93 & 1,03 \\
\hline & 2015 & 58 & 3,66 & 0,90 & 18 & 3,85 & 0,86 \\
\hline & TESTE T & \multicolumn{3}{|c|}{ Sig. (2-tailed) } & \multicolumn{3}{|c|}{ Sig. (2-tailed) } \\
\hline Essenciais (CORE) & & \multicolumn{3}{|c|}{0,01} & \multicolumn{3}{|c|}{0,05} \\
\hline $\begin{array}{l}\text { Funções } \\
\text { Administrativas (ADM) }\end{array}$ & & \multicolumn{3}{|c|}{0,41} & \multicolumn{3}{|c|}{0,82} \\
\hline
\end{tabular}

Fonte: autor 